\title{
Funktionelle Analyse des murinen Foxq1 Gens und die Charakterisierung magenspezifischer Gene
}

\author{
Dissertation \\ zur Erlangung des Doktorgrades \\ der Mathematisch-Naturwissenschaftlichen Fakultäten \\ der Georg-August-Universität zu Göttingen
}

\author{
vorgelegt von \\ Wolfgang Göring \\ aus Duisburg
}

Göttingen, 2006 
D 7

Referenet: $\quad$ Herr Prof. Dr. W. Engel

Korreferent: $\quad$ Frau PD Dr. S. Hoyer-Fender

Tag der mündlichen Prüfung: 01.11.06 
Für Saskia und Linus

Das Leben entspringt auf alle Fälle aus einer Zelle.

Doch manchmal endet's auch bei Strolchen in einer solchen.

(Heinz Erhardt) 


\section{INHALTSVERZEICHNIS}

\section{ABKÜRZUNGSVERZEICHNIS}

1 EINLEITUNG

1.1 Das Foxq1-Gen

1.2 Magenexprimierte Gene 3

Zielsetzung 4

2 MATERIAL \& METHODEN 5

MATERIAL

2.1 Chemikalien und Reagenzien 5

2.2 Biochemikalien und Enzyme $\quad 7$

$\begin{array}{lll}2.3 & \text { Gebrauchswaren } & 8\end{array}$

$\begin{array}{lll}2.4 & \text { Sterilisationsverfahren } & 8\end{array}$

2.5 Puffer und Stammlösungen 9

$\begin{array}{lll}2.6 & \text { Medien und Zusätze } & 12\end{array}$

$\begin{array}{lll}2.7 & \text { Längenstandards } & 12\end{array}$

2.8 Verwendete Vektoren und Bakterienstämme 12

$\begin{array}{llr}2.8 .1 & \text { Vektoren } & 12\end{array}$

$\begin{array}{lll}2.8 .2 & \text { Bakterienstämme } & 13\end{array}$ 
$2.9 \quad$ Gensonden, Oligonukleotide und Antikörper 13

$\begin{array}{lll}2.9 .1 & \text { Gensonden } & 13\end{array}$

$\begin{array}{lll}\text { 2.9.2 Synthetische Oligonukleotide } & 13\end{array}$

$\begin{array}{lll}2.9 .3 & \text { Antikörper } & 15\end{array}$

$\begin{array}{lll}2.10 & \text { Mausstämme } & 15\end{array}$

$\begin{array}{ll}\text { METHODEN } & 16\end{array}$

2.11 Methoden zur Isolierung und Konzentrationsbestimmung $\begin{array}{ll}\text { von Nukleinsäuren } & 16\end{array}$

2.11.1 Isolierung von Plasmid-DNA durch Minipräparation 16

$\begin{array}{ll}\text { 2.11.2 Herstellung von Glyzerinkryokulturen } & 16\end{array}$

2.11.3 Ethanolfällung von DNA aus wässrigen Lösungen 16

2.11.4 Isolierung von Gesamt-RNA aus Gewebe der Maus 17

$\begin{array}{ll}\text { 2.11.5 Konzentrationsbestimmung von Nukleinsäuren } & 17\end{array}$

$\begin{array}{lll}2.12 & \text { Polymerase-Kettenreaktion (PCR) } & 18\end{array}$

$\begin{array}{ll}\text { 2.12.1 Reverse Transkription } & 18\end{array}$

2.12.2 DNA-Amplifikation mittels Polymerase-Kettenreaktion 18

2.12.3 RT-PCR Analysen an Intron-losen Genen 19

$\begin{array}{ll}\text { 2.12.4 DNA-Sequenzanalyse } & 19\end{array}$

$\begin{array}{ll}2.13 \text { Gelelektrophoretische Methoden } & 20\end{array}$

2.13.1 Auftrennung von DNA über Agarosegele 20

2.13.2 Auftrennung von RNA über Formaldehyd-Agarosegele 20

2.14 Spaltung von Plasmid-DNA mit Restriktionsendonukleasen 21

2.15 Isolierung von DNA-Fragmenten aus Agarosegelen 21 
2.16 Transfertechniken und Hybridisierungen $\quad 21$

$\begin{array}{ll}\text { 2.16.1 Northern Blot } & 21\end{array}$

$\begin{array}{ll}\text { 2.16.2 Random Prime Markierung } & 22\end{array}$

2.16.3 Hybridisierung radioaktiver DNA-Sonden an membrangebundene Nukleinsäuren $\quad 22$

2.17 In vitro Transkription 22

2.17.1 Herstellung Digoxigenin-markierter RNA Sonden 22

2.17.2 Dot-Blot Analyse der in vitro Transkription 23

2.18 Fixierung von Magengewebe der Maus 23

2.18.1 Fixierung mit Paraformaldehyd (PFA) 23

$\begin{array}{ll}\text { 2.18.2 Fixierung für die Elektronenmikroskopie } & 24\end{array}$

2.18.3 Fixierung von Embryonen und Gewebe für die Hämatoxilin/Eosin (HE)-Färbung $\quad 24$

2.19 Herstellung von Gewebeschnitten $\quad 24$

2.20 Immunlokalisation von Proteinen in Parafinschnitten 25

2.21 Herstellung und Aufreinigung eines Gastrokine 2-GST Fusionsproteins 25

2.22 In situ Hybridisierung an Magengewebeschnitten 26

2.23 Whole mount in situ Hybridisierung an Embryonen 27

2.24 pH-Wertmessung des Magensaftes 28

$\begin{array}{llr}3 & \text { ERGEBNISSE } & 29\end{array}$

3.1 Expressionsanalysen von Foxq1 während der embryonalen

$\begin{array}{ll}\text { Magenentwicklung } & 29\end{array}$

3.2 Analyse von Foxq1-defizienten Mäusen 34

3.3 Haaranalyse Foxq1-defizienter Mäuse 35 
3.4 Konsequenzen der Foxq1 Defizienz für die Embryonalentwicklung der Maus 37

3.5 Strukturelle Untersuchung des Magens von Foxq1-defizienten Mäusen $\quad 40$

3.6 Expressionsanalyse von Magenzelltyp-spezifischen Markergenen 42

3.7 Funktion von Foxq1 bei der Magensäuresekretion 44

3.8 Ultrastrukturelle Analyse von Foxq1-defizienten Parietalzellen 47

3.9 Auswertung der PCR-basierten subtraktiven cDNA-Bibliothek 50

3.10 Charakterisierung des Gastrokine 2 Gens 52

3.11 Charakterisierung des Admp Gens 62

3.12 Charakterisierung des SA11 Gens 68

$4 \quad$ DISKUSSION $\quad 72$

$\begin{array}{lll}4.1 & \text { Der Magen } & 72\end{array}$

4.2 Die Rolle von Foxq1 bei der Magensäuresekretion 74

4.3 Funktion von Foxq1 in der Embryonal- und Haarentwicklung 78

4.4 Charakterisierung neuer magenexprimierter Gene $\quad 80$

$\begin{array}{llr}\text { 4.4.1 } & \text { Gastrokine } 2 & 80\end{array}$

$\begin{array}{lll}4.4 .2 \text { Admp } & 82\end{array}$

$\begin{array}{lll}4.4 .3 & \text { SA11 } & 83\end{array}$

$\begin{array}{lll}4.5 & \text { Ausblick } & 84\end{array}$

$5 \quad$ ZUSAMMENFASSUNG $\quad 86$

$\begin{array}{lll}6 & \text { LITERATURVERZEICHNIS } & 88\end{array}$ 


\section{ABKÜRZUNGSVERZEICHNIS}

${ }^{\circ} \mathrm{C} \quad$ Grad Celsius

Abb. Abbildung

AP Alkalische Phosphatase

BCIP 5-Brom-4-Chlor-3-Indolylphosphat $p$-Toluidinsalz

Bp Basenpaare

cM Zenti-Morgan

DEPC Diethylpyrocarbonat

DNA Desoxyribonukleinsäure

DIG Digoxigenin

dNTP Desoxyribonukleosidtriphosphat

DMF N,N-Dimethylformamid

dpc days post coitum (Tage nach Empfängnis)

DTT Dithiothreitol

EDTA Ethylendiamintetraessigsäure

h Stunde(n)

hEF humaner Elongations-Faktor-2 (HEF-2)

IPTG Isopropyl- $\beta$-D-thiogalactopyranosid

kB Kilobasenpaare

kDa Kilodalton

$\min \quad$ Minute(n)

MOPS 3 (N-Morpholino)-Propansulfonsäure

$\mathrm{NaCl} \quad$ Natriumchlorid

$\mathrm{NaOH} \quad$ Natriumhydroxid

NBT Nitro Blau Tatrazolium Chlorid 
PFA Paraformaldehyd

RNA Ribonukleinsäure

RT Raumtemperatur

SDS Natriumdodecylsulfat

Tab. Tabelle

üN über Nacht 


\section{EINLEITUNG}

Foxq1 gehört zur Gruppe der fork head Transkriptionsfaktoren, die zuerst von Weigel et al. (1989) mit dem Drosophila-Gen fork head beschrieben wurden. Fork head Transkriptionsfaktoren sind gekennzeichnet durch eine 110 Aminosäuren umfassende DNABindedomäne, die in allen fork head Genen hochkonserviert ist. Die Struktur dieser Bindungsdomäne konnte von Clark et al. (1993) mittels Kristallisationsexperimenten an HNF-3 $\gamma$ aufgeklärt werden. Mittlerweile wurden weit über 100 fork head Gene in unterschiedlichen Spezies wie z.B. Ciona intestinalis, Branchiostoma lanceolatum, Gallus gallus, Rattus norvegicus, Mus musculus und Homo sapiens beschrieben. Um eine Vereinheitlichung der Nomenklatur in Chordata zu erreichen, werden die fork head Gene seit 2000 (Kaestner et al., 2000) als Fox-Gene (,fork head box ${ }^{\text {“) }}$ ) bezeichnet und entsprechend der Homologie zwischen den fork head-Domänen in einzelne Subklassen unterteilt. Das Foxq1Gen gehört mit insgesamt drei Fox-Genen aus Rattus norvegicus, Mus musculus und Homo sapiens zur Q-Subklasse.

\subsection{Das Foxq1-Gen}

Das murine Foxq1-Gen wurde 1998 in unserer Arbeitsgruppe durch Screening einer Nierenspezifischen cDNA-Bibliothek mittels einer Sonde isoliert, welche die fork head-Domäne des HNF3 $\alpha$-Gens der Ratte enthielt. Das Foxq1-Gen ist lokalisiert auf dem Chromosom 13 der Maus, ungefähr 16,8 cM vom Zentromer entfernt (Frank und Zoll, 1998; Hong et al., 2001). Es besteht aus einem Exon und kodiert für eine Aminosäuresequenz, die 400 Aminosäuren beinhaltet. Durch eine Northern-Blot Analyse konnte eine starke Expression des 2,7 kB umfassenden Foxq1-Transkripts in der Niere und im Magen der adulten Maus gezeigt werden (Frank und Zoll, 1998). Eine schwache Expression konnte in Leber, Lunge, Darm und Gehirn detektiert werden. Des Weiteren wurde eine Foxq1-Expression während der prä- und postnatalen Entwicklung der Niere und des Magens in allen untersuchten Stadien beginnend mit 18,5 days post coitum (dpc) beobachtet. Mit Hilfe einer RT-PCR Analyse ließ sich ein Foxq1-Transkript in allen untersuchten embryonalen Stadien beginnend mit 10,5 dpc detektieren. In situ Hybridisierung an Gewebeschnitten der adulten Niere ließ eine Expression von Foxq1 in der äußeren Medulla, in den Markstrahlen und im Transitionalepithel des Nierenbeckens erkennen. 
Bieller et al. (2001) konnten eine starke Expression des humanen 2,7 kB umfassenden FOXQ1-Gens in der gastrischen Mucosa des menschlichen Magens zeigen. Mit Hilfe des humanen MTE Array konnte ferner eine starke Expression in der Speicheldrüse, der Trachea und der Blase beobachtet werden. Außerdem wurde eine stark gesteigerte Expression von FOXQ1 in einem Colonkarzinom im Vergleich zu normalem Colongewebe detektiert. Mittels Fluoreszenz in situ Hybridisierung (FISH) konnte FOXQ1 auf die zur Maus syntänen Region 6p23-25 des Menschen lokalisiert werden. Das vermutlich intronlose humane Gen kodiert für ein 403 Aminosäuren umfassendes Protein, dessen fork head-Domäne eine Homologie von 100 Prozent zur fork head-Domäne des Foxq1 der Maus aufweist. Die Homologie zum murinen Foxq1 über den gesamten kodierenden Bereich des Gens liegt bei 82 Prozent.

Im Rahmen einer Dissertation in der Arbeitsgruppe Zoll (Pasche, 2001) konnte eine vermutete Kernlokalisation des murinen Foxq1-Proteins mit Hilfe eines Foxq1-GFP Fusionsproteins in der NP1-Nierenzelllinie gezeigt werden. Ferner wurde in der Dissertation der Promotorbereich des Foxq1-Gens detailliert untersucht. Es konnte ein zwischen Maus und Mensch hochkonservierter $400 \mathrm{Bp}$ umfassender Bereich beginnend etwa $500 \mathrm{Bp}$ vor dem Translationsstartpunkt gefunden werden, der unter anderem putative Bindestellen für SPFaktoren, NF-Y, MZF-1 und Foxq1 enthält. Luciferase-Assays mit verschiedenen Promotorkonstrukten ließen eine essentielle Beteiligung zweier putativer SP-Bindungsstellen im Bereich von $641 \mathrm{Bp}$ bis $691 \mathrm{Bp}$ vor Translationsstart an der Transaktivierung des Foxq1Gens vermuten. Gel Retardation Assays mit spezifischen Antikörpern gegen Sp1- und Sp3Transkriptionsfaktoren konnten ferner eine Bindung von Sp1 bzw. Sp3 an die zuvor beschriebenen putativen Sp-Bindungsstellen aufdecken, wobei Sp1 mit höherer Affinität an die Bindungsstelle bei 641 Bp vor Translationsstart bindet. SP3 bindet bevorzugt an die SpBindungsstelle bei $691 \mathrm{Bp}$ vor Translationsstart.

Um die Funktion des Foxq1-Gens zu untersuchen, wurde im Rahmen der zuvor erwähnten Dissertation damit begonnen, Foxq1-defiziente Mäuse mittels homologer Rekombination zu generieren. Dafür wurde die gesamte kodierende Region des Gens deletiert. Die daraus resultierenden adulten Foxq1 ${ }^{-/}$-Mäuse zeigten jedoch keinen offensichtlichen Phänotyp.

Während der Erzeugung Foxq1-defizienter Mäuse wurde in einer Veröffentlichung von Hong et al. (2001) für Satin-Mäuse (sa) gezeigt, dass sie eine Mutation im Foxq1-Gen tragen. So wurde für das ursprüngliche sa Allel gezeigt, dass es eine durch $\gamma$-Strahlen induzierte intragenische Deletion von 67 Bp (Position 686 - 752 nach Translationsstart) im Foxq1-Gen aufweist. Diese Deletion führt zu einer verkürzten Form des Foxq1 Proteins, bei dem die Cterminale putative Transaktivierungsdomäne fehlt. Homozygote Satin-Mäuse weisen ein 
seidig glänzendes Fell auf, das aus einer Fehlentwicklung der innersten Haarschicht, der Medulla, resultiert. Des Weiteren wurde von dieser Arbeitsgruppe eine Expression von Foxq1 in den medullaren Vorläuferzellen mittels in situ Hybridisierung detektiert.

Im Rahmen dieser Dissertation sollte daraufhin der Phänotyp der Foxq1-defizienten Mäuse genauer analysiert werden. Neben der Untersuchung der Haarstruktur sollten vor allen Dingen die Entwicklung, die Histologie und die funktionelle Analyse des Magens von Foxq1 ${ }^{-/}$-Tieren im Vordergrund stehen. Hierzu wurden von Hong et al. (2001) keine Daten präsentiert.

\subsection{Magenexprimierte Gene}

Der Magen, seine Funktion und das Zusammenspiel der einzelnen Zelltypen der gastrischen Mucosa sind schon seit Jahren ein Feld des Interesses. Allerdings konnten erst in den letzten Jahren einzelne Gene identifiziert werden, die zum einen in die Magenentwicklung, die Zellerneuerung und die Synthese der verschiedenen Magensekrete involviert sind und zum anderen an der Genese von Magenkarzinomen beteiligt sind. So wurde für das in den Entero-endokrinen G-Zellen exprimierte und sekretierte Hormon Gastrin gezeigt, dass es neben der Stimulierung der Magensäuresekretion (Friis-Hansen et al., 1998) auch eine Rolle als Wachstumsfaktor der gastrischen Mucosa spielt. Ein erhöhter GastrinSpiegel führt $\mathrm{zu}$ einer Hyperplasie der Magenschleimhaut durch eine erhöhte Zahl an ECL

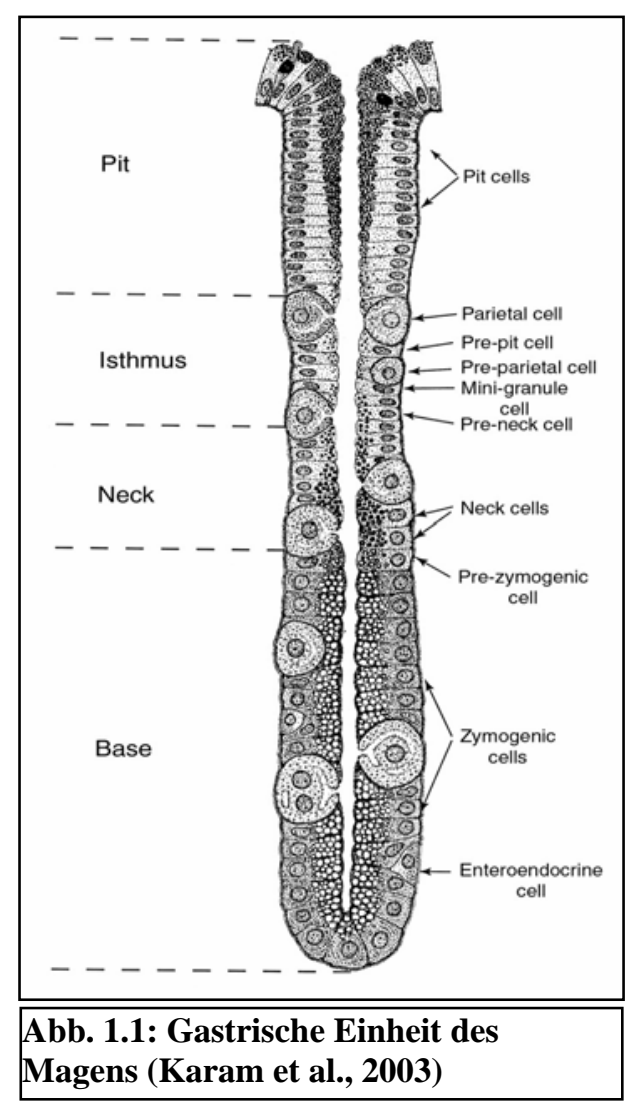
Zellen (enterochhromaffine-like) und Parietalzellen (Crean et al., 1969; Larsson et al., 1986). Anhaltend hohe Gastrinspiegel sind außerdem assoziiert mit ECL Zelltumoren (Hakanson und Sundler, 1990). Für das prädominant im Magen exprimierte TFF1-Gen wurde gezeigt, dass es einerseits die Regeneration der Schleimhaut stimuliert (Hoffmann, 2005) und andererseits als Tumorsuppressor Gen fungiert. TFF1-Null-Mäuse entwickelten in 30\% der Fälle Adenokarzinome (Lefebvre et al., 1996). In der Regel wird die Expression von TFF1 in Karzinomzellen nicht beobachtet (Henry et al., 1991; Muller und Borchard, 1993). Die Inaktivierung von TFF1 wurde durch Loss of Heterozygosity (Park et al., 2000) und 
Hypermethylierung des Promotors (Fujimoto et al., 2000) in Magenkarzinomen nachgewiesen.

Um weitere magenspezifisch bzw. prädominant im Magen exprimierte Gene zu finden, wurde in Vorarbeiten zu dieser Dissertation eine auf PCR basierende subtraktive cDNA-Bibliothek erstellt. Hierfür wurden die Transkriptome von Magen und Dünndarm miteinander verglichen. Die resultierenden cDNA-Fragmente wurden sequenziert und mittels Datenbankrecherche näher charakterisiert (siehe Tab. 3.4). Hieraus sollten nicht beschriebene bzw. unbekannte Gene, denen eine prädominante Magenexpression per Datenbankanalyse prognostiziert wurde, ausgewählt werden und zunächst mittels Northern-Blot Analyse an unterschiedlichen Geweben der Maus auf ihr Expressionsmuster hin untersucht werden. Magenspezifisch bzw. prädominant im Magen exprimierte Gene sollten daraufhin durch weitere Expressionsanalysen charakterisiert werden.

\section{Ziele der vorliegenden Arbeit:}

Im Rahmen dieser Dissertation sollten Foxq1-defiziente Mäuse, die auf den ersten Blick keinen von Wildtyp-Mäusen abweichenden Phänotyp zeigen, genauer untersucht werden. Besonderes Augenmerk sollte dabei auf die Analyse der Entwicklung, die Histologie und die funktionelle Analyse des Magens gerichtet werden. Hierfür wurden keinerlei Studien von Hong et al. (2001) oder einer anderen Arbeitsgruppe veröffentlicht. Ferner sollte der von Hong et al. (2001) beschriebene Haarphänotyp der homozygoten Satin-Mäuse auch an den Foxq1-defizienten Mäusen untersucht werden.

Um weitere magenspezifische bzw. prädominant im Magen exprimierte Gene zu charakterisieren, sollten Gene aus der subtraktiven cDNA-Bibliothek nach folgenden Kriterien ausgewählt werden:

- prognostizierte magenspezifische Expression bzw. prädominante Expression im Magen

- unbekannte oder nicht charakterisierte Gene

Die prognostizierte magenspezifische Expression bzw. prädominante Expression im Magen sollte mittels Northern-Blot Analyse verifiziert werden. Anschließend sollte eine weitere Charakterisierung durch detaillierte Expressionsstudien erfolgen. 


\section{MATERIAL UND METHODEN}

\section{MATERIAL}

\subsection{Chemikalien und Reagenzien}

Alle Substanzen, die nicht aufgeführt sind, wurden von den Firmen Roth (Karlsruhe) und Sigma-Aldrich (Deisenhofen) bezogen.

Chemikalien

Agar

Agarose

Ampicillin

Ampuwa

Aqua Polymount

BCIP (5-Brom-4-Chlor-3-

Indolylphosphat $p$-Toluidinsalz)

Bacto-Trypton

Borsäure

BugBuster ${ }^{\circledR}$ GST $•$ Bind $^{\mathrm{TM}}$ Purification Kit

Chloroform

Coomassie-Brilliant Blau R250

Dextransulfat

Diethylpyrocarbonat (DEPC)

DIG RNA Labeling Kit (SP6/T7)

DIG Nucleic Acid Detection Kit

N,N-Dimethylformamid (DMF)

Dithiothreitol (DTT)

DPBS

dNTPs (100mM)

\section{Hersteller}

Roth, Karlsruhe

Invitrogen, Karlsruhe

Roth, Karlsruhe

Fresenius AG, Bad Homburg

Polyscience, Warrington (USA)

Roth, Karlsruhe

Roth, Karlsruhe

Roth, Karlsruhe

Merck, Darmstadt

Mallinckrodt Baker B.V., Deventer (NL)

Fluka, Neu-Ulm

Amresco, Solon (USA)

Roth, Karlsruhe

Roche Diagnostics, Mannheim

Roche Diagnostics, Mannheim

Roth, Karlsruhe

Applichem, Darmstadt

PAN Biotech, Aidenbach

Invitrogen, Karlsruhe 
Ethylendiamintetraessigsäure (EDTA)

Entwickler

Eosin-Färbelösung

Essigsäure

Ethanol

Ethidiumbromid

Eukitt mounting medium

Ficoll 400

Fixierer

Formaldehyd

Formamid, deionisiert

Glutaraldehyd

Glycerol

Hämatoxilin-Färbelösung

Hefeextrakt

Heparin, Natriumsalz

Histamin Dihydrochlorid

Isopropyl- $\beta$-D-thiogalactopyranosid

(IPTG)

Kanamycin

Methanol

Milchpulver

3 (N-Morpholino)-Propansulfonsäure

(MOPS)

Natriumacetat

Natriumcacodylat

Natriumhydroxid

Nitro Blau Tatrazolium Chlorid (NBT)

NuPAGE® MOPS SDS Running buffer

NuPAGE® Novex 4-12\% Bis-Tris Gel

NuPAGE® LDS Sample buffer

Natriumdodecylsulfat (SDS)

Orange-G

Paraformaldehyd
Merck, Darmstadt

Kodak, Darmstadt

Sigma-Aldrich, Deisenhofen

Roth, Karlsruhe

Mallinckrodt Baker B.V., Deventer (NL)

Eurobio, Courtaboeuf (FR)

Fluka (Sigma-Aldrich), München

Applichem, Darmstadt

Kodak, Darmstadt

Merck, Darmstadt

Sigma-Aldrich, Deisenhofen

Serva, Heidelberg

Roth, Karlsruhe

Sigma-Aldrich, Deisenhofen

Roth, Karlsruhe

Roth, Karlsruhe

Sigma-Aldrich, Deisenhofen

Biomol, Hamburg

Sigma-Aldrich, Deisenhofen

Mallinckrodt Baker B.V., Deventer (NL)

Roth, Karlsruhe

Roth, Karlsruhe

Merck, Darmstadt

Sigma-Aldrich, Deisenhofen

Merck, Darmstadt

Sigma-Aldrich, Deisenhofen

Invitrogen, Karlsruhe

Invitrogen, Karlsruhe

Invitrogen, Karlsruhe

Roth, Karlsruhe

Sigma-Aldrich, Deisenhofen

Merck, Darmstadt 
Pentagastrin

Phenol

Puffer P1

Puffer P2

Puffer P3

QIAquick Gel Extraction Kit

Radioaktiv markiertes $\left[\alpha{ }^{32} \mathrm{P}\right]$-dCTP

Rapid-Hyb ${ }^{\circledR}$ Puffer

Rediprime ${ }^{\circledR} \mathrm{II}$

RNAse A

Saccharose

Salzsäure

TriReagent ${ }^{\circledR}$

Tris

Tween 20

VECTASHIELD ${ }^{\circledR}$ Mounting Medium
Sigma-Aldrich, Deisenhofen

Invitrogen, Karlsruhe

Qiagen, Hilden

Qiagen, Hilden

Qiagen, Hilden

Qiagen, Hilden

GE Healthcare, München

GE Healthcare, München

GE Healthcare, München

Qiagen, Hilden

Roth, Karlsruhe

Roth, Karlsruhe

Molecular Research Center, Cincinnati (USA)

Roth, Karlsruhe

Roth, Karlsruhe

Vector Laboratories, Burlingame (USA)

\subsection{Biochemikalien und Enzyme}

Enzym

Complete mini,

Proteinase Inhibitor Cocktail

MangoTaq

DNAse (RNAse frei)

Platinum-Taq-DNA Polymerase

Proteinase K, PCR grade

Restriktionsendonukleasen

Reverse Transkriptase SuperScript II

RNAse A

\section{Hersteller}

Roche Diagnostics, Mannheim

Bioline, Luckenwalde

Roche Diagnostics, Mannheim

Invitrogen, Karlsruhe

Roche Diagnostics, Mannheim

Invitrogen, Karlsruhe

Invitrogen, Karlsruhe

Sigma-Aldrich, Deisenhofen 


\subsection{Gebrauchswaren}

Nicht aufgeführte Gebrauchswaren wurden von den Firmen Omnilab (Göttingen), sowie Sarstedt (Nümbrecht) und Greiner (Frickenhausen) bezogen.

Gebrauchsware

Blotting Papier GB 002

Blotting Papier GB 003

Hybond $^{\circledR}$-XL Membran

Fixogum

MicroSpin S-200 HR Säule

Porablot NY plus Membran

Pipettenspitzen

Reaktionsgefäße

Röntgenfilme

SuperFrost Plus Objektträger

Turbo-Blot-Apparatur
Hersteller

Schleicher \& Schüll, Dassel

Schleicher \& Schüll, Dassel

GE Healthcare, München

Marabuwerke, Tamm

GE Healthcare, München

Macherey-Nagel, Düren

Sarstedt, Nümbrecht

Eppendorf, Hamburg

Perbio Science, Bonn

Menzel-Gläser, Braunschweig

Schleicher \& Schüll, Dassel

\subsection{Sterilisationsverfahren}

Gebrauchswaren, Lösungen und Kulturmedien wurden bei $121^{\circ} \mathrm{C}$ und 1,5 Bar autoklaviert oder über Nacht bei $220^{\circ} \mathrm{C}$ hitzesterilisiert. Hitzeempfindliche Lösungen wurden sterilfiltriert. Wässrige Lösungen für RNA-Präparationen und RNA-Analysen wurden mit $0,1 \%(\mathrm{v} / \mathrm{v})$ Diethylpyrocarbonat (DEPC) versetzt, für 12 bis $24 \mathrm{~h}$ bei RT inkubiert und anschließend autoklaviert. 


\subsection{Puffer und Stammlösungen}

Die Lösungen für den routinemäßigen Laborbetrieb wurden nach Sambrook et al. (1989) angesetzt. Die benötigten Chemikalien wurden den Erfordernissen gemäß in bidestilliertem oder DEPC-behandeltem Wasser gelöst und nach Bedarf autoklaviert oder sterilfiltriert.

Lösung/Puffer

Ampicillin-Stammlösung

AP (Alkalische Phosphatase)-Puffer

BCIP-Stocklösung

Blockierungslösung

(in situ-Hybridisierung)

Blockpuffer I

Coomassie-Entfärbelösung

Coomassie-Färbelösung

50 x Denhardts Lösung

\section{Zusammensetzung}

$50 \mathrm{mg} / \mathrm{ml}$ in $\mathrm{H}_{2} \mathrm{O}$

$100 \mathrm{mM} \mathrm{NaCl}$

$50 \mathrm{mM} \mathrm{MgCl}_{2}$

$100 \mathrm{mM}$ Tris/ $\mathrm{HCl} \mathrm{pH} 9,5$

$50 \mathrm{mg} / \mathrm{ml}$ in DMF

4\% Bovines Serum Albumin (BSA)

1x PBS

5\% Milchpulver

1x PBS

$30 \%(\mathrm{v} / \mathrm{v})$ Methanol

$10 \%$ (v/v) Essigsäure

$30 \%$ (v/v) Methanol

$10 \%(\mathrm{v} / \mathrm{v})$ Essigsäure

0,05 \% (w/v) Coomassie-Brilliant Blau R250

$1 \%(\mathrm{w} / \mathrm{v})$ Rinderserumalbumin

$1 \%(\mathrm{w} / \mathrm{v})$ Polyvinylpyrrolidon

$1 \%(w / v)$ Ficoll 400 
Denaturierungslösung

DEPC- $\mathrm{H}_{2} \mathrm{O}$

dNTP-Mix

Histamin-Stammlösung

Hybridisierungslösung (in situ)

IPTG-Stammlösung

Kanamycin-Stammlösung

Lachs-Spermien-DNA

NBT/BCIP-Färbelösung

NBT-Stocklösung

10x MOPS Puffer
$1,5 \mathrm{M} \mathrm{NaCl}$

$0,5 \mathrm{M} \mathrm{NaOH}$

0,1\% (v/v) Diethylpyrocarbonat (DEPC)

Inkubation für $24 \mathrm{~h}$ unter Rühren und

anschließend Dampfdrucksterilisation

$10 \mathrm{mM}$ dATP

$10 \mathrm{mM}$ dGTP

$10 \mathrm{mM}$ dCTP

10 mM dTTP in Ampuwa

$50 \mathrm{mg} / \mathrm{ml}$ in $0,9 \% \mathrm{NaCl}$-Lösung

$40 \%(\mathrm{v} / \mathrm{v})$ deionisiertes Formamid

$10 \%(\mathrm{w} / \mathrm{v})$ Dextransulfat

1x Denhardts Lösung

4x SSC

$250 \mu \mathrm{g} / \mathrm{ml}$ Hefe t-RNA

$100 \mathrm{mM}$ in $\mathrm{H}_{2} \mathrm{O}$

$50 \mathrm{mg} / \mathrm{ml}$ in $\mathrm{H}_{2} \mathrm{O}$

$100 \mu \mathrm{g} / \mathrm{ml}$ (Scherung durch Sonifikation)

$200 \mathrm{ml}$ NBT/BCIP-Stocklösung (Roche)

oder

$45 \mu 1$ NBT-Stocklösung +

$35 \mu 1$ BCIP-Stocklösung

in $10 \mathrm{ml} \mathrm{AP-Puffer}$

$75 \mathrm{mg} / \mathrm{ml}$ in $70 \% \mathrm{DMF}$

$50 \mathrm{mM}$ Natriumacetat 
10 mM EDTA

200 mM MOPS (pH 7,0)

Neutralisationslösung

0,5 M Tris/HCl (pH 5,5)

$1.5 \mathrm{M} \mathrm{NaCl}$

Paraformaldehyd-Lösung (4 \%)

$4 \%(w / v)$ PFA

in $1 \mathrm{x}$ PBS auf $60^{\circ} \mathrm{C}$ erhitzen

$1 \times$ PBS

$130 \mathrm{mM} \mathrm{NaCl}$

$7 \mathrm{mM} \mathrm{Na}_{2} \mathrm{HPO}_{4}$

$4 \mathrm{mM} \mathrm{NaH}_{2} \mathrm{HPO}_{4}$

$1 \times$ PBT

$0.1 \%$ Tween-20 in $1 \times$ PBS

Pentagastrin-Stammlösung

$20 \mathrm{mg} / \mathrm{ml}$ in DMF

RNA-Ladepuffer

Stopp-Mix

0,025\% Ethidiumbromid

RNA-Probenpuffer

1,5 x MOPS-Puffer

9,25\% Formaldehyd

$60 \%$ Formamid

Puffer 1 (in situ)

$100 \mathrm{mM}$ Tris/ $\mathrm{HCl} \mathrm{pH}$ 7,5

$150 \mathrm{mM} \mathrm{NaCl}$

$20 \times \mathrm{SSC}$

$3 \mathrm{M} \mathrm{NaCl}$

$0.3 \mathrm{M} \mathrm{Na}_{3}$ Citrat (pH 7.0)

Stopp-Mix

15\% Ficoll 400

200 mM EDTA

$0.1 \%$ Orange $\mathrm{G}$ 
$5 \times \mathrm{TBE}$

$445 \mathrm{mM}$ Tris/ $\mathrm{HCl}(\mathrm{pH} 8,0)$

445 mM Borsäure

$10 \mathrm{mM}$ EDTA

\subsection{Medien und Zusätze}

LB-Medium ( $\mathrm{pH} 7,5)$

$1 \%(w / v)$ Trypton

$0,5 \%(w / v)$ Hefeextrakt

$1 \%(\mathrm{w} / \mathrm{v}) \mathrm{NaCl}$

Zusätze zur Selektion:

Ampicillin $(50 \mu \mathrm{g} / \mathrm{ml})$

Kanamycin $(50 \mu \mathrm{g} / \mathrm{ml})$

IPTG $(100 \mu \mathrm{M})$

$0,4 \%$ X-Gal

Agarplatten enthielten 1,5\% (w/v) Agar.

S.O.C. Medium

Invitrogen, Karlsruhe

\subsection{Längenstandards}

1 kB DNA Ladder

0,5 - $10 \mathrm{~Kb}$ RNA Ladder
Invitrogen, Karlsruhe

Invitrogen, Karlsruhe

\subsection{Verwendete Vektoren und Bakterienstämme}

\subsubsection{Vektoren}

pBlueScript II SK +/-

pET41a $(+)$

pGEM $^{\circledR}$-T Easy Vector System II
Stratagene, La Jolla (USA)

Merck, Darmstadt

Promega, Mannheim 


\subsubsection{Bakterienstämme}

Escherichia coli DH5a Invitrogen, Karlsruhe

Escherichia coli BL21(DE3) Merck, Darmstadt

\subsection{Gensonden, Oligonukleotide und Antikörper}

\subsubsection{Gensonden}

HEF-2 (Rapp et al., 1989; Hanes et al., 1992)

Zur Überprüfung der Integrität und der Quantität von RNA wurde ein cDNA-Fragment für den humanen Elongations-Faktor-2 (HEF-2) benutzt. Das als Gensonde verwendete 1,6 Kb Fragment wurde mit Bam HI und Bgl II aus der HEF-2-cDNA abgespalten, die dem Institut für Humangenetik freundlicherweise von Prof. Dr. K.H. Scheit, Max-Planck-Institut für Biophysikalische Chemie, Göttingen, zur Verfügung gestellt wurde.

Zur Erstellung aller anderen Sonden wurde mittels PCR ein Fragment amplifiziert und in pGEM $^{\circledR}$-T Easy kloniert. Durch Restriktion mit EcoRI wurden cDNA-Fragmente abgespalten, die als spezifische Gensonden verwendet wurden.

\subsubsection{Synthetische Oligonukleotide}

Alle für die Experimente verwendeten Oligonukleotide wurden von der Firma Operon (Köln) synthetisiert und im lyophilisierten Zustand erworben, mit Ampuwa auf eine Konzentration von $100 \mu \mathrm{M}(100 \mathrm{pmol} / \mu \mathrm{l})$ eingestellt und als Stock bei $-20^{\circ} \mathrm{C}$ gelagert.

Name Sequenz

AmylinF1

5'-CATGCAGACTTGGGCTGTAG-3'

AmylinR1

5'-TTCAGGAAATCACCAGAGCA-3' 


\begin{tabular}{|c|c|}
\hline AmyF1 & 5'-GGCTGTCGGATTTATGTTGG-3' \\
\hline AmyR1 & 5'-GCAATAAATGGGTCCTCAGC-3' \\
\hline CckbrF1 & 5'-GATGGTGATAATGACAGCGAGA-3' \\
\hline CckbrR1 & 5'-AGGTGTAGCTCAGCAAGTGGAT-3' \\
\hline EzrinF1 & 5'-CGAGAAGAAGAGGCGAGAGA-3' \\
\hline EzrinR1 & 5'-TGTAGCCCATAGGCTCTGCT-3' \\
\hline Foxq1_5'F1 & 5'-TTGGAGGTGTTCGTCCCACGCGCA-3' \\
\hline Foxq1_5'R1 & 5'-CAGTGGAGATGGCACGTCGTCGTC-3' \\
\hline mGAPDH-F & 5'-CATCACCATCTTCCAGGAGC-3' \\
\hline mGAPDH-R & 5'-ATGACCTTGCCCACAGCCTT-3' \\
\hline GastF1 & 5'-AGATGCCTCGACTGTGTGTG-3' \\
\hline GastR1 & 5'-GGCTCTGGAAGAGTGTTGCT-3' \\
\hline Hist2RezF1 & 5'-ТССТСАССАСССТСАТСТТС-3' \\
\hline Hist2RezR1 & 5'-ATCCCATCCACCAGTCCATA-3' \\
\hline HKAF1 & 5'-GCTGACATGATCTTGCTGGA-3' \\
\hline HKAR1 & 5'-CCTGCTGGAAAACAGAGAGG-3' \\
\hline HPRTF1 & 5'-CGTCGTGATTAGCGATGATG-3' \\
\hline HPRTR1 & 5'-TATGTCCCCCGTTGACTGAT-3' \\
\hline MYLKF1 & 5'-CGAGAACATCATGTGTGTCAAC-3' \\
\hline MYLKR1 & 5'-CCATGTTCTTGGTGTCTTTCAT-3' \\
\hline NHE2F1 & 5'-TCTTCGGGAAAGTCTCAGGA-3' \\
\hline NHE2R1 & 5'-GGGAATCAGTGGCTTGACTC-3' \\
\hline PepsF1 & 5'-GGAAGAACCTGGCATTTTCA-3' \\
\hline PepsR1 & 5'-ССТCСТCAAAGTTGCTCCTG-3' \\
\hline SomaF1 & 5'-CCTGAGGACCTGCGACTAGA-3' \\
\hline SomaR1 & 5'-GGGCCAGGAGTTAAGGAAGA-3' \\
\hline SX-RTF1 & 5'-AGTTGGGATCATCATCGGAG -3' \\
\hline SX-RTR1 & 5'-AGCTCTGGGTGTGGTTGAAT -3' \\
\hline Tph1F1 & 5'-GGCTTGCTTTCTTCCATCAG-3' \\
\hline TphR1 & 5'-TCCAGGTGTGCATTTTCAGA-3' \\
\hline
\end{tabular}




\subsubsection{Antikörper}

Anti-Digoxigenin-AP, Fab-Fragments

Anti-Somatostatin

Anti- $\mathrm{H}^{+}, \mathrm{K}^{+}$ATPase ( $\beta$-Untereinheit)

Schaf Anti-Maus AP

(Alkalische Phosphatase) konjugiert

Ziege Anti-Kaninchen FITC

(Fluoreszeinisothiocyanat) konjugiert

Ziege Anti-Maus FITC

(Fluoreszeinisothiocyanat) konjugiert
Roche Diagnostics, Mannheim

Zymed (Invitrogen), Karlsruhe

Acris Antibodies, Hiddenhausen

Sigma-Aldrich, Deisenhofen

Sigma-Aldrich, Deisenhofen

Sigma-Aldrich, Deisenhofen

\subsection{Mausstämme}

Die verwendeten Mäuse der Stämme 129Sv, C57BL/6J und CD1 stammten aus institutseigenen Beständen oder dem Max-Planck Institut für experimentelle Medizin (Göttingen). Die Haltungsbedingungen bestanden aus einem zwölfstündigen Hell-DunkelRhythmus bei $22^{\circ} \mathrm{C}$ und $55 \pm 5 \%$ relativer Luftfeuchtigkeit. Tierfutter wurde von der Firma ssniff-Spezialdiäten (Soest) bezogen. 


\section{METHODEN}

\subsection{Methoden zur Isolierung und Konzentrationsbestimmung von Nukleinsäuren}

\subsubsection{Isolierung von Plasmid-DNA durch Minipräparation}

Die Isolierung von Plasmid-DNA im analytischen Maßstab (Minipräparation) wurde mit den Lösungen des QIAGEN-Plasmid-Kits (QIAGEN, Hilden) mittels alkalischer Lyse (Birnboim und Doly, 1979; Birnboim, 1983) aus 5 ml LB-Übernachtkulturen mit entsprechendem plasmidkodiertem Antibiotikum durchgeführt, wobei auf die Reinigung über Anionenaustauschersäulen verzichtet wurde. Die Qualität dieser DNA ist hinreichend gut, um sie in Sequenzierungsreaktionen, in Restriktionen und für die Insert-Isolierung einzusetzen.

\subsubsection{Herstellung von Glyzerinkryokulturen}

Glyzerinkryokulturen wurden aus den LB-Übernachtkulturen der Plasmid-Minipräparationen durch Zugabe von $500 \mu \mathrm{l}$ sterilem Glyzerin $\mathrm{zu} 800 \mu \mathrm{l}$ der Bakteriensuspension, anschließender Durchmischung und Lagerung bei $-80^{\circ} \mathrm{C}$ hergestellt.

\subsubsection{Ethanolfällung von DNA aus wässrigen Lösungen}

Die Ethanolfällung wurde eingesetzt, um DNA zu konzentrieren und sie von Salzverunreinigungen zu befreien. Zur Fällung von Plasmid-DNA oder PCR-Produkten wurde der Ansatz mit 1/10 Vol 3 M Natriumacetat-Lösung (pH 5,2) und 3 Vol kaltem 96\%igem Ethanol versetzt. Die Präzipitation erfolgte durch Inkubation für 15 min bei $-80^{\circ} \mathrm{C}$ oder für $2 \mathrm{~h}$ bei $-20^{\circ} \mathrm{C}$. Der Ansatz wurde für $30 \mathrm{~min}$ bei $16000 \mathrm{x}$ g zentrifugiert und das Pellet mit 70\%igem Ethanol gewaschen. Anschließend wurde das Pellet getrocknet und in einem entsprechenden Volumen $\mathrm{H}_{2} \mathrm{O}$ aufgenommen. 


\subsubsection{Isolierung von Gesamt-RNA aus Gewebe der Maus}

(modifiziert nach Chomczynski und Sacchi, 1987)

RNA wurde mit Hilfe von TriReagent ${ }^{\circledR}$ (Molecular Research Center, Cincinnati (USA)) nach Herstellerangaben isoliert. Zum Schutz vor RNasen wurden RNase-freie Kunststoff EinwegGefäße und Filterspitzen verwendet. Frische oder bei $-80^{\circ} \mathrm{C}$ gelagerte Gewebe wurden in einem Glas/Glas-Potter in 0,5-1 ml TriReagent ${ }^{\circledR}$ bei Raumtemperatur aufgeschlossen, mit 100 - $200 \mu$ Chloroform gemischt (15 s Vortex) und nach einer Inkubationszeit von $10 \mathrm{~min}$ zentrifugiert (15 min, $16000 \times \mathrm{g}, 4^{\circ} \mathrm{C}$ ). Dadurch bildet sich eine untere organische Phase, welche die Proteine enthält, eine durch DNA gebildete Interphase und eine wässrige obere Phase, in der die RNA gelöst ist. Die RNA-Phase wird in ein neues Gefäß überführt und durch Zugabe von 250 - $500 \mu$ l (bezogen auf das TriReagent ${ }^{\circledR}$ Volumen) Isopropanol gefällt, zentrifugiert (15-30 min, $15000 \times \mathrm{g}, 4^{\circ} \mathrm{C}$ ), mit $800 \mu 1$ 70\%igem Ethanol gewaschen und in RNAse freien $\mathrm{H}_{2} \mathrm{O}$ gelöst.

\subsubsection{Konzentrationsbestimmung von Nukleinsäuren}

Die Konzentration von Mini-Präparation und isolierter Gesamt-RNA wurde mit einem Spektralphotometer (BioPhotometer, Eppendorf) bestimmt. Nach Abgleichen des Nullwertes konnten die Absorption der gemessenen Nukleinsäurelösung (bei $260 \mathrm{~nm}$ ) bestimmt und gleichzeitig Verunreinigungen durch Proteine (bei $280 \mathrm{~nm}$ ) bzw. Salze (bei $320 \mathrm{~nm}$ ) festgestellt werden. Die Berechnung der Nukleinsäurekonzentration wurde nach folgender Formel durchgeführt:

$\mathrm{C}[\mu \mathrm{g} / \mu \mathrm{l}]=(\mathrm{E} 260) \times \mathrm{f} \times \mathrm{c}$

$\mathrm{C}=$ Nukleinsäurekonzentration der gemessenen Probe; $\mathrm{E}=$ Extinktion;

$\mathrm{f}=$ Verdünnungsfaktor; $\mathrm{c}=$ nukleinsäurespezifischer Koeffizient in $\mu \mathrm{g} / \mu \mathrm{l}$

für doppelsträngige DNA: $\mathrm{c}=0,05 \mu \mathrm{g} / \mu \mathrm{l}$

für einzelsträngige DNA: $c=0,025 \mu \mathrm{g} / \mu \mathrm{l}$

für RNA: $\mathrm{c}=0,04 \mu \mathrm{g} / \mu \mathrm{l}$ 


\subsection{Polymerase-Kettenreaktion (PCR)}

2.12.1 Reverse Transkription (Loh et al., 1989)

Bei der Erststrang-Synthese dient die mRNA als Matrize für das Enzym Reverse Transkriptase, welches eine der mRNA komplementäre cDNA synthetisiert. Hierbei können entweder ein Oligo(dT)-Primer, der mit dem Poly(A)-Schwanz der mRNA hybridisiert, oder ein genspezifischer Primer verwendet werden. Im Falle des Oligo(dT) -Primers werden alle vorhandenen mRNAs revers transkribiert, während bei der Verwendung eines genspezifischen Primers Transkripte umgeschrieben werden, an die der Primer binden kann. Im Idealfall sind dies nur die Transkripte eines Gens. In einer anschließenden PCR wird mit Hilfe von sequenzspezifischen Primern ein DNA-Fragment amplifiziert. Die RT-PCR wurde mit Hilfe der SuperScript ${ }^{\mathrm{TM} I I}$ Reversen Transkriptase von Invitrogen (Karlsruhe) durchgeführt.

Für die Erststrang-Synthese wurden $1 \mathrm{ng}$ - $5 \mu \mathrm{g}$ RNA zusammen mit $1 \mu$ l Oligo(dT)-Primer $(500 \mu \mathrm{g} / \mathrm{ml})$ und $1 \mu \mathrm{dNTP}-M i x(10 \mathrm{mM})$ eingesetzt. Mit RNase-freiem Wasser wurde der Ansatz auf ein Gesamtvolumen von $12 \mu$ laufgefüllt. Zunächst erfolgte die Denaturierung der RNA bei $65^{\circ} \mathrm{C}$ für $10 \mathrm{~min}$. Nach dem Abkühlen auf Eis wurden $4 \mu \mathrm{l}$ x First-Strand Puffer und $2 \mu 10,1 \mathrm{M}$ DTT zugegeben und für $2 \mathrm{~min}$ auf $42^{\circ} \mathrm{C}$ temperiert. Anschließend folgten die Zugabe von $1 \mu$ SuperScript ${ }^{\mathrm{TM} I I}$ RT (Invitrogen, Karlsruhe) und eine 50 minütige Inkubation bei $42^{\circ} \mathrm{C}$. Zuletzt wurde das Enzym für $15 \mathrm{~min}$ bei $70^{\circ} \mathrm{C}$ inaktiviert.

2.12.2 DNA-Amplifikation mittels Polymerase-Kettenreaktion (Saiki et al., 1988)

Die Polymerase-Kettenreaktion (PCR) wurde mit folgendem Reaktionsansatz durchgeführt:

$\begin{array}{ll}\mathrm{x} \mu \mathrm{l} & \text { Template-DNA }(10-200 \mathrm{ng} \text { DNA }) \\ 1 \mu \mathrm{l} & \text { forward Primer }(10 \mathrm{pmol} / \mu \mathrm{l}) \\ 1 \mu \mathrm{l} & \text { reverse Primer }(10 \mathrm{pmol} / \mu \mathrm{l}) \\ 1 \mu \mathrm{l} & \text { dNTP-Mix }(10 \mathrm{mM}) \\ 5 \mu \mathrm{l} & \text { Taq-Polymerase Puffer }(10 \mathrm{x}) \\ 0,4 \mu \mathrm{l} & \text { Taq-Polymerase }(2,5 \mathrm{U} / \mu \mathrm{l}) \\ \text { ad } 50 \mu \mathrm{l} \text { Ampuwa }\end{array}$


Die DNA-Amplifikation erfolgte mittels 30-40 Zyklen in einem PTC-200 Thermocycler der Firma MJ Research. Die Anzahl der Zyklen, die einzelnen Temperaturschritte und die jeweilige Dauer der Zyklen mussten für jedes DNA-Fragment und die dafür eingesetzten Primer neu gewählt werden. Ein Zyklus bestand aus folgenden Einzelschritten:

$\left.\begin{array}{lll}95^{\circ} \mathrm{C} & 5 \mathrm{~min} \\ 94^{\circ} \mathrm{C} & 30 \mathrm{~s} \\ \mathrm{x}^{\circ} \mathrm{C} \text { (primerspezifisch) } & 30 \mathrm{~s} \\ 72^{\circ} \mathrm{C} & 1 \mathrm{~min} / \mathrm{kb}\end{array}\right\} \begin{aligned} & \text { Vordenaturierung } \\ & 72^{\circ} \mathrm{C} \\ & 5 \mathrm{~min}\end{aligned} \begin{aligned} & \text { Denaturierung } \\ & 4^{\circ} \mathrm{C}\end{aligned}$

\subsubsection{RT-PCR Analysen an Intron-losen Genen}

Bei der RT-PCR Analyse von Intron-losen Genen muss vorher die genomische DNA, die nach der RNA-Präparation in geringen Mengen vorhanden ist, eliminiert werden. Dazu wurden 2 - $5 \mu$ RNA einer DNAse-Behandlung nach Herstellerangaben (Roche, Mannheim) unterzogen.

Um die Eliminierung der DNA zu bestätigen wurde eine Kontroll-PCR mit der behandelten RNA durchgeführt und auf einem Agarosegel aufgetragen. Wenn kein Signal nach der PCR mit behandelter RNA zu erkennen war, konnte diese RNA für die weitere RT-PCR Analyse verwendet werden.

2.12.4 DNA-Sequenzanalyse (Sanger et al., 1977)

Die nichtradioaktive Sequenzierung basiert auf dem Prinzip des Kettenabbruchverfahrens (Sanger et al., 1977), wobei vier Didesoxynukleotide zum Einsatz kommen, die jeweils mit verschiedenen Fluoreszenzfarbstoffen markiert sind, welche wiederum während der gelelektrophoretischen Analyse über Laserabtastung automatisch detektiert werden. Die Sequenzreaktion wurde mit $200 \mathrm{ng} / \mathrm{kb}$ Plasmid-DNA, 10 pmol sequenzspezifischem Primer und $4 \mu$ ET-Mix (DYEnamic ET Dye Terminator Kit (MegaBACE), GE Healthcare, 
München) in einem Gesamtansatz von $10 \mu$ aufgefüllt. Die Kettenabbruchreaktion wurde als PCR in einem Thermocycler mit dem folgenden PCR-Programm betrieben:

\begin{tabular}{|c|c|c|c|}
\hline $95^{\circ} \mathrm{C}$ & $1 \mathrm{~min}$ & & Denaturierung \\
\hline $95^{\circ} \mathrm{C}$ & $20 \mathrm{~s}$ & & Denaturierung \\
\hline $60^{\circ} \mathrm{C}$ & $30 \mathrm{~s}$ & 25 Zyklen & Annealing \\
\hline $60^{\circ} \mathrm{C}$ & $1 \mathrm{~min}$ & & Elongation \\
\hline $60^{\circ} \mathrm{C}$ & $5 \mathrm{~min}$ & & Elongation \\
\hline
\end{tabular}

Anschließend wurde der Ansatz mit $10 \mu \mathrm{H} 2 \mathrm{O}$ aufgefüllt und über eine Sephadex MultiScreen-HV Platte (Millipore) aufgereingt. Die gelelektrophoretische Analyse erfolgte mit der automatischen Sequenzieranlage MegaBACE ${ }^{\text {TM}} 1000$ der Firma GE Healthcare (ehemals Amersham).

\subsection{Gelelektrophoretische Methoden}

\subsubsection{Auftrennung von DNA über Agarosegele}

Zur Analyse und Größenbestimmung von DNA wurden $0,8 \%$ bis 1,5\%ige Agarosegele mit 0,4 $\mu \mathrm{M}$ Ethidiumbromid eingesetzt. Die DNA-Lösungen wurden mit 1/5 Stopp-Mix versetzt und bei $100 \mathrm{~V}$ für 1 bis $2 \mathrm{~h}$ elektrophoretisch aufgetrennt. Als Laufpuffer diente 0,5x TBE. Durch Interkalation von Ethidiumbromid in die DNA-Doppelhelix konnte die DNA unter UV-Beleuchtung sichtbar gemacht werden.

\subsubsection{Auftrennung von RNA über Formaldehyd-Agarosegele}

Die Auftrennung erfolgte in 1\% bis 1,5\%igen Formaldehydgelen nach Sambrook et al. (1989). Die RNA-Proben wurden in 2 Volumen RNA-Probenpuffer $10 \mathrm{~min}$ bei $65^{\circ} \mathrm{C}$ denaturiert und anschließend 5 min auf Eis abgekühlt. Nach Zugabe von $6 \mu$ RNA- 
Ladepuffer wurden die Proben mit 1x MOPS-Puffer als Laufpuffer bei 30 bis $40 \mathrm{~V}$ üN bei $4^{\circ} \mathrm{C}$ elektrophoretisch aufgetrennt.

\subsection{Spaltung von Plasmid-DNA mit Restriktionsendonukleasen}

Standardmäßig wurden $10 \mathrm{U}$ Enzym pro $1 \mu \mathrm{g}$ DNA über 1-2 Std. beim Temperaturoptimum des verwendeten Enzyms nach Herstellerangaben eingesetzt. Die Vollständigkeit der Restriktion wurde in einer Agarose-Gelelektrophorese überprüft.

\subsection{Isolierung von DNA-Fragmenten aus Agarosegelen}

Die Isolierung von DNA-Restriktionsfragmenten aus Agarosegelen erfolgte mit Hilfe des QIAquick Gel Extraction Kit (Qiagen, Hilden). Diese Methode beruht auf dem von Vogelstein und Gillespie (1979) beschriebenen Prinzip der reversiblen Bindung von Nukleinsäuren an Partikel eines Anionenaustauschersilikats. Die gewünschte Bande wurde nach gelelektrophoretischer Auftrennung unter UV-Licht (354 nm oder $374 \mathrm{~nm}$ ) aus dem Agarosegel ausgeschnitten und die DNA den Herstellerangaben folgend extrahiert.

\subsection{Transfertechniken und Hybridisierungen}

\subsubsection{Northern Blot}

Die elektrophoretisch aufgetrennte RNA wurde durch Diffusion nach der von Sambrook et al. (1989) beschriebenen Methode 12 bis 16 h lang auf eine Nitrocellulose- (GE Healthcare, München) oder eine Nylon- (Macherey-Nagel, Düren) Membran transferiert. Anschließend wurde die RNA bei $80^{\circ} \mathrm{C}$ für $2 \mathrm{~h}$ an die Membran fixiert. 


\subsubsection{Random Prime Markierung}

Für die radioaktive Markierung von DNA-Fragmenten wurde das Rediprime ${ }^{\circledR}$ II Kit (GE Healthcare, München) benutzt. 20 bis 25 ng DNA wurden in $46 \mu 1$ TE-Puffer gelöst, 5 min denaturiert und auf Eis abgekühlt. Dieser Ansatz wurde mit $4 \mu 1\left[\alpha^{32} \mathrm{P}\right] \mathrm{dCTP}$ und dem Rediprime ${ }^{\circledR} \mathrm{II}-$ Ansatz gemischt und für $1 \mathrm{~h}$ bei $37^{\circ} \mathrm{C}$ inkubiert. Der Ansatz wurde über eine MicroSpin S-200 HR Säule (GE Healthcare, München) aufgereinigt.

\subsubsection{Hybridisierung radioaktiver DNA-Sonden an membrangebundene Nukleinsäuren}

Die Membran wurde für $2 \mathrm{~h}$ bei $65^{\circ} \mathrm{C}$ mit $10 \mathrm{ml}$ Rapid-Hyb ${ }^{\circledR}$ Puffer (GE Healthcare, München) durchgeführt. Nach der Vorhybridisierung wurde das aufgereinigte, radioaktiv markierte DNA-Sonde für $5 \mathrm{~min}$ denaturiert, $3 \mathrm{~min}$ auf Eis abgekühlt und zur Vorhybridisierungslösung gegeben. Die Hybridisierung erfolgte $\ddot{\mathrm{N}}$ bei $65^{\circ} \mathrm{C}$. Anschlißend wurde die Membran einmal 15 min bei $65^{\circ} \mathrm{C}$ mit 2x SSC/0,1\% SDS und einmal für 10 bis 30 min mit $0,2 \mathrm{x}$ SSC gewaschen. Anschließend erfolgte eine Autoradiographie bei $-80^{\circ} \mathrm{C}$ für einige Stunden bis zu mehreren Tagen.

\subsection{In vitro Transkription}

\subsubsection{Herstellung Digoxigenin-markierter RNA Sonden}

Für die in situ und die whole mount in situ Hybridisierung wurde DNA-Proben in vitro transkribiert. Dazu wurde das gewünschte DNA-Fragment in den pGEM $^{\circledR}$-T Easy kloniert, der Bindungsstellen für die SP6- und T7-RNA-Polymerase beinhaltet. Es wurden 2 Klone ausgesucht, die das DNA-Fragment in gegenläufiger Orientierung trugen. Das Plasmid wurde so linearisiert, dass die in vitro Transkription vom T7-Translationsstart beginnen konnte. Nach der Aufreinigung mit Hilfe von RNAse freien Lösungen wurde der Ansatz nach Herstellerangaben (Roche, Mannheim) erstellt und inkubiert. Die entstandene Digoxigenin- 
markierte RNA wurde mit $\mathrm{LiCl}$ und Ethanol gefällt und in $30 \mu 1$ RNAse freiem Wasser aufgenommen. Zur Kontrolle wurde $1 \mu$ lauf eine 1,2\%-iges Agarosegel aufgetragen.

\subsubsection{Dot-Blot Analyse der in vitro Transkription}

Von den Verdünnungsreihen der in vitro Transkription und einer Standardprobe mit bekannter Konzentration (Roche, Mannheim) wurden jeweils 1 bis $2 \mu$ auf eine Nylonmembran (Macherey-Nagel, Düren) gegeben. Die Membran wurde für 3 min luftgetrocknet. Anschließend wurde die RNA mittels UV-Crosslinking an die Membran gebunden. Danach wurde die Membran mit Blockpuffer I 30 min bei RT inkubiert. Die Inkubation mit Anti-Digoxigenin-AP Antikörper (Roche, Mannheim) (1:5000 in 1x PBS/2\% Milchpulver) erfolgte im Anschluss daran für $2 \mathrm{~h}$ bei RT. Nach dreimaligem Waschen für 10 min mit Waschpuffer (1x PBS/2\% Milchpulver) wurde die Membran für 1 min in AP-Puffer äquilibriert. Durch Zugabe der AP-Färbelösung (10ml AP-Puffer, 35 $\mu 1$ BCIP-Stocklösung, $45 \mu \mathrm{l}$ NBT Stocklösung) wurde die Farbentwicklung gestartet. Nach Erreichen der gewünschten Farbintensität wurde die Reaktion mit $\mathrm{dH}_{2} \mathrm{O}$ gestoppt. Durch einen Vergleich mit der Standardreihe konnte eine Abschätzung der Konzentrationen der in vitro Transkriptionsansätze vorgenommen werden.

\subsection{Fixierung von Magengewebe der Maus}

Der Magen der Maus wurde entnommen und entlang der großen Kurvatur aufgeschnitten. Um den restlichen Mageninhalt zu entfernen, wurde der Magen dreimal in PBS gewaschen.

Für die anschließende Fixierung in Paraformaldehyd (PFA) wurde der Mausmagen auf eine Korkplatte mit Nadeln aufgespannt. Für die Fixierung für die Elektronenmikroskopie wurde der Magen nicht aufgespannt.

\subsubsection{Fixierung mit Paraformaldehyd (PFA)}

Der auf Kork aufgespannte Magen wurde üN in $4 \%$ PFA-Lösung bei $4^{\circ} \mathrm{C}$ inkubiert. Nach anschließendem Waschen in PBS wurde der Magen mittels einer aufsteigenden Alkoholreihe 
(50\% Ethanol, 70\% Ethanol, 100\% Ethanol je 1 h) entwässert. Nachdem die Korkplatte enfernt wurde, erfolgte eine Inkubation in Methylbenzoat üN bei RT. Anschließend wurde der Magen in Xylol für $2 \mathrm{~h}$ inkubiert. Es folgte eine 2-stündige Inkubation in Xylol/Paraplast (1:1 bei $\left.60^{\circ} \mathrm{C}\right)$. Danach wurde das Gewebe in Paraplast $\left(60^{\circ} \mathrm{C}\right)$ überführt und für 1 bis 2 Tage bei $60^{\circ} \mathrm{C}$ inkubiert und im Anschluss daran in Paraplast eingebettet. Die Blöcke wurden bis zur Verwendung bei $4^{\circ} \mathrm{C}$ gelagert.

\subsubsection{Fixierung für die Elektronenmikroskopie}

Der Magen der Maus wurde entnommen, in PBS gewaschen und in Fixierunglösung (1\% PFA, 3\% Glutaraldehyd in 0,1M Cacodylatpuffer $\mathrm{pH}$ 7,4) überführt. Die Gewebeproben wurden im Anschluss daran auf Eis an Herrn PD Dr. med. Matthias Ochs, Experimentelle Morphologie, Universität Bern $(\mathrm{CH})$ geschickt, der die elektronenmikroskopische Untersuchung der Parietalzellen vornahm.

\subsubsection{Fixierung von Embryonen und Gewebe für die Hämatoxilin/Eosin (HE)-Färbung}

Embryonen am Tage 10,5 pc und der Magen von adulten Mäusen wurden entnommen und in Bouin-Fixativ fixiert. Die weitere Behandlung der fixierten Proben wurde von Herrn PD Dr. Jörg Männer, Zentrum für Anatomie, Universität Göttingen vorgenommen.

\subsection{Herstellung von Gewebeschnitten}

Das eingebettete Gewebe wurde mit einem Mikrotom (Jung RM 2035 von Leica, Nussloch) mit einer Schichtdicke von $5 \mu \mathrm{m}$ geschnitten. Die Schnitte wurden auf $45^{\circ} \mathrm{C}$ warmes $\mathrm{dH}_{2} \mathrm{O}$ gelegt, mit einem Objektträger (Menzel-Gläser, Braunschweig) aufgenommen und auf einer Wärmeplatte getrocknet. Nach Inkubation bei $45^{\circ} \mathrm{C}$ üN wurden die Schnitte bei $4^{\circ} \mathrm{C}$ bis zur Verwendung gelagert. 


\subsection{Immunlokalisation von Proteinen in Parafinschnitten}

Die Schnittpräparate wurden in Xylol inkubiert, in einer absteigenden Alkoholreihe gewässert und anschließend in 1x PBS für 10 min inkubiert. Anschließend wurden die Präparate in Blockierungslösung (4\% BSA/10\% Schafsserum in 1x PBS) für $1 \mathrm{~h}$ blockiert. Die Inkubation mit dem spezifischen Erstantikörper wurde üN bei $4^{\circ} \mathrm{C}$ in Hybridisierungslösung (4\% BSA/1\% Schafsserum in 1x PBS) durchgeführt. Die Verdünnung der Antikörper erfolgte gemäß den Herstellerangaben. Anschließend wurden die Objektträger dreimal 10 min bei RT mit 1x PBS gewaschen. Die Umsetzung mit dem Sekundärantikörper (Verdünnung nach Herstellerangaben) wurde für $2 \mathrm{~h}$ bei RT in Hybridisierungslösung durchgeführt. Nach anschließendem dreimalige Waschen in 1x PBS wurden die Schnittpräparate entweder mit VECTASHIELD $^{\circledR}$ (Vector Laboratories, Burlingame (USA)) überschichtet und eingedeckelt (FITC konjugierte Sekundärantikörper) oder zur Farbumsetzung mit NBT/BCIP-Färbelösung inkubiert (Alkalische Phosphatase gekoppelte Sekundärantikörper). Nach Eintreten der gewünschten Farbintensität wurde die Farbreaktion in 1x PBS gestoppt. Anschließend wurden die Schnittpräparate mit Aqua Polymount (Polyscience, Warrington (USA)) überschichtet und eingedeckelt. Danach erfolgte die mikroskopische Analyse.

\subsection{Herstellung und Aufreinigung eines Gastrokine 2-GST Fusionsproteins}

Für die Erstellung eines Fusionsproteins wurde ein 240 Bp (79 Aminosäuren + Stoppkodon) umfassender Bereich in korrekter Orientierung in den pET41a(+)-Expressionsvektor, der über einen GST-Tag verfügt, kloniert. Das daraus resultierende Gastrokine 2-GST Fusionsprotein besteht aus 299 Aminosäuren. Dies entspricht einem Molekulargewicht von ungefähr 33 Kilodalton (kDa). Für die Expression des Fusionsproteins wurde das Konstrukt in den E. coliStamm BL21(DE3) transformiert. Ein Liter LB-Kulturmedium (+ Kanamycin) wurde mit einem transformierten Klon versetzt und während einer Übertagkultur bei $37^{\circ} \mathrm{C}$ geschüttelt. Das Bakterienwachstum wurde durch Überprüfung der optischen Dichte (OD) kontrolliert. Nach Erreichen einer OD von 0,5 wurde die Expression des Fusionsproteins durch eine Zugabe von 1mmol IPTG (Endkonzentration $1 \mathrm{mM}$ ) und eine dreistündige Inkubation bei $37^{\circ} \mathrm{C}$ induziert. Anschließend wurden die Bakterien pelletiert. Die Isolierung der bakteriellen

Proteine und die Aufreinigung des Fusionsproteins wurde mit Hilfe des BugBuster ${ }^{\circledR}$ GST•Bind ${ }^{\text {TM }}$ Purification Kit (Merck, Darmstadt) nach Herstellerangaben durchgeführt. Zur 
Überprüfung der Aufreinigung wurden unterschiedliche Fraktionen der Aufreinigung auf einem SDS-Polyacrylamidgel (NuPAGE® Novex 4-12\% Bis-Tris Gel, Invitrogen (Karlsruhe)) aufgetrennt und mittels Coomassie-Färbung angefärbt.

\subsection{In situ Hybridisierung an Magengewebeschnitten}

(modifiziert nach Herstellerangaben (IG Applikation Manual (Roche, Mannheim))

Alle Lösungen für die in situ Hybridisierung, die vor oder während der Hybridisierung gebraucht wurden, waren mit DEPC- $\mathrm{dH}_{2} \mathrm{O}$ hergestellt worden. Die Schnittpräparate wurden in Xylol inkubiert, in einer absteigenden Alkoholreihe gewässert und anschließend in 1x PBS für 10 min inkubiert. Nach einer Behandlung mit 0,3\% Triton X-100 in 1x PBS für 15 min wurden die Schnitte für $10 \mathrm{~min}$ in 1x PBS gewaschen. Es folgte eine Inkubation mit Proteinase $\mathrm{K}\left(20 \mu \mathrm{g} / \mathrm{ml}\right.$ in $1 \mathrm{x}$ PBS ) für $30 \mathrm{~min}$ bei $37^{\circ} \mathrm{C}$. Nach anschließendem zweimaligen Waschen mit 1x PBS für je 5 min wurden die Schnittpräparate zur Vorhybrisierung mit Hybridisierungspuffer überschichtet und bei $42^{\circ} \mathrm{C}$ bis $55^{\circ} \mathrm{C}$ h vorhybridisiert. Währenddessen wurde pro Objektträger zu $94 \mu$ l Hybridisierungslösung $5 \mu 1$ LachsspermienDNA $(10 \mu \mathrm{g} / \mu \mathrm{l}$; vorher denaturieren) und 5-10 ng Digoxigenin-markierte RNA gegeben. Dieser Ansatz wurde für $2 \mathrm{~min}$ bei $70^{\circ} \mathrm{C}$ inkubiert und gut gemischt. Die Vorhybridisierungslösung wurde entfernt und es wurden $100 \mu 1$ der Hybridisierungslösung auf den Objektträger aufgetragen. Nach Auflegen eines Deckglases wurde die Hybridisierungslösung mittels Fixogum versiegelt. Die Hybridisierung erfolgte üN bei $42^{\circ}$ bis $55^{\circ} \mathrm{C}$ in einer Feuchtkammer. Anschließend wurde das Fixogum vorsichtig entfernt und die Deckel wurden durch eintauchen der Objektträger in 2x SSC/1\% SDS abgelöst. Es erfolgte ein zweimaliges Waschen bei RT in $2 x$ SSC/1\% SDS. Im Anschluss daran wurden die Objektträger zweimal 20 min bei $60^{\circ} \mathrm{C}$ inkubiert. Nach Überführung der Schnittpräparate in Puffer 1 (100mM Tris/HCl pH 7,5; $150 \mathrm{mM} \mathrm{NaCl)}$ erfolgte optional zur Beseitigung des Hintergrunds eine Inkubation mit RNAse A in Puffer 1 für 1 bis 10 min. Nach zweimaligem Waschen in Puffer 1 wurden die Objektträger mit Blockierungslösung überschichtet und für 30 bis $120 \mathrm{~min}$ inkubiert. Es folgte eine Inkubation mit der Antikörperlösung (AntiDigoxigenin-AP, 1:500 in Blockierungslösung) üN bei $4^{\circ} \mathrm{C}$. Anschließend wurden die Schnitte dreimal in Puffer 1 gewaschen und kurz in AP-Puffer äquilibriert. Die Farbreaktion erfolgte durch Zugabe der NBT/BCIP-Färbelösung und wurde nach Erreichen der gewünschten Farbintensität nach 2 bis $24 \mathrm{~h}$ durch waschen in 1x PBS gestoppt. Die 
Schnittpräparate wurden mit Aqua Polymount überschichtet, eingedeckelt und der mikroskopischen Analyse unterzogen.

\subsection{Whole mount in situ Hybridisierung an Embryonen}

(modifiziert nach Belo et al., 1997)

Alle Lösungen bis nach der Hybridisierung wurden mit DEPC- $\mathrm{dH}_{2} \mathrm{O}$ erstellt. Die Embryonen wurden am gewünschten Tag post coitum in 1x PBS präpariert. Embryonen, die älter als 9,5 dpc waren, wurden mit einer Nadel dreimal im Kopfbereich perforiert. Für die hier durchgeführten Experimente wurden Embryonen 10,5 dpc verwendet. Nach einer Inkubation bei $4{ }^{\circ} \mathrm{C}$ üN in $4 \%$ Paraformaldehydlösung (in 1x PBS) wurden die Embryonen zweimal mit 1x PBT (1x PBS mit 0,1\% Tween-20) gewaschen und anschließend in einer aufsteigenden Methanolreihe entwässert. (25\%, 50\%, 75\%, 100\% Methanol in 1x PBT je $10 \mathrm{~min})$. Die Embryonen konnten in Methanol bis zu 2 Monate bei $-20^{\circ} \mathrm{C}$ gelagert werden. Für die whole mount in situ Hybridisierung wurden die Embryonen zunächst in einer aufsteigenden Methanolreihe $(75 \%, 50 \%, 25 \%$ Methanol in 1x PBT je 10 min) gewässert. Anschließend wurden die Embryonen für $1 \mathrm{~h}$ bei RT in $6 \% \mathrm{H}_{2} \mathrm{O}_{2}$ in $1 \mathrm{x}$ PBT gebleicht. Nach dreimaligem Waschen in 1x PBT für je 5 min, erfolgte eine Inkubation der Embryonen in $10 \mu \mathrm{g} / \mathrm{ml}$ Proteinase K in 1x PBT für 6 min. Danach wurden die Embryonen für zweimal 10 min bei RT in Glycine-Lösung (2mg/ml Glycine in 1x PBT; frisch herstellen) geschwenkt. Es folgten ein dreimaliges Waschen in 1x PBT für 5 min bei RT und eine Nachfixierung in 4\% Paraformaldehyd $/ 0,2 \%$ Glutaraldehyd in 1x PBT (frisch herstellen). Nach drei Waschritten in 1x PBT für 5 min bei RT, wurden die Embryonen mit Prähybridisierungslösung (50\% Formamide, deionisiert; $5 \mathrm{x}$ SSC pH 4,5; 1\% SDS; 50 $\mu \mathrm{g} / \mathrm{ml}$ Hefe tRNA; 50 $\mu \mathrm{g} / \mathrm{ml}$ Heparin) für 1 bis $2 \mathrm{~h}$ bei $70^{\circ} \mathrm{C}$ inkubiert. Die Prähybridisierungslösung wurde entfernt, durch Hybridisierungslösung (Prähybridisierungslösung mit $1 \mu \mathrm{g} / \mathrm{ml}$ Dig-markierter Probe) ersetzt und $\ddot{\mathrm{N}}$ bei $70^{\circ} \mathrm{C}$ inkubiert. Im Anschluss wurden die Embryonen dreimal $30 \mathrm{~min}$ in Waschlösung 1 (50\% Formamid; 5x SSC pH 4,5; 1\% SDS; angewärmt) und dreimal 5 min in TNT-Lösung (10 mM Tris/HCl pH 7,5; 0,5 M NaCl; 0,1\% Tween-20) gewaschen. Es folgte eine Inkubation mit RNAse A (100 $\mu \mathrm{g} / \mathrm{ml}$ RNAse A in TNT-Lösung) für $1 \mathrm{~h}$ bei $37^{\circ} \mathrm{C}$. Danach wurden die Embryonen 5 min bei RT in einem 1:1 Gemisch aus TNT-Lösung und Waschlösung 2 (50\% Formamid; 2x SSC pH 4,5; 0,2\% SDS) gewaschen. Es folgten 3 Waschritte mit Waschlösung 2 für $30 \mathrm{~min}$ bei $65^{\circ} \mathrm{C}$. Anschließend wurden die Embryonen für 
dreimal 5 min in MAB-Lösung (100 mM Maleinsäure; $150 \mathrm{mM} \mathrm{NaCl} ; 2 \mathrm{mM}$ Levamisol; 0,1\% Tween-20 (frisch herstellen; einstellen auf $\mathrm{pH} 7,5)$ ) überführt und danach in MAB/BlockLösung ( $2 \%$ Roche Blockreagenz in MAB-Lösung bei $65^{\circ} \mathrm{C}$ lösen; anschließend auf Eis abkühlen) für $2 \mathrm{~h}$ bei RT blockiert. Nach Entfernen der Blockierungslösung wurden die Embryonen mit Antikörperlösung (Anti-Digoxigenin-AP Antikörper (1:5000) in MAB/BlockLösung) üN bei $4^{\circ} \mathrm{C}$ inkubiert. Es folgten einstündige Waschritte während des ganzen Tags mit MAB-Lösung bei RT mit anschließendem Waschen üN bei $4^{\circ} \mathrm{C}$ mit MAB-Lösung. Im Anschluss wurden die Embryonen in AP-Puffer überführt und dreimal 30 min inkubiert. Anschließend erfolgte die Farbumsetzung in NBT/BCIP-Färbelösung bis zum Erreichen der gewünschten Färbintesität (2 bis 24 h). Die Embryonen wurden daraufhin dreimal 10 min in 1x PBT (pH 4,5) inkubiert und mit 4\% Paraformaldehyd $/ 0,1 \%$ Glutaraldehyd üN bei $4^{\circ} \mathrm{C}$ nachfixiert.

\subsection{4 pH-Wertmessung des Magensaftes}

(modifiziert nach Wood und Dubois, 1983)

Foxq1 $1^{-/}$- und Wildtypmäusen wurde üN das Futter und die Einstreu entzogen. Für die Überprüfung des basalen pH-Wertes des Magensaftes wurde den Mäusen der Magen entnommen und entlang der großen Kurvatur geöffnet. Es folgte eine Inkubation für 5 min in 1x PBS mit gelegentlichem Schütteln. Anschließend wurde der Magen aus der Lösung genommen und auf einem Whatmannfilter trocken getupft. Die Feuchtmasse des Magens wurde bestimmt. Die Lösung wurde gegebenenfalls durch Zentrifugation vom restlichen Mageninhalt befreit. Anschließend wurde der $\mathrm{pH}$-Wert dieser Lösung bestimmt. Um die Auswirkungen eines Sekretagog-Stimulus durch Histamin oder Gastrin zu untersuchen, wurde den Mäusen dieses intraperitoneal verabreicht. $30 \mathrm{~min}$ nach Histamingabe $(10 \mu \mathrm{g} / \mathrm{g}$ Körpergewicht) und 60 min nach Pentagastrininjektion ( $1 \mu \mathrm{g} / \mathrm{g}$ Körpergewicht) wurde der pHWert des Magensaftes nach oben beschriebener Vorgehensweise bestimmt. 


\subsection{Expressionsanalysen von Foxq1 während der embryonalen Magenentwicklung}

Für Foxq1 konnte bereits eine Expression in Magen und Niere der adulten Maus gezeigt werden (Frank und Zoll, 1998). Außerdem wurde im Rahmen einer früheren Dissertation (Frank, 1997) eine Expression während der pränatalen und postnatalen Magenentwicklung ab Tag 18,5 dpc mittels Northern Blot Analyse nachgewiesen. Mit Hilfe einer RT-PCR Analyse konnte in derselben Dissertation die Expression von Foxq1 auch in früheren pränatalen Stadien, beginnend mit 8,5 dpc, beobachtet werden. Im Rahmen der vorgelegten Dissertation sollte die Expression in früheren Stadien der embryonalen Mausentwicklung untersucht werden. Dafür wurde durch einen RT-PCR Assay die Expression von Foxq1 in Morulae, embryonalen Stammzellen (ES) und post-implatativen Stadien von 8,5 dpc bis 12,5 dpc untersucht. Hierbei konnte eine Expression in allen untersuchten Stadien gezeigt werden (Abb. 3.1.1).

\section{Foxq1 \\ Gapdh}
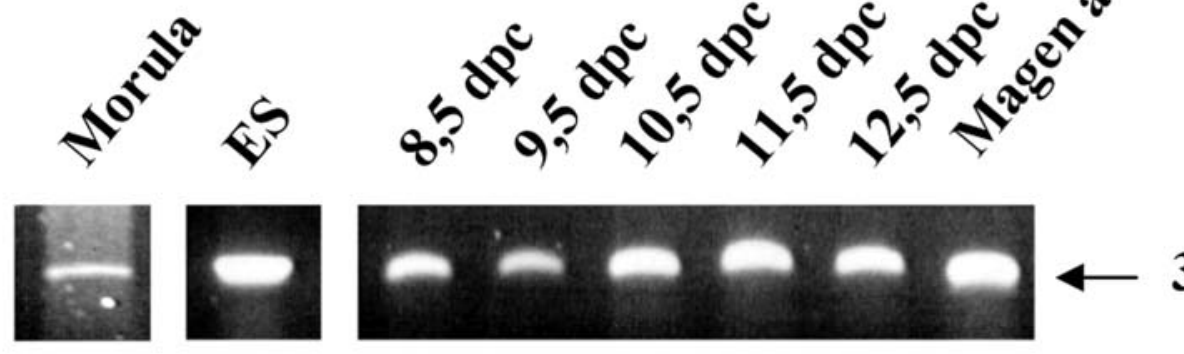

353 Bp
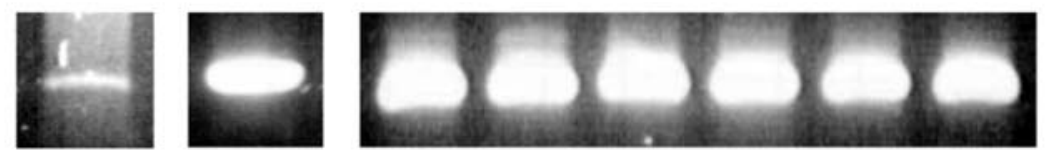

302 Bp

\section{Abb. 3.1.1: Foxq1 Expression in pränatalen Mausstadien}

RT-PCR Assay mit RNA unterschiedlicher pränataler Entwicklungsstufen der Maus. Ein Foxq1 Transkript lässt sich bereits im Morulastadium der embryonalen Mausentwicklung und in ES Zellen detektieren. In allen untersuchten späteren Stadien (8,5 dpc bis 12,5 dpc) ist ebenfalls ein Transkript nachweisbar. Gapdh = Glyceraldehyd-3-Phosphat Dehydrogenase 
Mit Hilfe der Northern-Blot Analyse sollte außerdem die Expression von Foxq1 in der Magenentwicklung genauer untersucht werden. Hierfür wurde RNA des gesamten Embryos (8,5 dpc bis 14,5 dpc) oder RNA des Magens (15,5 dpc bis adult) verwendet. Ein Foxq1 Transkript ließ sich in Magen-RNA aller Stadien beginnend mit 15,5 dpc nachweisen, wobei eine Zunahme der Expression ab 18,5 dpc zu beobachten war. Kein Transkript ließ sich dagegen in Gesamt-RNA von Embryonen früherer Entwicklungsstadien erkennen (Abb. 3.1.2).

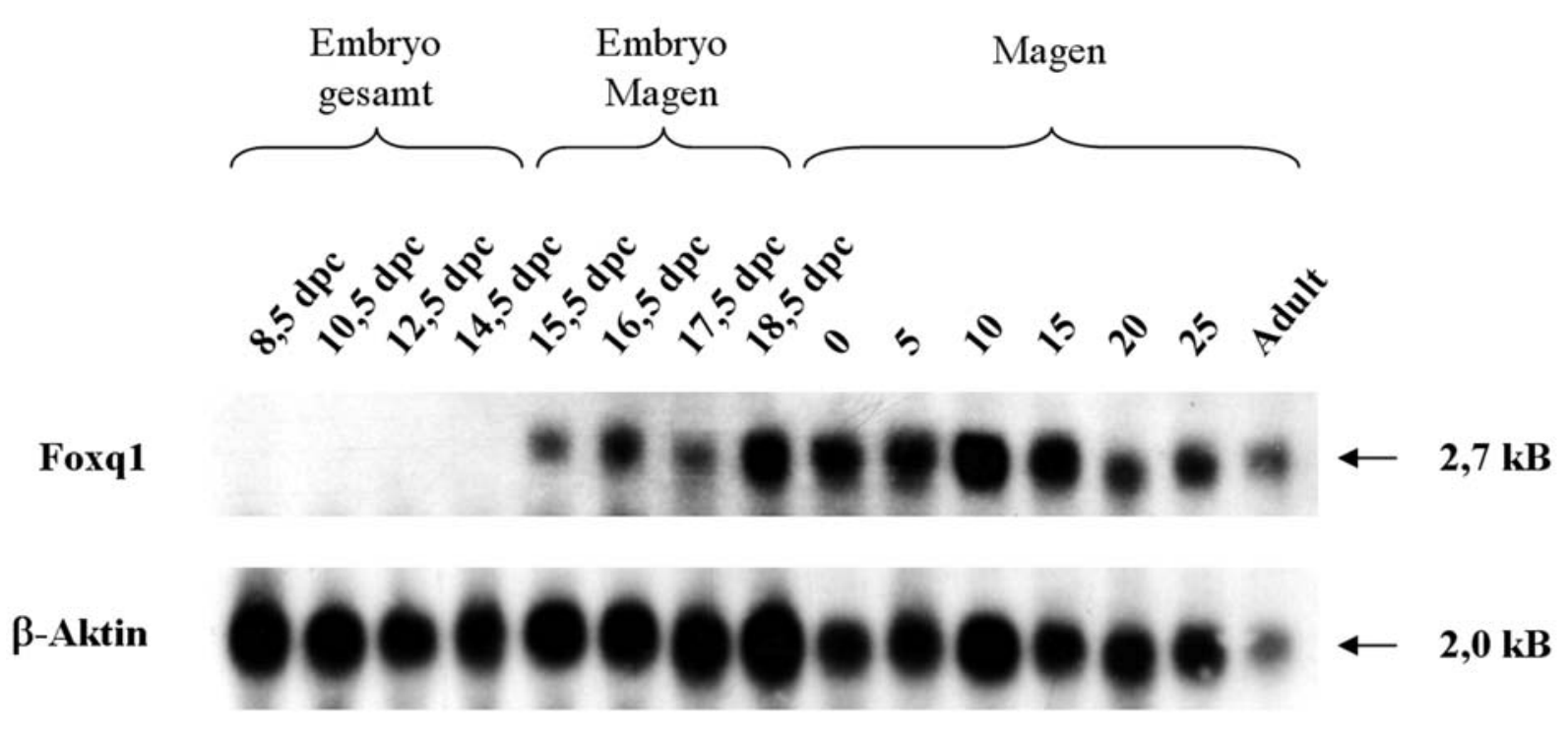

\section{Abb. 3.1.2: Foxq1 Expression während der pränatalen und postnatalen Magenentwicklung}

Northern-Blot Analyse mit RNA aus gesamtem Embryo (8,5 dpc-14,5 dpc) oder mit RNA des Magens (15,5 dpc bis adult). Foxq1 Expression ist ab 15,5 dpc detektierbar. Frühere Stadien zeigen keine Expression. Eine Rehybridisierung erfolgte mit $\beta$-Aktin.

Die Ergebnisse dieser Studien zur embryonalen Foxq1-Expression veranlassten uns dazu, die Expression von Foxq1 im Mausembryo genauer zu untersuchen. Hierfür wurde eine whole mount in situ Hybridisierung an Embryonen 10,5 dpc durchgeführt. Mittels eines Foxq1 spezifischen DNA-Abschnitts wurden durch in vitro Transkription mit SP6- bzw. T7-RNAPolymerase RNA-Sonden hergestellt. Von diesen Sonden fungierte jeweils eine Sonde als Sense- bzw. Antisense-Sonde. Die whole mount in situ Hybridisierung mit der AntisenseSonde ließ nach kurzer, einstündiger Inkubation in der Färbelösung eine Foxq1 Expression im 
Rautenhirnbereich (Rhombencephalon) erkennen (Abb. 3.1.3 A bis C). Eine längere Exposition von drei Stunden führte zusätzlich zu einer Färbung im Mes- und Prosencephalon (Abb. 3.1.3 D bis F). Die Hybridisierung mit der Sense-Sonde lieferte keine Färbung der Embryonen (Abb. 3.1.3 G).
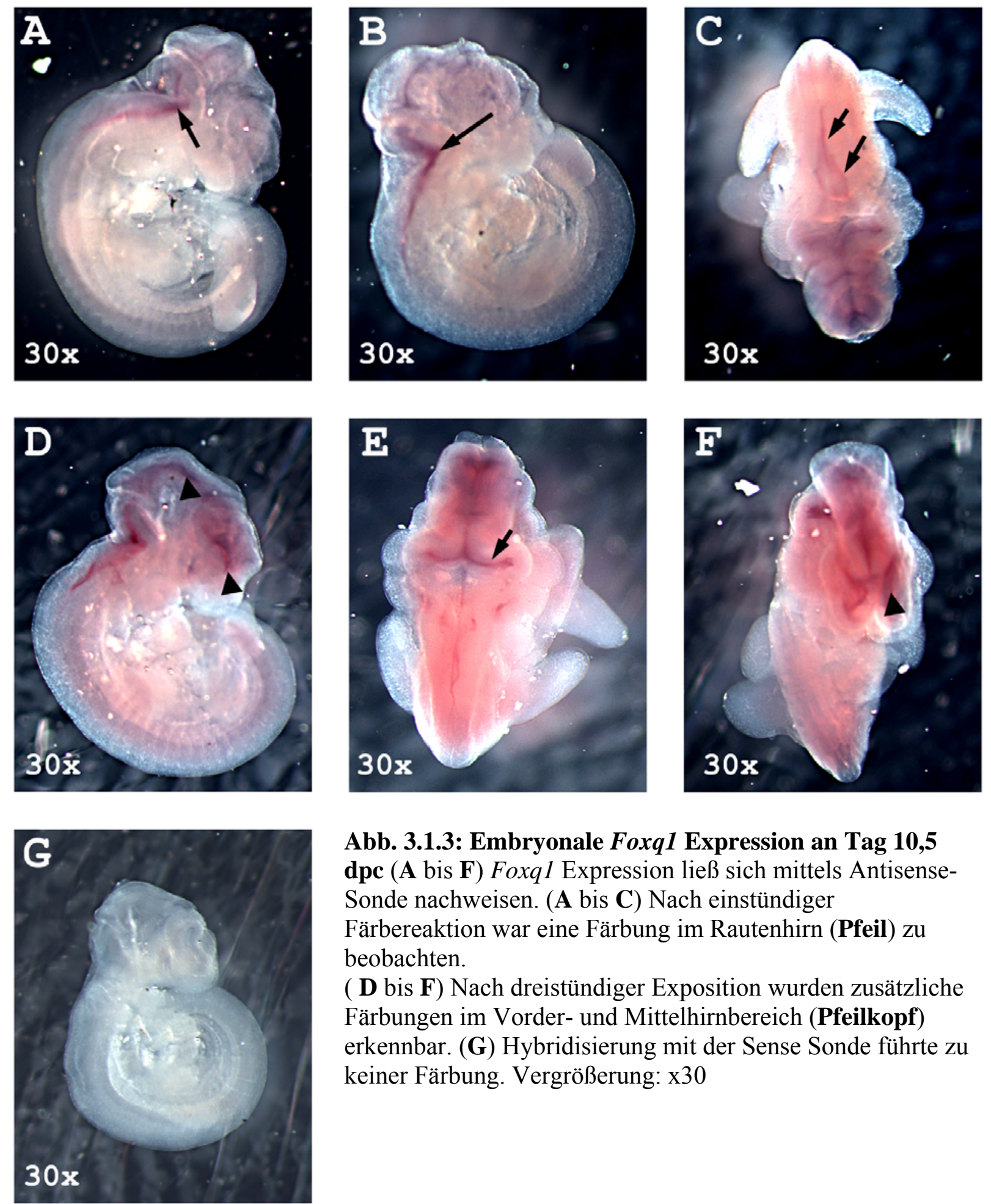

Abb. 3.1.3: Embryonale Foxq1 Expression an Tag 10,5 dpc (A bis F) Foxq1 Expression ließ sich mittels AntisenseSonde nachweisen. (A bis C) Nach einstündiger Färbereaktion war eine Färbung im Rautenhirn (Pfeil) zu beobachten.

( D bis F) Nach dreistündiger Exposition wurden zusätzliche Färbungen im Vorder- und Mittelhirnbereich (Pfeilkopf) erkennbar. (G) Hybridisierung mit der Sense Sonde führte zu keiner Färbung. Vergrößerung: x30 
Wie bereits erwähnt (3.1), wurde für Foxq1 eine starke Expression im Magen gezeigt (Frank und Zoll, 1998). Um die zellspezifische Expression von Foxq1 im Magen aufzudecken, wurde eine in situ Hybridisierung an Magenschnitten durchgeführt. Als Sonden wurden die oben erwähnten Sense- bzw. Antisense-RNA-Sonden verwendet. Foxq1 Expression war nur nach Hybridisierung mit der Antisense-Sonde zu beobachten (Abb. 3.1.4 I bis III). Hybridisierung mit der Sense-Sonde ließ kein Signal erkennen (Abb. 3.1.4 IV). Foxq1 positive Zellen in den Magenschnitten lassen ihrer Gestalt und Lage nach vermuten, dass es sich um Parietalzellen handelt. Um diese Vermutung zu erhärten, wurde die Verteilung von Parietalzellen in der gastrischen Mucosa untersucht. Hierfür wurde ein Antikörper gegen den Parietalzellspezifischen Marker $\mathrm{H}^{+}, \mathrm{K}^{+}$ATPase verwendet. Die Parietalzellen wurden durch eine Immunfärbung detektiert (Abb. 3.1.4 V). Foxq1 und $\mathrm{H}^{+}, \mathrm{K}^{+}$ATPase weisen das gleiche Expressionsmuster in der Magenschleimhaut auf, so dass davon ausgegangen werden kann, dass es sich bei den Foxq1 exprimierenden Zellen der gastrischen Mucosa um Parietalzellen handelt. 

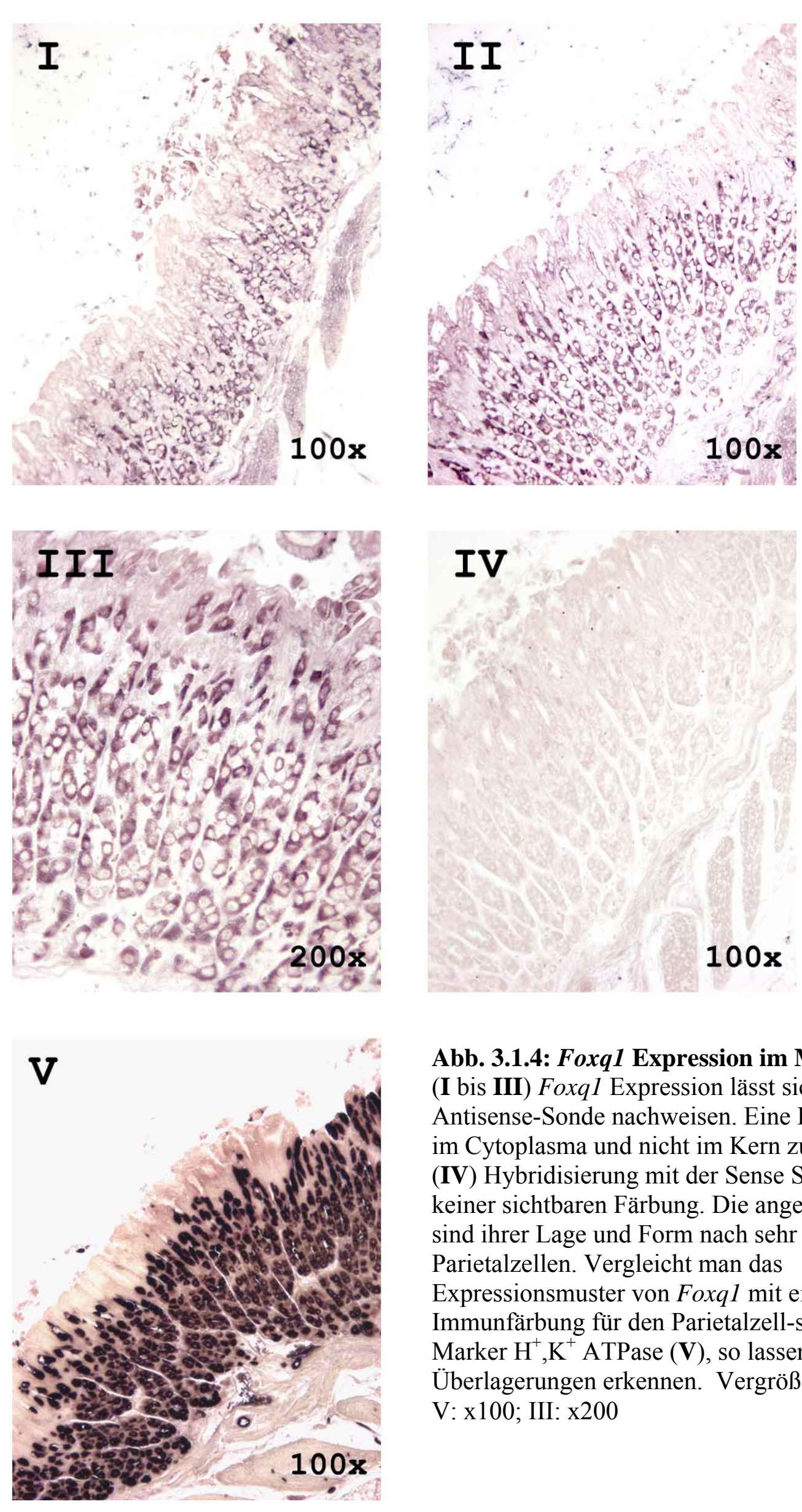

Abb. 3.1.4: Foxq1 Expression im Magengewebe (I bis III) Foxq1 Expression lässt sich mittels Antisense-Sonde nachweisen. Eine Färbung ist nur im Cytoplasma und nicht im Kern zu finden (III). (IV) Hybridisierung mit der Sense Sonde führt zu keiner sichtbaren Färbung. Die angefärbten Zellen sind ihrer Lage und Form nach sehr wahrscheinlich Parietalzellen. Vergleicht man das Expressionsmuster von Foxq1 mit einer Immunfärbung für den Parietalzell-spezifischen Marker $\mathrm{H}^{+}, \mathrm{K}^{+}$ATPase (V), so lassen sich starke Überlagerungen erkennen. Vergrößerung: I, II, IV + V: x100; III: x200 


\subsection{Analyse von Foxq1-defizienten Mäusen}

Um die physiologische Funktion von Foxq1 aufzuklären, wurden im Rahmen einer vorherigen Dissertation (Pasche, 2002) Foxq1-defiziente Mäuse mittels homologer Rekombination generiert, wobei die gesamte kodierende Region des Foxq1-Gens deletiert wurde. Um die Inaktivierung von Foxq1 zu überprüfen, wurde zunächst eine Northern Blot Analyse an Magen RNA von 3 Monate alten Wildtyp-, Foxq1 ${ }^{+/-}$- und Foxq1 ${ }^{-/}$-Mäusen durchgeführt. Mittels Hybridisierung mit einer Foxq1-spezifischen Sonde aus dem 5, codierenden Bereich ließ sich ein starkes Signal bei Wildtypmäusen, eine reduzierte Signalstärke bei heterozygoten Tieren und kein Signal im Magen von Foxq1-defizienten Mäusen beobachten (Abb. 3.2).
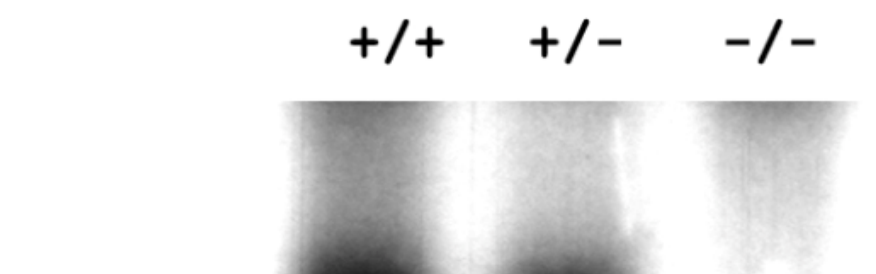

Foxq1

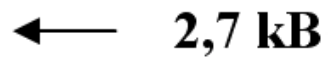

hEF

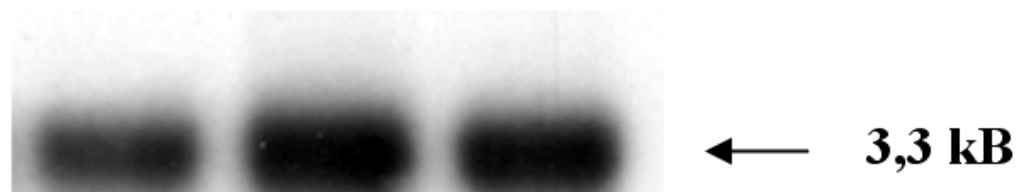

Abb. 3.2: Analyse der Foxq1-Inaktivierung im Mausmagen

Northern Blot Analyse an Magen-RNA aus Wildtyp-, Foxq $1^{+/-}$- und Foxq1 ${ }^{-/}$-Mäusen.

Foxq1 Expression ist in Wildtypmäusen deutlich, in heterozygoten Mäusen schwächer und in Foxq1 ${ }^{-/}$-Mäusen gar nicht zu erkennen. Die Rehybridisierung wurde mit $h E F$ durchgeführt. 


\subsection{Haaranalyse Foxq1-defizienter Mäuse}

In einer zuvor erschienen Veröffentlichung (Hong et al, 2001) wurde eine Foxq1 Expression in den prämedullären Zellen der Haarwurzel beschrieben. Ferner wurde gezeigt, dass homozygote Satin ( $s a$ ) Mäusen, die durch eine Bestrahlung mit $\gamma$-Strahlen erzeugt wurden, eine Deletion im kodierenden 3'-Bereich des Foxq1-Gens aufweisen. Satin Mäuse sind durch eine Fehlbildung der inneren Haarschicht, der Medulla, gekennzeichnet. Nach außen hin resultiert dies in einem seidig glänzenden Fell. Diese Beobachtungen veranlassten uns dazu, das Fell und die Haarstruktur von Foxq1 $1^{-/}$-Mäusen genauer zu untersuchen. Hierbei ließ sich feststellen, dass Foxq1-defiziente Mäuse ebenfalls den von Hong et al. (2001) beschriebenen Haarphänotyp zeigen. Neben dem seidig glänzenden Fell (Abb. 3.3 A und B) konnte mit Hilfe von Durchlichtmikroskopaufnahmen der Haare gezeigt werden, dass die beschriebene Fehlbildung der Medulla (Abb. 3.3 C und D) ebenfalls besteht. Untersuchungen der äußeren Haarstruktur und der Haarwurzel mittels eines Rasterelektronenmikroskops ließen dahingegen keine Unterschiede zwischen Wildtyp- und Foxq1 $1^{-/}$-Haaren erkennen (Abb. $3.3 \mathrm{E}$ bis H). 

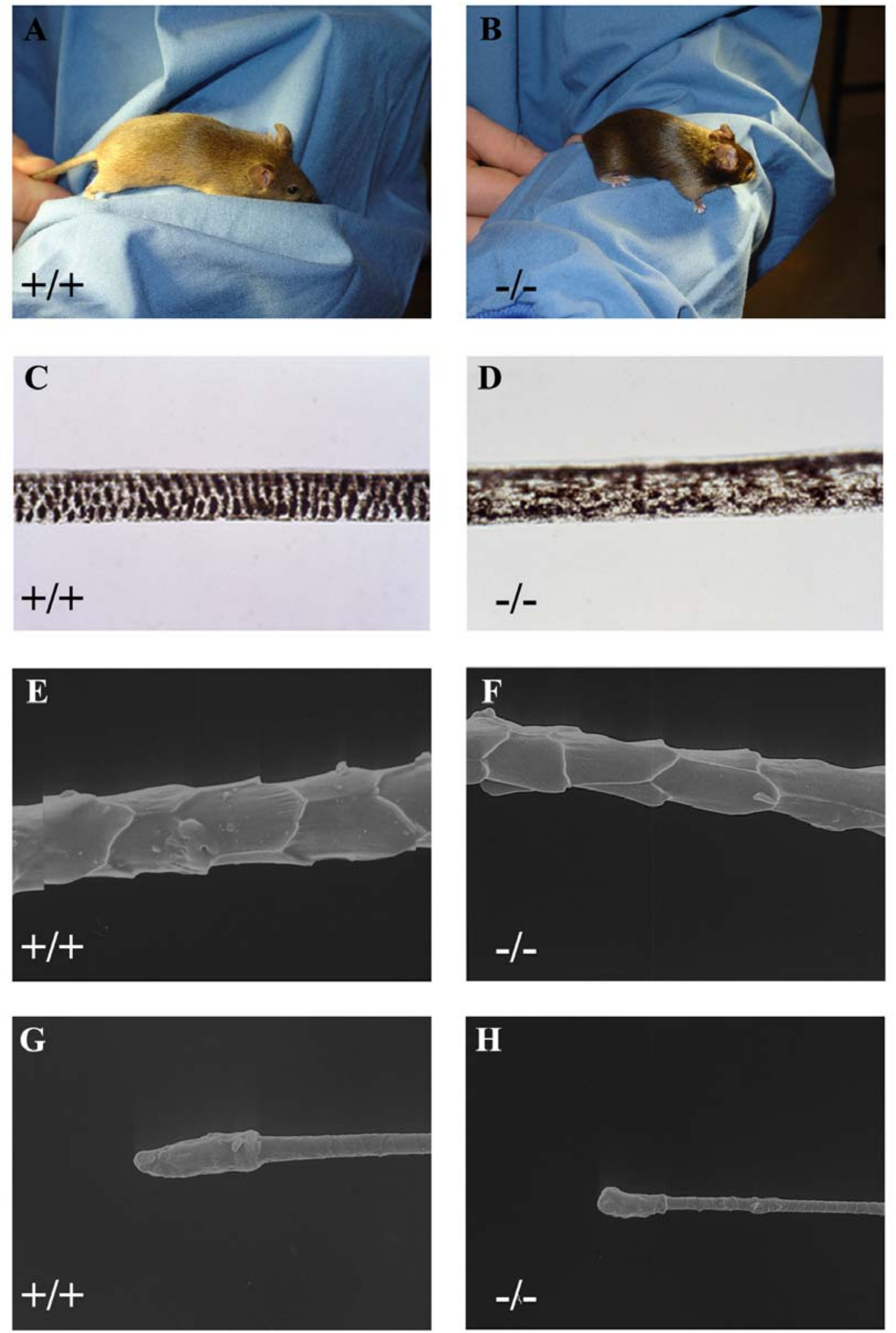

\section{Abb. 3.3: Haaranalyse von Wildtyp- und Foxq1 $1^{--}$-Mäusen.}

(A und B) Makroskopischer Vergleich des Fells von (A) Wildtyp- und (B) Foxq ${ }^{-/-}$-Mäusen. (C und D) Analyse der Haare im Durchlichtmikroskop. (D) Hierbei ist deutlich die Störung der inneren, medullaren Haarstruktur bei Foxq1 $1^{-/-}$-Mäusen zu erkennen. (C) Haare von Wildtypmäusen zeigen das typische gebänderte Muster. (E bis $\mathbf{H})$ Elektronenmikoskopische Untersuchungen der ( $\mathbf{E}$ und $\mathbf{F})$ äußeren Haarstruktur und ( $\mathbf{G}$ und $\mathbf{H})$ der Haarwurzel zeigten keine Unterschiede. 


\subsection{Konsequenzen der Foxq1 Defizienz für die Embryonalentwicklung der Maus}

Wie unter 3.1 gezeigt, wird Foxq1 schon während der frühen Embryonalentwicklung der Maus exprimiert. Um zu überprüfen, ob der Verlust der Foxq1 Expression Auswirkungen auf die Embryonalentwicklung hat, wurden zunächst die Nachkommen von heterozygoten Kreuzungen auf einem C57BL/6Jx129/Sv-Hybridhintergrund und auf einem 129/SvInzuchthintergrund genotypisiert und die Daten ausgewertet. Es ließ sich eine Reduzierung von ungefähr $40 \%$ des Anteils an Foxq1 $1^{-/}$-Tieren auf dem Hybridhintergrund beobachten. Das Verhältnis von Wildtypmäusen zu Foxq1 ${ }^{+/}$-Tieren und zu Foxq1 $1^{-/}$-Tieren wich mit 1,3 : 2,1 : 0,6 signifikant von der erwarteten Mendelschen Verteilung ab (Tab. 3.1a). Diese signifikante Abweichung von der Mendelschen Verteilung wurde auf dem 129/Sv-Hintergrund nicht festgestellt.

Tab. 3.1a Analyse der Nachkommen $(\mathrm{n}=100)$ aus heterozygoten Verpaarungen

C57BL/6JX129/Sv-Hintergrund

\begin{tabular}{ccc}
\multicolumn{3}{c}{ Genotyp } \\
\hline$+/+$ & $+/-$ & $-/-$ \\
31,7 & 53,3 & 15,0 \\
1,3 & 2,1 & 0,6
\end{tabular}

$129 / \mathrm{Sv}$-Hintergund

\begin{tabular}{lccc} 
& \multicolumn{3}{c}{ Genotyp } \\
\cline { 2 - 4 } & $+/+$ & $+/-$ & $-/-$ \\
Prozent & 30,9 & 46,8 & 22,3 \\
Verhältnis & 1,2 & 1,9 & 0,9
\end{tabular}

Tab. 3.1b Wurfgrößen von Foxq1 ${ }^{-/-}$(C57BL/6JX129/Sv-Hybridhintergrund) und Wildtyp Verpaarungen

\begin{tabular}{ccc} 
& \multicolumn{2}{c}{ Genotyp der Eltern } \\
\cline { 2 - 3 } Wurfgröße & $+/+\mathrm{X}+/+$ & $-/-\mathrm{X}-/-$ \\
$9,1+/-1,3$ & $4,5+/-2,2$
\end{tabular}


Die Reduktion des Anteils an Foxq1-defizienten Nachkommen ließ uns eine erhöhte Absterberate von Foxq1 ${ }^{-/}$-Embryonen während der Schwangerschaft vermuten. Diese Vermutung wurde außerdem erhärtet durch die Beobachtung, dass Foxq1 ${ }^{-/}$x Foxq1 $1^{-/}$Kreuzungen eine signifikante Reduzierung der Wurfgröße um ungefähr 50\% aufwiesen (Tab. $3.1 b)$.

Unter Berücksichtigung der embryonalen Expression von Foxq1 im Kopf (3.1.3) sollten die Ursachen und der Zeitpunkt der embryonalen Letalität mit besonderem Augenmerk auf Fehlbildungen des Kopfes genauer untersucht werden. Dafür wurden Embryonen zu unterschiedlichen Zeitpunkten der Embryonalentwicklung aus Foxq1 $1^{-/}$-Verpaarungen präpariert und analysiert. Die Untersuchungen zeigten, dass Fehlbildungen im Kopfbereich bei etwa 50\% der Embryonen an 10,5 dpc zu beobachten waren (3.4.1). Solche Fehlbildungen konnten bei Embryonen an 12,5 dpc nur vereinzelt festgestellt werden. Dahingegen ließen sich Fehlbildungen in anderen embryonalen Körperteilen $\mathrm{zu}$ keinem untersuchten Zeitpunkt beobachten. Neben diesen Ergebnissen ließ sich eine deutliche Abnahme an Embryonen nach 10,5 dpc feststellen, die einherging mit einer Zunahme an resorbierten Embryonen. Diese Beobachtungen lassen vermuten, dass Embryonen mit Fehlbildungen des Kopfes an 10,5 dpc im Verlauf der Embryonalentwicklung absterben. Fehlbildungen oder eine Reduktion der Embryonenanzahl an 8,5 dpc konnten nicht beobachtet werden, was darauf hindeutet, dass Foxq1 Defizienz keine sichtbaren Auswirkungen auf die frühe Embryonalentwicklung hat.

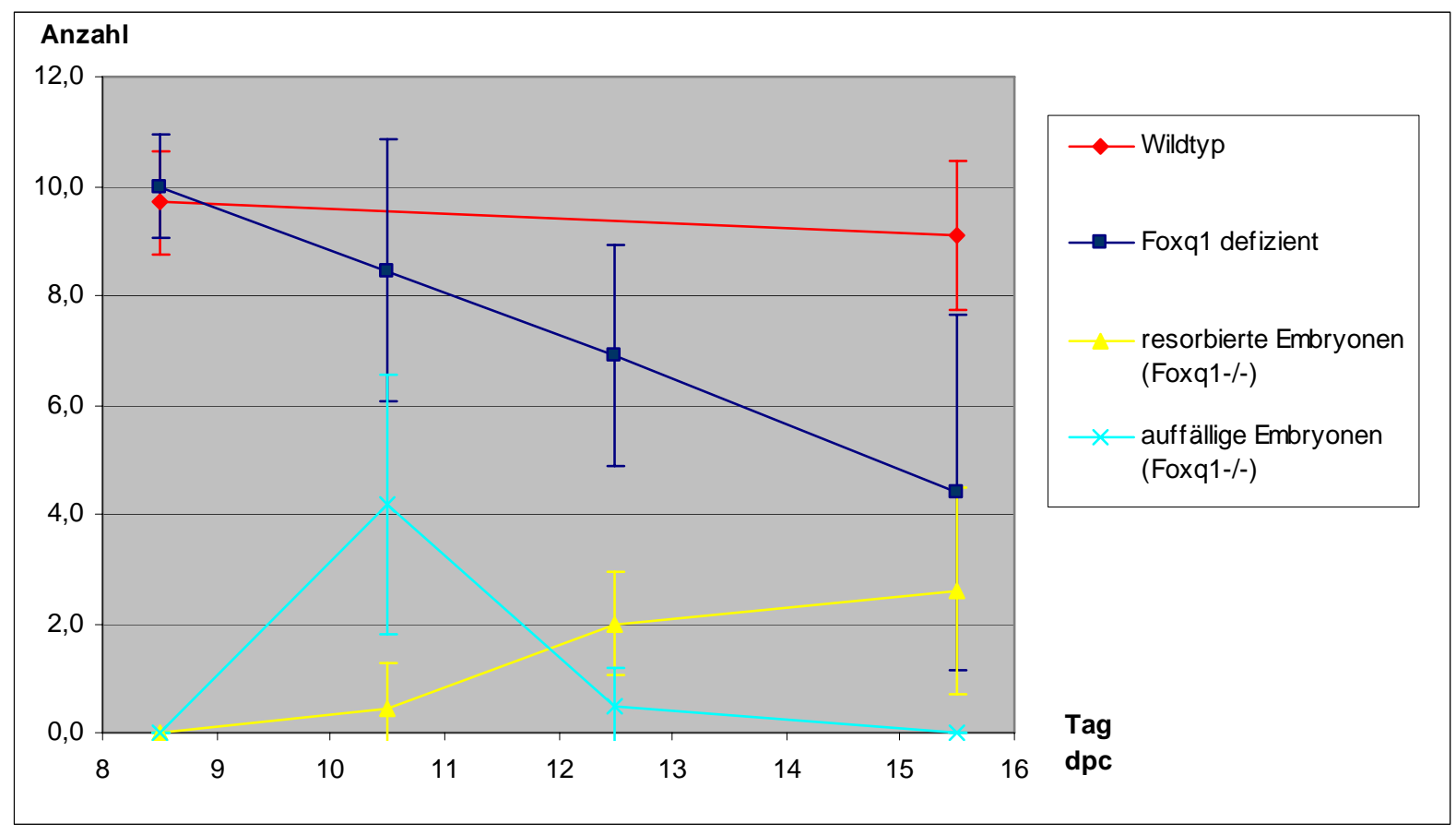




\section{Abb. 3.4.1: Analyse von Embryonen aus Foxq1 ${ }^{-/-}$-Verpaarungen}

Graphische Darstellung der Embryonenanalyse von Wildtyp- und Foxq1 ${ }^{-/}$-Verpaarungen zu unterschiedlichen Zeitpunkten der Entwicklung. Alle Stadien zeigen den Mittelwert aus zehn Würfen mit der dazugehörigen Standardabweichung. Während der Embryonalentwicklung zwischen dem Tag 8,5 dpc und 15,5 dpc ließ sich eine Dezimierung um etwa 50\% der Embryonen aus Foxq1 ${ }^{-/}$-Verpaarungen beobachten. Die Hälfte der vorhandenen Embryonen am Tag 10,5 dpc zeigte Auffälligkeiten, die sich in bei 12,5 dpc Embryonen vereinzelt finden ließen.

Um die Fehlbildungen im Kopfbereich der Mausembryonen, die vermutlich die Ursache für die embryonale Letalität sind, genauer zu untersuchen, wurden Embryonen aus Foxq1 $1^{-/}$Verpaarungen an 10,5 dpc präpariert, fixiert und in Paraffin eingebettet. Die anschließenden HE-Färbungen an Schnittpräparaten dieser Embryonen, ließen eine Störung der Ausbildung des dritten und der lateralen Ventrikel erkennen (Abb. 3.4.2).
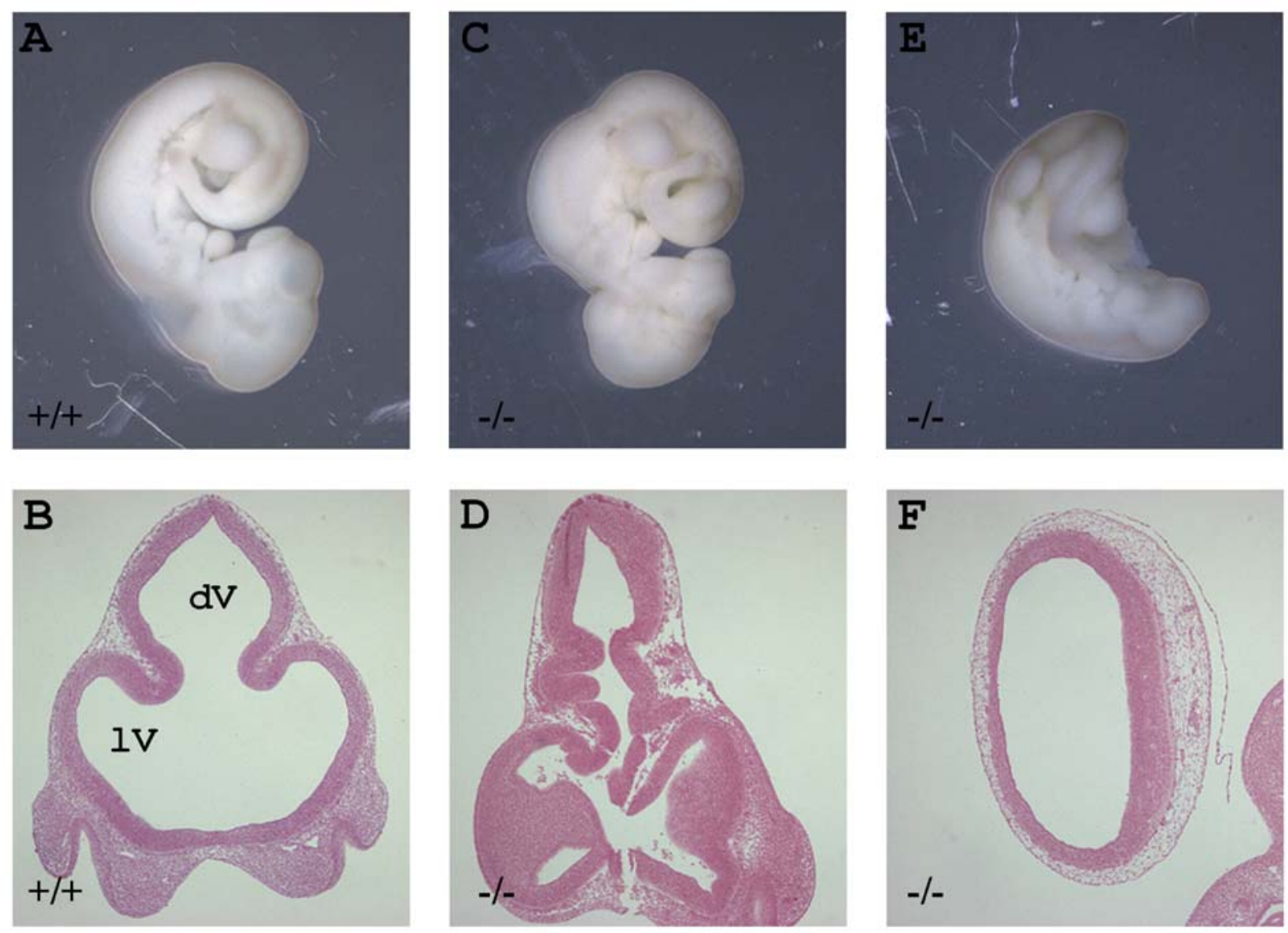

\section{Abb. 3.4.2: HE-Färbung von Embryonen an Tag 10,5 dpc}

Embryonen aus (A) Wildtyp- und (C und E) Foxq1 $1^{-/}$-Verpaarungen.

Vorderhirnfehlbildungen waren sichtbar in $(\mathbf{C})$ weniger schwerer und in $(\mathbf{E})$ sehr schwerer Form. (B,D,F) Dazugehörige Schnittpräparate nach HE-Färbung. Im Vergleich mit dem (B) Wildtyp ließen sich (D) Fehlbildung des dritten (dV) und der lateralen Ventrikel (IV) bis hin zu einem zylinderförmigen $\operatorname{Kopf}(\mathbf{F})$ erkennen. 
Diese Fehlbildungen waren in weniger schwerer Ausbildung (Abb. 3.4.2 C und D) und in schwerer Ausbildung bis hin zu einem zylinderförmigen Kopfbereich (Abb. 3.4.2 E und F) zu beobachten. Unter den nicht betroffenen Foxq1 ${ }^{-/-}$-Embryonen konnten prä- und postnatal bis hin zur adulten Maus keine Entwicklungsstörungen beobachtet werden.

\subsection{Strukturelle Untersuchung des Magens von Foxq1-defizienten Mäusen}

Wie bereits gezeigt, wird Foxq1 schon früh im embryonalen Magen exprimiert (Abb.3.1.2). Unter der Annahme, dass Foxq1 involviert ist in die Magenentwicklung, wurden histologische Analysen an Schnitten des adulten Mausmagens mittels HE-Färbung durchgeführt. Unterschiede in der Struktur der Magenschleimhaut, der Submucosa und des Magenmuskels konnten im Vergleich zu Wildtyppräparaten (Abb. $3.5 \mathrm{~A}$ und B) nicht festgestellt werden. Die Anordnung der Zellen innerhalb der gastrischen Einheit erschien ebenfalls nicht verändert. Da Foxq1 in den Parietalzellen der Magenschleimhaut exprimiert wird, wurde die Anzahl und die Anordnung der Parietalzellen innerhalb der Mucosa in Foxq1 defizienten Mäusen untersucht. Eine Immunfärbung an Schnittpräparaten von Mägen aus Wildtyp- und Foxq1 ${ }^{-/}$-Tieren mittels eines Antikörpers gegen die Parietalzell-spezifische $\mathrm{H}^{+}, \mathrm{K}^{+}$ATPase ließen keinen Unterschied in Anzahl und Anordnung von Parietalzellen (Tab. 2; Abb. 3.5 C und D) erkennen. 

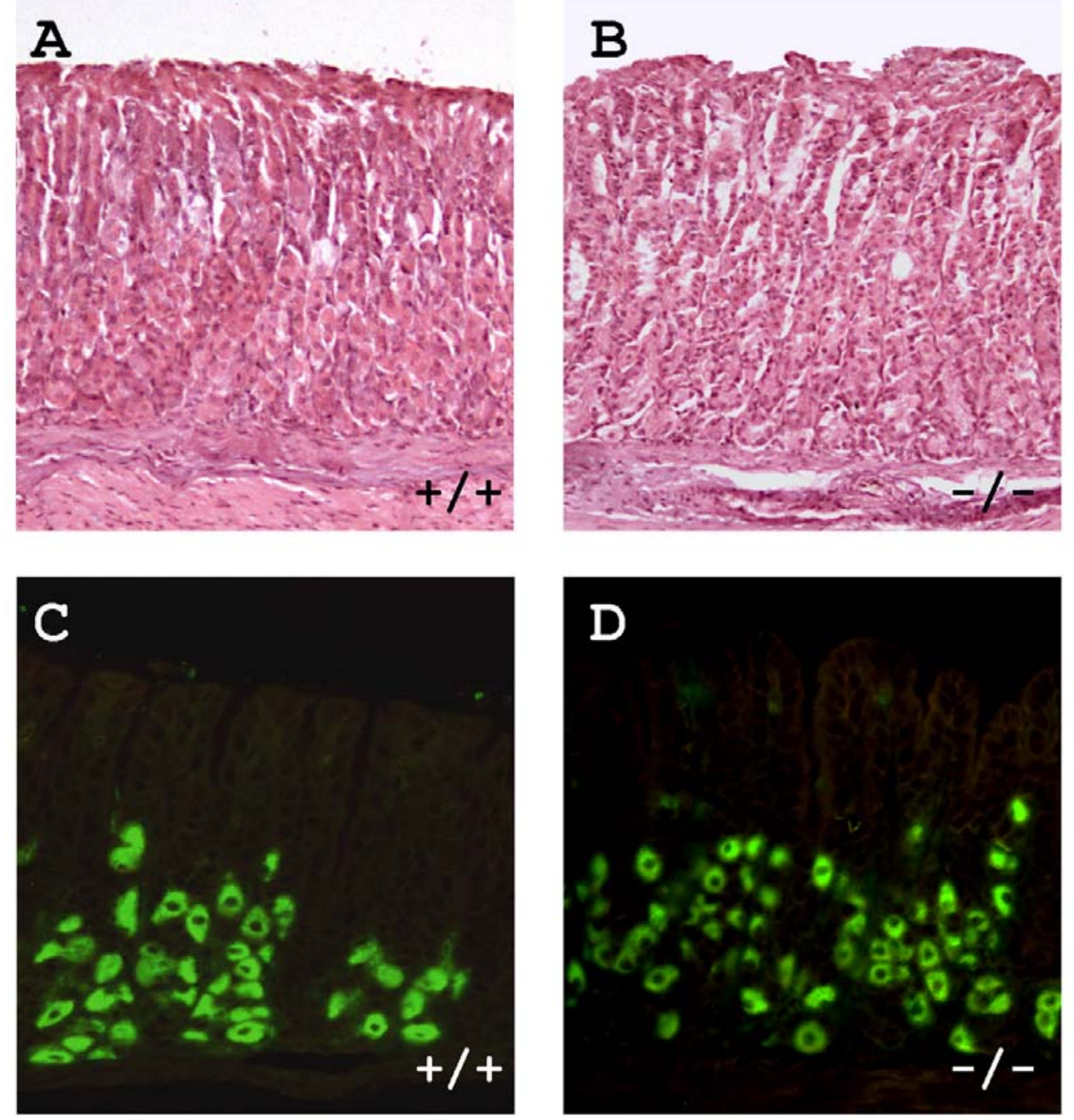

Abb. 3.5: HE- und Immunfärbung an adultem Mausmagen

(A und B) HE-Färbung von (A) Wildtyp- und (B) Foxq1 $1^{--}$-Magen. (C und D) Expression von $\mathrm{H}^{+}, \mathrm{K}^{+}$ATPase ( $\beta$ Untereinheit) im glandulären Magenbereich von $(\mathbf{C})$ Wildtyp und (D) Foxq1 $1^{-/-}$-Tieren. Vergrößerung: A + B: x200; C + D: x100

Tab. 2: Parietalzellanzahl der gastrischen Mucosa von Wildtypmäusen und Foxq1 -defizienten Mäusen

Wildtyp $\quad$ Foxq1-/-

Parietalzellanzahl

$91+/-13,2$

$89,6+/-13,1$ 


\subsection{Expressionsanalyse von Magenzelltyp-spezifischen Markergenen}

Die in 3.5 durchgeführten Untersuchungen gaben lediglich einen groben Überblick über etwaige Veränderungen in der Histologie des Magens von Foxq1-defizienten Mäusen. Eine RT-PCR Analyse sollte deshalb Hinweise auf die Expression unterschiedlicher Zelltypspezifischer Markergene geben. Unterschiede in der Expression könnten zum einen auf eine Änderung in der Anzahl dieser Zelltypen hindeuten. Dies ist vor allen Dingen hilfreich für Zelltypen, die nur in geringer Anzahl in den gastrischen Einheiten des Magens vorhanden sind (Entero-endokrine Zellen, ECL-Zellen). Zum anderen könnten Expressionsunterschiede auf eine Regulation der Expression dieser Markergene durch Foxq1 zurückzuführen sein.

Mittels der RT-PCR Analyse konnte eine verringerte Expression von Somatostatin (Sst) im Foxq1-defizientem Magen aufgedeckt werden (Abb. 3.6.1 A). Dieses Ergebnis konnte durch eine Northern-Blot Analyse verifiziert werden (Abb. 3.6.1 B). Die mittels RT-PCR zu beobachtende alternierende Expression von Pepsinogen (Pgc) ließ sich mit Hilfe der Northern-Blot Analyse nicht bestätigen.

A

Zymogene Zellen

Enteroendokrine Zellen

ECL-Zellen

Zymogene Zellen

Parietalzellen

Pitzellen

$$
+/+\quad+/-\quad-/-
$$$$
-1-
$$$$
\text { - }-1
$$$$
-\infty
$$$$
000
$$$$
\text { Tph1 }
$$$$
\text { Amy } 2
$$$$
-\infty
$$$$
00
$$$$
\text { Atp4a } \square \sigma
$$$$
\text { Slc9a2 }
$$$$
\text { SX }
$$

Gapdh
B

$$
\text { +/+ +/+ -/- -/- }
$$

sst

Gast
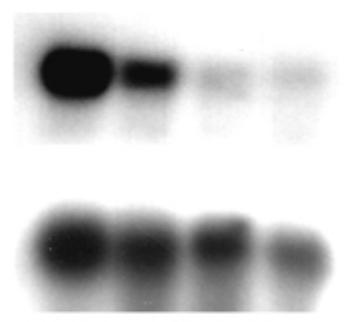

Atp4a

Pgc

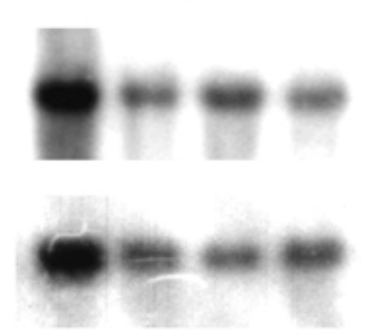

$\mathrm{hEF}$ 


\section{Abb. 3.6.1: Funktionelle Analyse von Foxq1 mittels Magenzelltyp-spezifischer Markergene}

(A) RT-PCR Assay und (B) Northern-Blot Analyse von verschiedenen Zelltyp-spezifischen Markergenen zeigte eine stark verringerte Expression von Somatostatin (Sst) im Foxq1 ${ }^{-{ }_{-}}$Magen. Pgc = Pepsinogen; Sst = Somatostatin; Iapp = Amylin; Gast = Gastrin; Tph1 = Tryptophan hydroxylase 1; Amy2 = Amylase 2; Atp4a $=H^{+}, K^{+}$ATPase ( $\alpha$ Untereinheit); Slc9a2 = Solute carrier family 9 (sodium/hydrogen exchanger), member 2; Gapdh = Glyceraldehyd-3-Phosphat Dehydrogenase; $S X=$ Stomach gene on $X$ chromosome; ECLZellen $=$ Enterochromaffin-like Zellen

Expressionsunterschiede für die anderen untersuchten Zelltyp-spezifischen Markergene (Entero-endokrine Zellen: Iapp (D-Zellen), Gast (G-Zellen); ECL-Zellen: Tph1; Parietalzellen: Atp4a, Slc9a2; Pitzellen: SX; Zymogene Zellen: Amy2) konnten mittels dieser RT-PCR Analyse nicht beobachtet werden (3.6.1 A).

Da Somatostatin nur von den entero-endokrinen D-Zellen im glandulären Bereich und im Antrum des Magens exprimiert wird, sollte überprüft werden, ob die verringerte Expression von Somatostatin das Ergebnis einer reduzierten D-Zellzahl oder das Ergebnis einer verminderten Expression in den D-Zellen ist. Für diese Untersuchung wurde durch eine Immunfärbung mittels Somatostatin-Antikörper die D-Zellzahl in Foxq1 defizienten Mägen ermittelt. Somatostatin exprimierende D-Zellen waren hierbei in gleicher Menge im Foxq1 defizienten Magen und im Wildtyp-Magen zu beobachten (Tab. 3; Abb. 3.6.2).
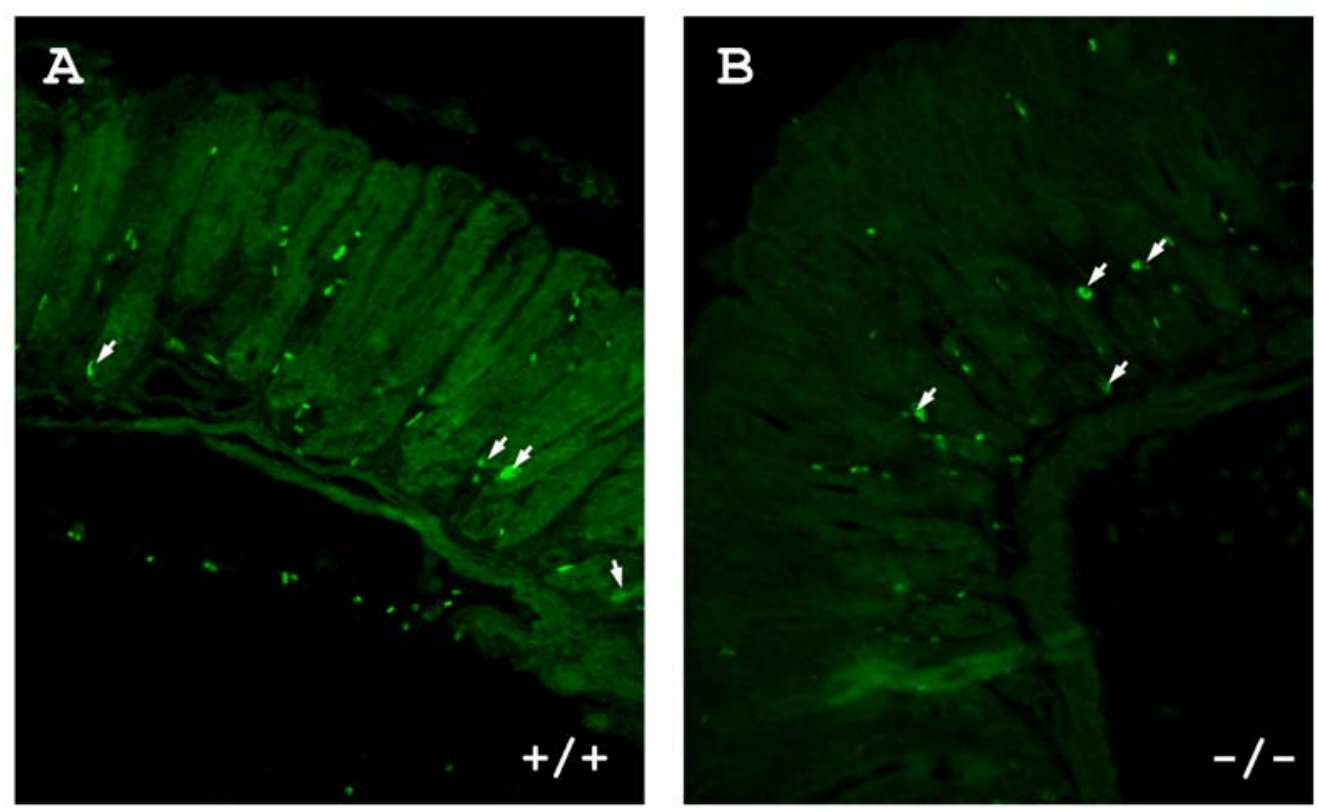


\begin{abstract}
Abb. 3.6.2: Histologische Bestimmung von Somatostatin exprimierenden D-Zellen. Magenschnitte von (A) Wildtyptieren und von (B) Foxq1-defizienten Tieren wurden mittels Immunfärbung mit einem Somatostatin-Antikörper auf Vorhandensein von Somatostatin exprimierende entero-endokrine D-Zellen untersucht. Vorhandene D-Zellen sind durch einen weißen Pfeil gekennzeichnet. Andere sichtbare Signale stammen von einer Kreuzhybridisierung des verwendeten Zweitantikörpers mit Erythrozyten. Vergrößerung: x100
\end{abstract}

Tab. 3: D-Zellanzahl der gastrischen Mucosa von Wildtypmäusen und Foxq1-defizienten Mäusen

\begin{tabular}{lll} 
& Wildtyp & Foxq1-/- \\
\cline { 2 - 2 } Parietalzellanzahl & $2,9+/-0,9$ & $2,3+/-1,3$
\end{tabular}

Ferner spricht auch die unveränderte Expression von Amylin (Iapp) (Abb. 3.6.1 A), welches ausschließlich in entero-endokrinen D-Zellen exprimiert wird, dafür, dass der Unterschied in der Somatostatinexpression nicht auf eine Verringerung der D-Zellanzahl zurückzuführen ist.

\title{
3.7 Funktion von Foxq1 bei der Magensäuresekretion
}

Die spezifische Expression von Foxq1 in den Magensäure sezernierenden Parietalzellen und die stark verringerte Expression von Somatostatin, welches eine wichtige Rolle in der Regulierung der Magensäuresekretion spielt, ließ uns eine Beteiligung von Foxq1 an der Sekretion oder der Regulation der Magensäuresekretion vermuten. Aufgrund dessen wurde der pH-Wert des Magensaftes von Foxq1 ${ }^{-/}$-Mäusen im Vergleich zu Wildtypmäusen untersucht. Es konnte gezeigt werden, dass keine Änderungen der basalen pH-Werte zu beobachten war (Abb. 3.7.1 A und B). Anschließend wurde die Magensäuresekretion nach Sekretagog-Stimulation (Histamin oder Gastrin) untersucht. 

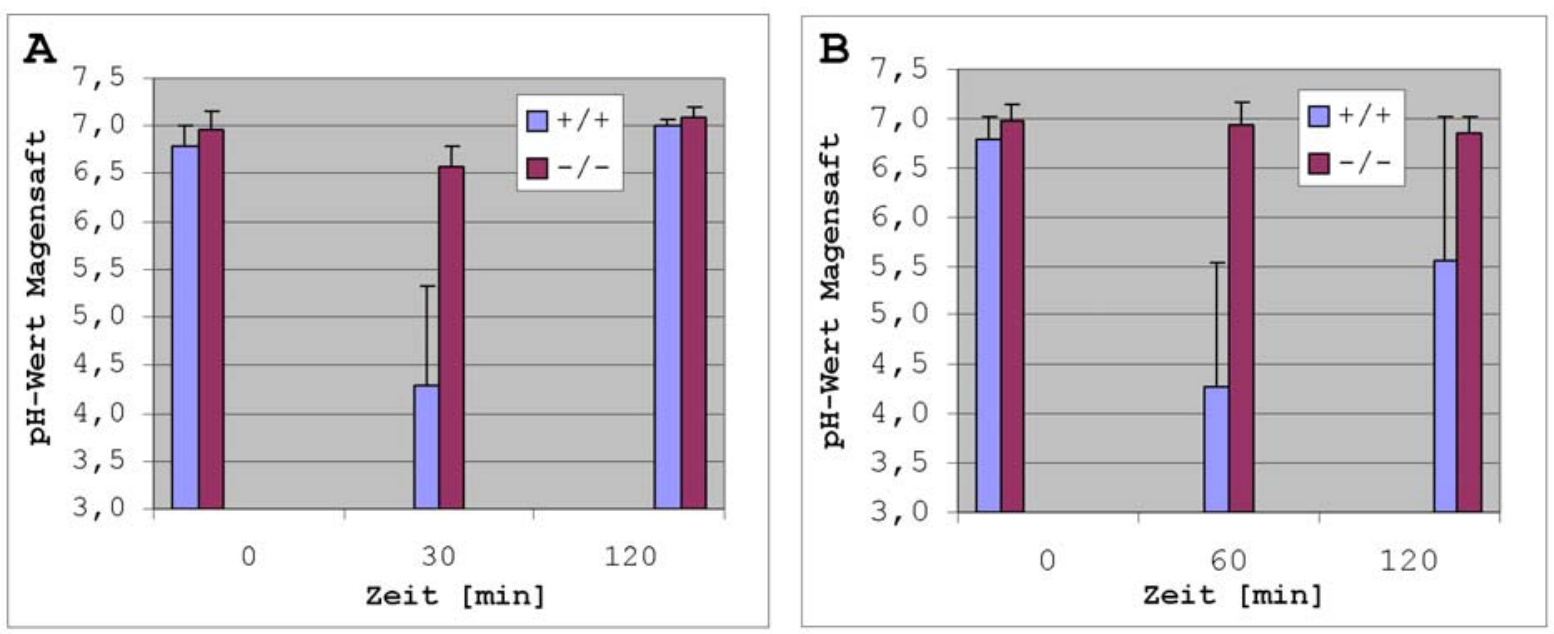

\section{Abb. 3.7.1: pH-Wert Bestimmung nach Skretagog-Stimulation.}

Graphische Darstellung der pH-Wertmessung. (A) Histamin (10 $\mu \mathrm{g} / \mathrm{g} \mathrm{KG)} \mathrm{und} \mathrm{(B)} \mathrm{Gastrin}$ $(1 \mu \mathrm{g} / \mathrm{g} \mathrm{KG})$ wurden Foxq1 $1^{-/-}$- und Wildtyp-Mäusen intraperitoneal verabreicht. Die Mäuse wurden zu den angegebenen Zeitpunkten nach Injektion getötet und der gastrische pH-Wert wurde gemessen. Die Werte repräsentieren den Mittelwert von 6 Messungen mit dazugehöriger Standardabweichung. $\mathrm{P}<0,001 ;+/+=$ Wildtyp; $-/-=$ Foxq1 $^{-/-}$

Der intragastrine pH-Wert in Mägen von Wildtypmäusen fiel 30 min nach HistaminStimulation vom basalen $\mathrm{pH}$-Wert 6,79 $\pm 0,22$ auf einen Wert von 4,30 $\pm 1,02$ (Abb 3.7.1 A). Die Gastrin-Stimulation ließ den pH-Wert 60 min nach Stimulation auf einen Wert von 4,27 \pm 1,26 absinken (Abb. 3.7.1 B). Im Gegensatz dazu wurde nach beiden SekretagogStimulationen in Foxq1 $1^{-/}$-Mäusen eine signifikant $(\mathrm{P}<0,001)$ geringere Magensäuresekretion beobachtet.

Um die Ursachen dieser reduzierten Magensäuresekretion (Hypochlorhydrie) zu untersuchen, wurde zunächst die Expression des Histamin- und des Gastrin-Rezeptors, Histaminrezeptor H2 (Hrh2) und Cholecystokininrezeptor b (Cckbr), untersucht. Hierbei handelt es sich um die spezifischen Rezeptoren von Histamin und Gastrin, die in der Plasmamembran von Parietalzellen lokalisiert sind. Da die Expression der Gene zu gering war um in einer Northern-Blot Analyse detektiert zu werden, wurde mit Hilfe einer semiquantitativen RTPCR die Expression der Gene in Foxq1 $1^{-/}$-Mägen mit der Expression in Wildtyp verglichen. Mittels dieser Methode ließen sich keine signifikanten Expressionsunterschiede von Hrh2 (Abb. 3.7.2 A) und Cckbr (Abb. 3.7.2 B) erkennen.

Hoggatt et al. (2001) konnten eine Reprimierung von Telokin (MYLK) durch Foxq1 in glatter Muskulatur mittels Luciferase Assay zeigen. Des Weiteren weisen Foxq1 ${ }^{-/}$-Mäuse einen ähnlichen Phänotyp der Magensäuresekretion auf, wie er für Ezrin knockdown-Mäuse $\left(\right.$ Vil $2^{k d / k d}$ ) beschrieben wurde (Tamura et al., 2005). Daraufhin wurde eine mögliche 
Regulation der Expression von MYLK und Ezrin im Magen von Foxq1-defizienten Mäusen mittels einer semiquantitativen RT-PCR Analyse untersucht. Mit Hilfe dieser Methode konnten keine signifikanten Unterschiede in den Expressionen beider Genen zwischen Foxq1 $1^{-/}$- und Wildtyp-Mäusen beobachtet werden (Abb. 3.7.2 C).

A

Anzahl PCR Zyklen 22 $25 \quad 28$ 31 35

H2 Rezeptor

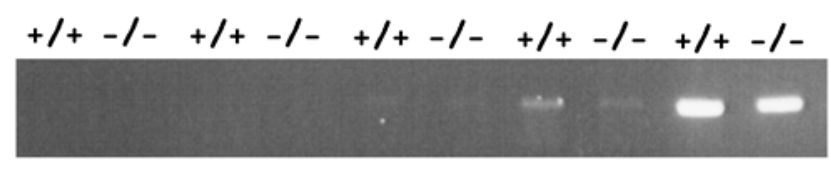

Gapdh

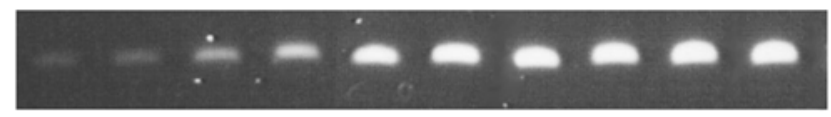

B

Anzahl PCR Zyklen

30 34 36

Cckbr

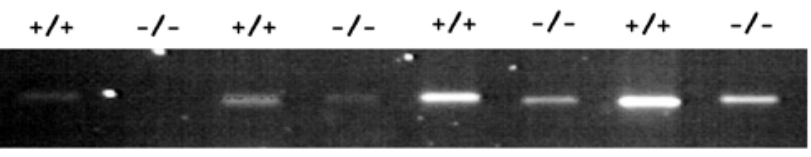

HPRT

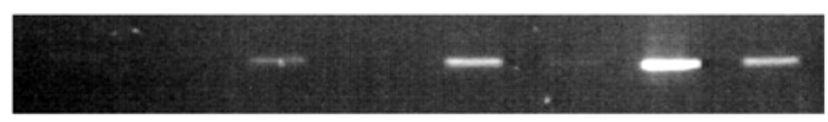

C

Anzahl PCR Zyklen

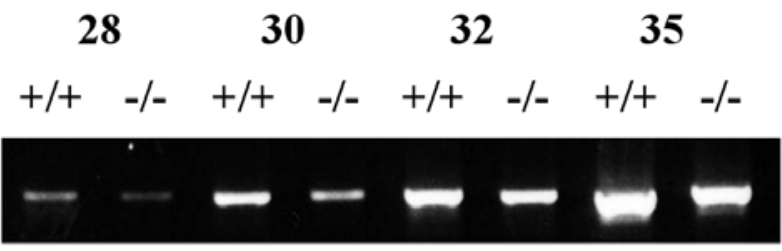

MYLK

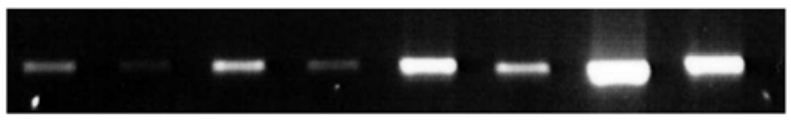

HPRT

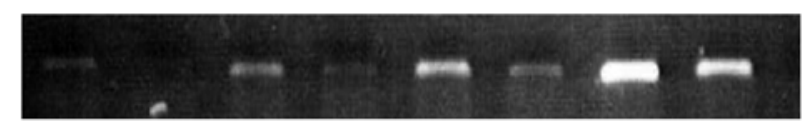

Abb. 3.7.2: Semiquantitative RT-PCR Analyse der Expression von Hrh2, Cckbr, Ezrin und MYLK.

Die Expression von (A) Hrh2, (B) Cckbr, (C) Ezrin und MYLK wurde in Foxq1 $1^{-/}$- und Wildtyp-Mäusen mittels semiquantitativer RT-PCR Analyse untersucht. +/+=Wildtyp; -/- = Foxq1 ${ }^{--} ;$Cckbr $=$Cholecystokininrezeptor b; Ezrin = Vilin 2; Gapdh $=$Glyceraldehyd-3Phosphat Dehydrogenase; HPRT = Hypoxanthin Huanin Phosphoribosyl Transferase 1; H2 Rezeptor $=$ Histaminrezeptor H2; MYLK = Myosin Light Chain Kinase 


\subsection{Ultrastrukturelle Analyse von Foxq1-defizienten Parietalzellen}

Um die Frage zu beantworten, ob die beobachtete Hypochlorhydrie aus ultrastrukturellen Fehlbildungen von Parietalzellen hervorgeht, wurden elektronenmikroskopische Analysen an Magenschnitten durchgeführt. Hierfür wurden nicht behandelte, Histamin- und Gastrinstimulierte Wildtyp- und Foxq1 ${ }^{-/}$-Mäuse untersucht. In nicht stimulierten Wildtyp- und Foxq1 ${ }^{-/}$-Mäusen waren weder auf lichtmikroskopischer (Abb. $3.8 \mathrm{~A}$ und B) noch auf elektronenmikroskopischer (Abb. 3.8 C und D) Ebene Unterschiede in der Parietalzellstruktur zu erkennen. Die Histaminbehandlung der Mäuse hatte keinen sichtbaren Effekt auf die Parietalzellen. Es ließen sich weder im Lichtmikroskop (Abb. 3.8 E und F) noch im Elektronenmikroskop Unterschiede zwischen unbehandelten und behandelten Tieren beobachten (Abb. $3.8 \mathrm{G}$ und $\mathrm{H}$ ). Unterschiede zwischen der Wildtyp- und der Foxq1 ${ }^{-/}$Gruppe waren nicht zu beobachten. Die Gastrinbehandlung führte dahingegen zu einer so massiven Reaktion des gastrischen Epithels von Wildtypmäusen, dass die Erweiterung der Lumina in der gastrischen Einheiten schon im Lichtmikroskop zu erkennen war (Abb. 3.8 I). Im Elektronenmikroskop lässt sich erkennen, dass es zu einer massiven Ausdehnung der Canaliculi innerhalb der Parietalzellen kommt, die teilweise in einer glatten CanaliculusOberfläche ohne sichtbare Tubulovesikel resultierte (Abb. $3.8 \mathrm{~K})$. Diese Veränderungen waren in Gastrin behandelten Foxq1-defizienten Mäusen weder im Lichtmikroskop (Abb. 3.8 J) noch auf elektronenmikroskopischer Eben (Abb. 3.8 L) zu beobachten. 

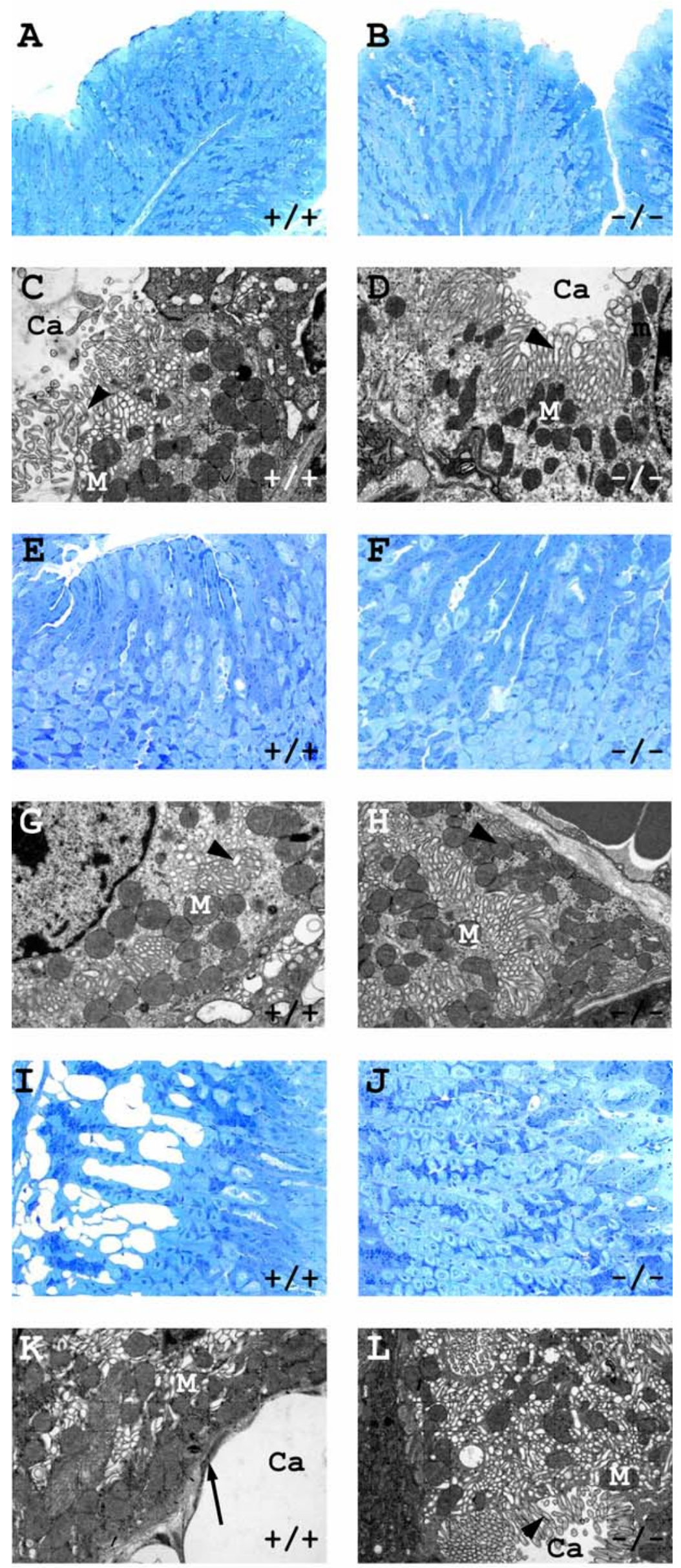
Abb. 3.8: Ultrastrukturelle Analyse von Parietalzellen im glandulären Magenepithel von Wildtyp- und Foxq1 $1^{-/}$-Mäusen.

(A bis D) In Schnittpräparaten von nicht stimulierten Mäusen zeigten sich keine Unterschiede zwischen Wildtyp- und Foxq1 $1^{-/}$-Mägen im Lichtmikroskop (A und B) und auf

elektronenmikroskopischer Ebene (C und D). Beide Gruppen ließen gut ausgebildete

Canaliculi (Ca) mit Tubulovesikeln (Pfeilkopf), und eine hohe Anzahl an Mitochondrien (M) erkennen. ( $\mathbf{E}$ bis $\mathbf{H})$ Histaminbehandlung ließ weder auf lichtmikroskopischer Ebene ( $\mathbf{E}$ und F) noch im Elektronenmikroskop ( $\mathbf{G}$ und $\mathbf{H})$ sichtbare Auswirkungen auf die Struktur der Parietalzellen von Wildtyp- und Foxq1 ${ }^{-/-}$-Tieren erkennen.(I bis L) Gastrinbehandlung führte zu Reaktionen des gastrischen Epithels in Wildtypmäusen, die sowohl im Lichtmikroskop (I) als auch im Elektronenmikroskop $(\mathbf{K})$ zu beobachten sind. Teilweise waren die Canaliculi so extrem aufgebläht, dass eine glatte Canaliculus-Oberfläche zu erkennen war (Pfeil). Gastrinbehandelte Foxq1 ${ }^{--}$-Tiere ließen keine Veränderungen ( $\mathbf{J}$ und $\mathbf{L}$ ) erkennen. Vergrößerungen: A + B: x200; C + D: x13000; E + F: x400; G + H: x13000; I + J: x400; K + L: x13000.

Im Rahmen dieser Dissertation konnte gezeigt werden, dass Foxq1 am Tag 10,5 der Embryonalentwicklung im Rhomb-, Mes- und Prosencephalon exprimiert wird. Ferner wurde eine Expression von Foxq1 während der pränatalen Magenentwicklung ab 15,5 dpc nachgewiesen. Im adulten Magen konnte eine Expression in den Magensäure sekretierenden Parietalzellen beobachtet werden. Die funktionelle Analyse von Foxq1-defizienten Mäusen lässt aufgrund der beobachteten Fehlbildungen des Kopfes bei 10,5 dpc Foxq1 ${ }^{-/-}$-Embryonen eine Beteiligung an der Ausbildung des embryonalen Kopfes vermuten. Außerdem konnte durch eine funktionelle Magenanalyse in adulten Foxq1 $1^{-/}$-Tieren gezeigt werden, dass Foxq1 an der Regulation der Magensäuresekretion der Parietalzellen beteiligt ist. Foxq1 könnte hier teilhaben an der Signaltransduktion des Sekretagog-Signals innerhalb der Parietalzellen, die letztendlich zur Fusion der Tubulovesikel mit der Canaliculusmembran führt und so die Magensäuresekretion stimuliert. 


\subsection{Auswertung der PCR-basierten subtraktiven cDNA-Bibliothek}

Im Rahmen von Vorarbeiten $\mathrm{zu}$ dieser Dissertation wurde eine auf PCR basierende subtraktive cDNA-Bibliothek erstellt, die differentiell im Magen exprimierte Gene detektierte. Als Vergleich fungierte das Transkriptom aus Colongewebe. Von diesen als differentiell im Magen exprimierten Genen wurde im Rahmen einer anderen Arbeit bereits ein Gen charakterisiert. Hierbei handelt sich um das $S X$ Gen (benannt nach seiner chromosomalen Lokalisation), das ausschließlich im Magen exprimiert wird. Für diese Promotionsarbeit sollten aus den übrigen Genen solche ausgewählt werden, die unbekannt, bzw. nicht näher charakterisiert waren. Hierfür sollte dann eine nähere Charakterisierung durchgeführt werden. Aus den 23 als differentiell im Magen exprimierten Genen, wurden folgende drei Gene für die weitere Charakterisierung ausgewählt: Gastrokine 2, Admp und SA11.

\begin{tabular}{|c|c|c|c|}
\hline & Name & $\begin{array}{l}\text { Chromosomale } \\
\text { Lokalisation }\end{array}$ & Expression \\
\hline 1 & $\begin{array}{l}\text { UDP glucuronosyltransferase } 2 \text { family, } \\
\text { polypeptide B5 (Ugt2b5) }\end{array}$ & $5 \mathrm{E} 1$ & Leber \\
\hline 2 & $\begin{array}{l}\text { Microsomal glutathione S-transferase } 1 \\
\text { (Mgst1) }\end{array}$ & $6 \mathrm{G} 1$ & Ubiquitär \\
\hline 3 & $\begin{array}{l}\text { Pyruvate dehydrogenase E1 alpha } 1 \\
\text { (Pdha1) }\end{array}$ & X F3-F4 & Ubiquitär \\
\hline 4 & Gastrokine $1(G k n 1)$ & $6 \mathrm{D} 2$ & Magen \\
\hline 5 & $\begin{array}{l}\text { 1110032A04Rik (Androgen down regulated } \\
\text { gene expressed in mouse prostate (Admp)) }\end{array}$ & $3 \mathrm{E} 3$ & $\begin{array}{l}\text { Prostata, Niere, } \\
\text { Gehirn [Singh et al, } \\
\text { 2005], Blase }\end{array}$ \\
\hline 6 & Glutathione S-transferase, alpha 4 (Gsta4) & $9 \mathrm{E} 1$ & Ubiquitär \\
\hline 7 & Tissue factor pathway inhibitor 2 (Tfpi2) & $6 \mathrm{~A} 2$ & $\begin{array}{l}\text { Leber, Niere, } \\
\text { Placenta [Miyagi et } \\
\text { al, 1996] }\end{array}$ \\
\hline 8 & Major urinary protein 2 (Mup2) & $4 \mathrm{~B} 3$ & Leber \\
\hline 9 & Major urinary protein 1 (Mup1) & $4 \mathrm{~B} 3$ & Leber \\
\hline 10 & Albumin 1 (Alb1) & $5 \mathrm{E} 2$ & Leber \\
\hline
\end{tabular}




\begin{tabular}{|c|c|c|c|}
\hline 11 & RIKEN cDNA 1100001G20 gene; (SA11) & $11 \mathrm{C}$ & unbekannt \\
\hline 12 & Peroxiredoxin $1(\operatorname{Prd} x 1)$ & $4 \mathrm{D} 1$ & Ubiquitär \\
\hline 13 & Fibrinogen, B beta polypeptide & $3 \mathrm{E} 3$ & Leber \\
\hline 14 & $\begin{array}{l}\text { Alcohol dehydrogenase } 7 \text { (class IV), mu or } \\
\text { sigma polypeptide (Adh7) }\end{array}$ & $3 \mathrm{H} 1$ & $\begin{array}{l}\text { Magen, Leber, } \\
\text { Lunge, Blase, Niere, } \\
\text { Haut }\end{array}$ \\
\hline 15 & Dedicator of cytokinesis 9 (Dock9) & $14 \mathrm{E} 5$ & Ubiquitär \\
\hline 16 & SX & $\mathrm{X}$ & $\begin{array}{l}\text { Magen } \\
\text { (Vorläuferzellen der } \\
\text { Isthmusregion) }\end{array}$ \\
\hline 17 & Male sterility domain containing 2 (Mlstd2) & $7 \mathrm{~F} 2$ & Ubiquitär \\
\hline 18 & Major urinary protein 3 (Mup3) & $4 \mathrm{~B} 3$ & Leber, Magen \\
\hline 19 & $\begin{array}{l}\text { Solute carrier family } 12, \text { member } \\
2(\text { Slc12a2) }\end{array}$ & $18 \mathrm{D} 3$ & Ubiquitär \\
\hline 20 & chitinase, acidic (Chia) & $3 \mathrm{~F} 3$ & Magen \\
\hline 21 & RIKEN cDNA 2810007J24 gene; & $7 \mathrm{~A} 1$ & unbekannt \\
\hline 22 & $\begin{array}{l}\text { Solute carrier organic anion transporter } \\
\text { family, member 1a1 (Slco1a1) }\end{array}$ & 6 A3-A5 & Gallenblase \\
\hline 23 & $\begin{array}{l}\text { RIKEN cDNA } 1810036 \mathrm{H} 07 \text { gene } \\
\text { (Gastrokine 2) }\end{array}$ & $6 \mathrm{D} 2$ & $\begin{array}{l}\text { Magen (Pitzellen des } \\
\text { glandulären Epithels) } \\
\text { (eigene Ergebnisse) }\end{array}$ \\
\hline
\end{tabular}

Tab. 3.4: Übersicht der Gene, die mittels einer PCR-basierenden subtraktiven cDNABibliothek und anschließender Datenbankrecherche als differentiell im Magen exprimiert gefunden wurden. Angegeben sind der Name, die chromosomale Lokalisation und die bisher bekannte Expression des Gens in der Maus. Die grau unterlegten Gene sollen im Rahmen dieser Dissertation charakterisiert werden (Admp, SA11, Gastrokine 2). 


\subsection{Charakterisierung des Gastrokine 2 Gens}

Das Gastrokine 2 Gen ist in der Maus auf Chromosom 6 D2 lokalisiert und erstreckt sich über etwa 6000 Basenpaare. Es besteht aus sechs Exons (Abb. 3.10.1 B), welche für eine mRNA von 777 Nukleotiden kodieren. Der Translationsstartpunkt befindet sich in Exon 1. Das korrespondierende putative Protein besteht aus 184 Aminosäuren. Datenbankanalysen sagen eine Signalsequenz und eine Brichosdomäne voraus. Die Brichosdomäne ist eine erst vor kurzer Zeit beschriebene Proteindomäne die aus etwa 100 Aminosäuren besteht und sowohl konservierte Sequenzbereiche, als auch strukturelle Homologien aufweist (Sanchez-Pulido et al., 2002). Proteine mit einer Brichosdomäne werden unter anderem in Verbindung gebracht mit ARDS (Acute Respiratory Distress Syndrome) und Magentumoren. (Yoshikawa et al., 2000; Shiozaki et al., 2001; Mulugeta et al., 2005) Ferner konnte mit Hilfe von Datenbankanalysen gezeigt werden, dass Gastrokine 2 konserviert in Amniota ist und sowohl auf Aminosäureebene als auch auf Nukleotidebene eine hohe Homologie zwischen den Arten aufweist (Abb. 3.10.1 D). 


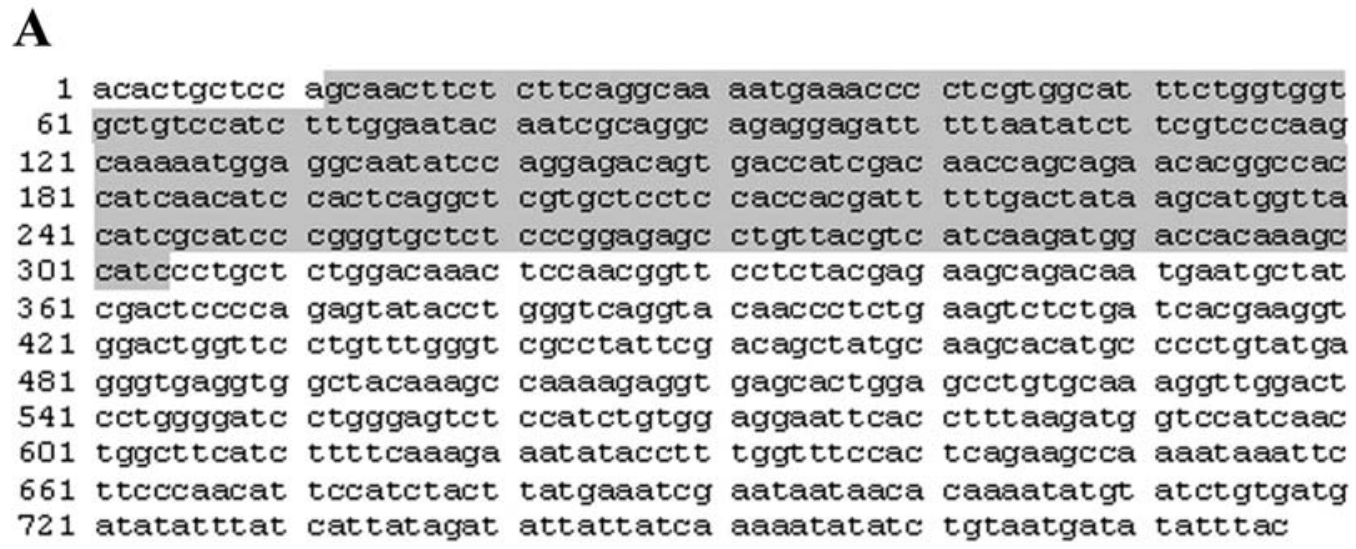

B

$\underset{\substack{\text { Region } \\ \text { Region }}}{\text { Ex1 (ATG) }}$

C

D

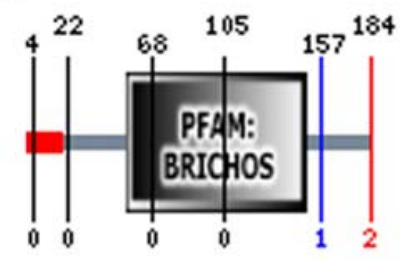

\begin{tabular}{|l|l|l|l|}
\hline Organismus & Name des Gens & $\begin{array}{l}\text { Homologie } \\
\text { Aminosäure } \\
\mathbf{( \% )}\end{array}$ & $\begin{array}{l}\text { Homologie } \\
\text { Nukleotide (\%) }\end{array}$ \\
\hline H.sapiens & GDDR /TFIZ1 & 69,6 & 76,4 \\
\hline P.troglodytes & LOC470392 & 67,5 & 76,3 \\
\hline C.familiaris & LOC612594 & 69.0 & 75.5 \\
\hline R.norvegicus & $\begin{array}{l}\text { RGD1311934_ } \\
\text { predicted }\end{array}$ & 88.9 & 89.4 \\
\hline G.gallus & GDDR & 41.4 & 55.2 \\
\hline
\end{tabular}

\section{Abb. 3.10.1: Datenbankanalyse des Gastrokine 2 Gens}

Mittels Datenbankanalyse wurde die (A) mRNA Sequenz von Gastrokine 2 beschrieben. Der grau unterlegte Bereich wurde für die Generierung einer spezifischen Sonde für die NorthernBlot Analyse und die in situ Hybridisierung verwendet. Ferner wurden Vorhersagen über die Exon-Intron-Struktur (B) des Gastrokine 2 Gens und über die Domänenstruktur (C) des korrespondierenden Proteins erstellt. (D) Tabellarische Auflistung der Homologien der putativen orthologen Gene zum murinen Gastrokine 2 Gen. Dargestellt sind die Homologien auf Aminosäure- und Nukleotidebene.

$$
\text { - = Signalsequenz; Ex = Exon; ATG = Translationsstartpunkt. }
$$


Um die gewebespezifische Expression des Gastrokine 2 Gens zu untersuchen, wurde eine Northern-Blot Analyse an RNA aus unterschiedlichen Geweben durchgeführt (Abb. 3.10.2). Hierbei wurde in den untersuchten Geweben eine starke Expression ausschließlich im Magen gefunden.

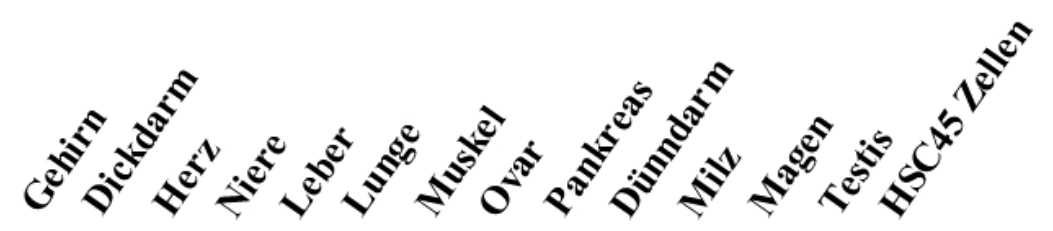

Gastrokine 2
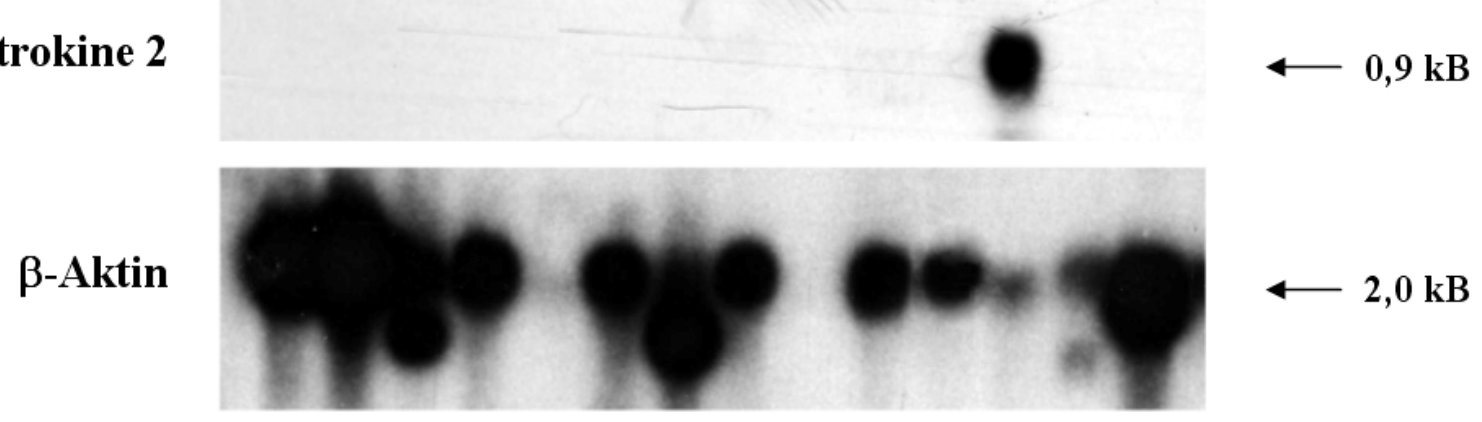

Abb. 3.10.2: Northern-Blot Analyse des Gastrokine 2 Gens an RNA unterschiedlicher

Gewebe Eine Northern-Blot Analyse wurde an RNA aus unterschiedlichen Geweben mittels einer Gastrokine 2-spezifischen Sonde durchgeführt. Eine Expression ist ausschließlich im Magen zu detektieren. Die Rehybridisierung erfolgte mit $\beta$-Aktin.

Es wurde eine Northern-Blot Analyse mit RNA aus den verschiedenen Magenteilen Vormagen, Glandula und Antrum vorgenommen. Um die Regulation während der Nahrungsaufnahme zu überprüfen, wurde RNA zweier unterschiedlicher Ernährungszustände eingesetzt. Zum einen wurde den Mäusen vor der Magenpräparation die Nahrung über Nacht entzogen. Auf der anderen Seite wurde der Magen von normal gefütterten Mäusen für die RNA-Isolation verwendet (Abb. 3.10.3). Unabhängig vom Ernährungszustand der Maus ist eine Expression nur im glandulären Bereich und im Antrumbereich des Magens zu beobachten. Gastrokine 2 Expression im Vormagen beider Gruppen war nicht zu erkennen. 


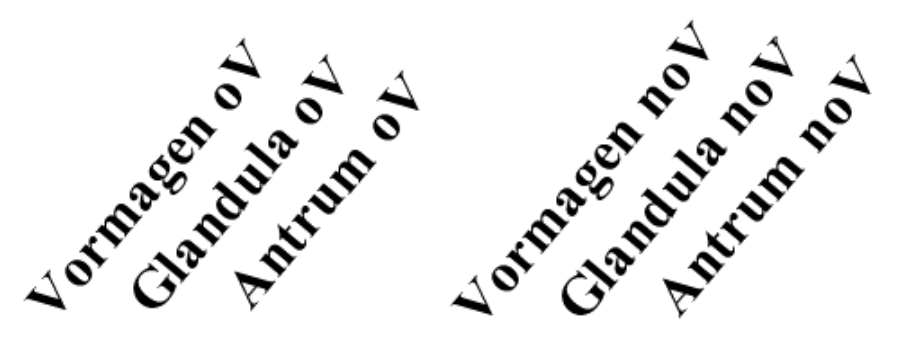

\section{Gastrokine 2}

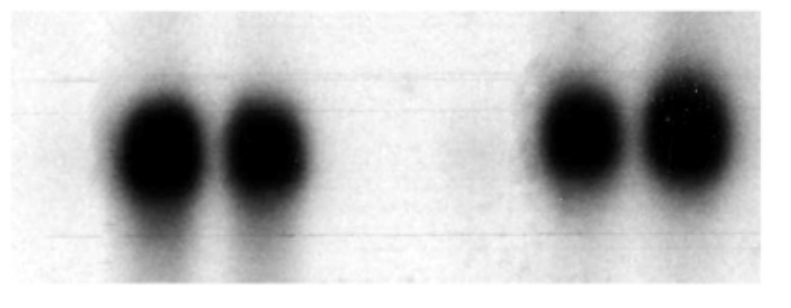

$\longleftarrow 0,9 \mathrm{kB}$

$\beta$-Aktin

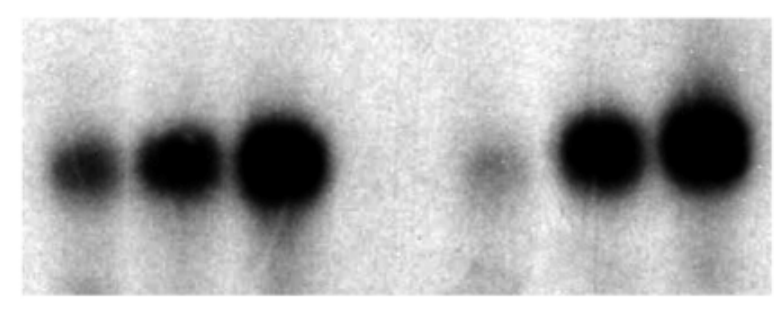

$\longleftarrow 2,0 \mathrm{kB}$

Abb. 3.10.3: Northern-Blot Analyse des Gastrokine 2 Gens mit RNA aus unterschiedlichen Magenteilen

Eine Northern-Blot Analyse wurde mit RNA aus unterschiedlichen Magenteilen mit unterschiedlicher Ernährungslage (oV und noV) durchgeführt. Eine Expression ist in beiden Gruppen nur im glandulären Bereich und im Antrum zu beobachten. Die Rehybridisierung erfolgte mit $\beta$-Aktin. oV $=$ ohne Verpflegung; Nahrungsentzug über Nacht; noV = normale Verpflegung

Um diejenigen Zellen zu detektieren, die Gastrokine 2 im Magen exprimieren, wurde eine in situ Hybridisierung mittels spezifischer Sense- und Antisense-RNA-Sonden an Magenschnitten durchgeführt. Eine Färbung mittels der Antisense-Sonde konnte dabei nur im Cytoplasma von Zellen im Pitbereich der gastrischen Einheit beobachtet werden (Abb. 3.10.4 A bis D). 

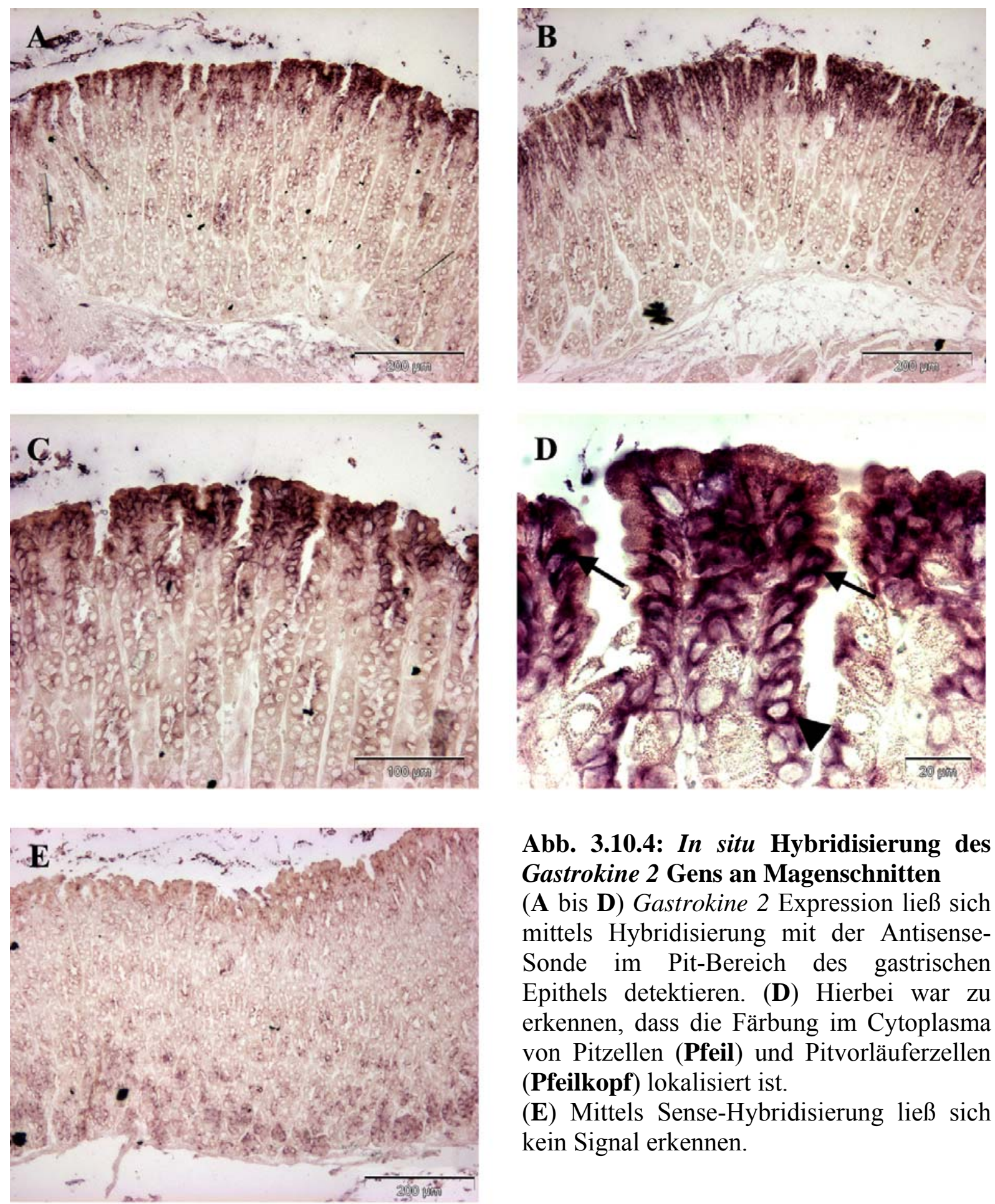

Abb. 3.10.4: In situ Hybridisierung des Gastrokine 2 Gens an Magenschnitten

(A bis D) Gastrokine 2 Expression ließ sich mittels Hybridisierung mit der AntisenseSonde im Pit-Bereich des gastrischen Epithels detektieren. (D) Hierbei war zu erkennen, dass die Färbung im Cytoplasma von Pitzellen (Pfeil) und Pitvorläuferzellen (Pfeilkopf) lokalisiert ist.

(E) Mittels Sense-Hybridisierung ließ sich kein Signal erkennen. 
Bei den angefärbten Zellen handelt es sich aufgrund der Lage in der Pitregion und dem Vorhandensein von vielen sekretorischen Granula vermutlich um Pitzellen und deren Vorläuferzellen (Abb. 3.10.4 D). Hybridisierung mit der Sense-Sonde zeigte keine Signale (Abb. 3.10.4 E).

Für das Gastrokine 2 Gen sollte die Expression während der prä- und postnatalen Entwicklung der Maus untersucht werden. Ein besonderes Augenmerk sollte hierbei auf die Magenentwicklung gelegt werden. Hierfür wurde eine Northern-Blot Analyse mit RNA aus Gesamtembryonen bzw. aus prä- und postnatalem Magengewebe vorgenommen (Abb. 3.10.5).

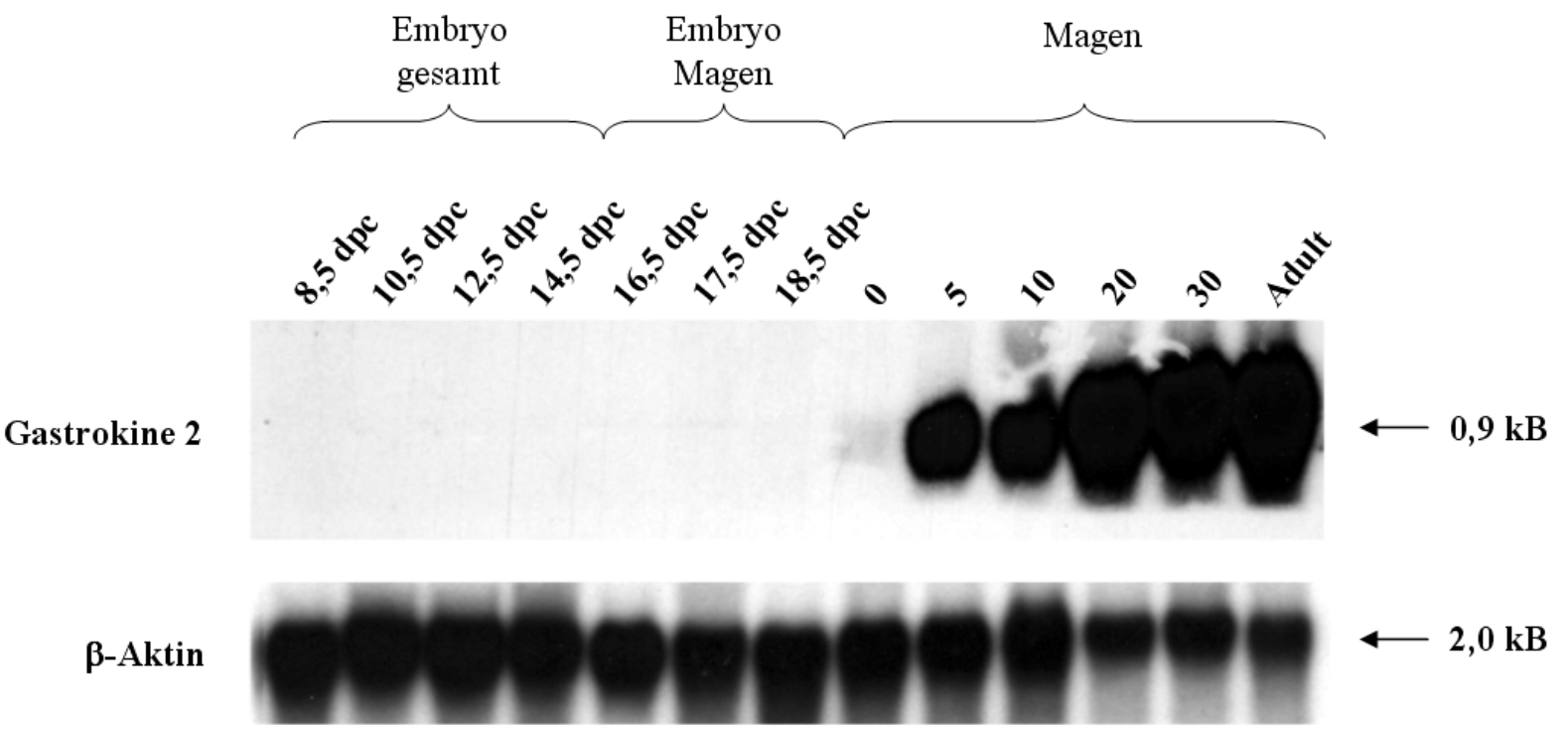

Abb. 3.10.5: Analyse der Gastrokine 2 Expression während der Magenentwicklung

Mittels einer Northern-Blot Analyse an Gesamt- bzw. Magen-RNA unterschiedlicher prä- und postnataler Entwicklungsstadien konnte der Beginn der Gastrokine 2-Expression auf kurz nach der Geburt datiert werden. Pränatale Expression konnte nicht beobachtet werden. 
Mittels dieser Analyse konnte der Beginn der Expression als perinatal beschrieben werden. Eine pränatale Expression konnte weder in RNA aus Magengewebe noch in RNA des gesamten Embryos nachgewiesen werden.

Um die Expression von Gastrokine 2 auf Proteineben beschreiben zu können, wurde damit begonnen, einen spezifischen Antikörper gegen Gastrokine 2 mittels GST-Fusionsprotein zu generieren. Zur Erstellung des Fusionsproteins wurde zunächst ein 79 Aminosäuren umfassender C-terminaler Bereich ausgewählt. Das korrespondierende 3'-Fragment inklusive Stoppkodon der Gastrokine 2 cDNA wurde in den Expressionsvektor pET 41a(+) kloniert (Abb. 3.10.6).

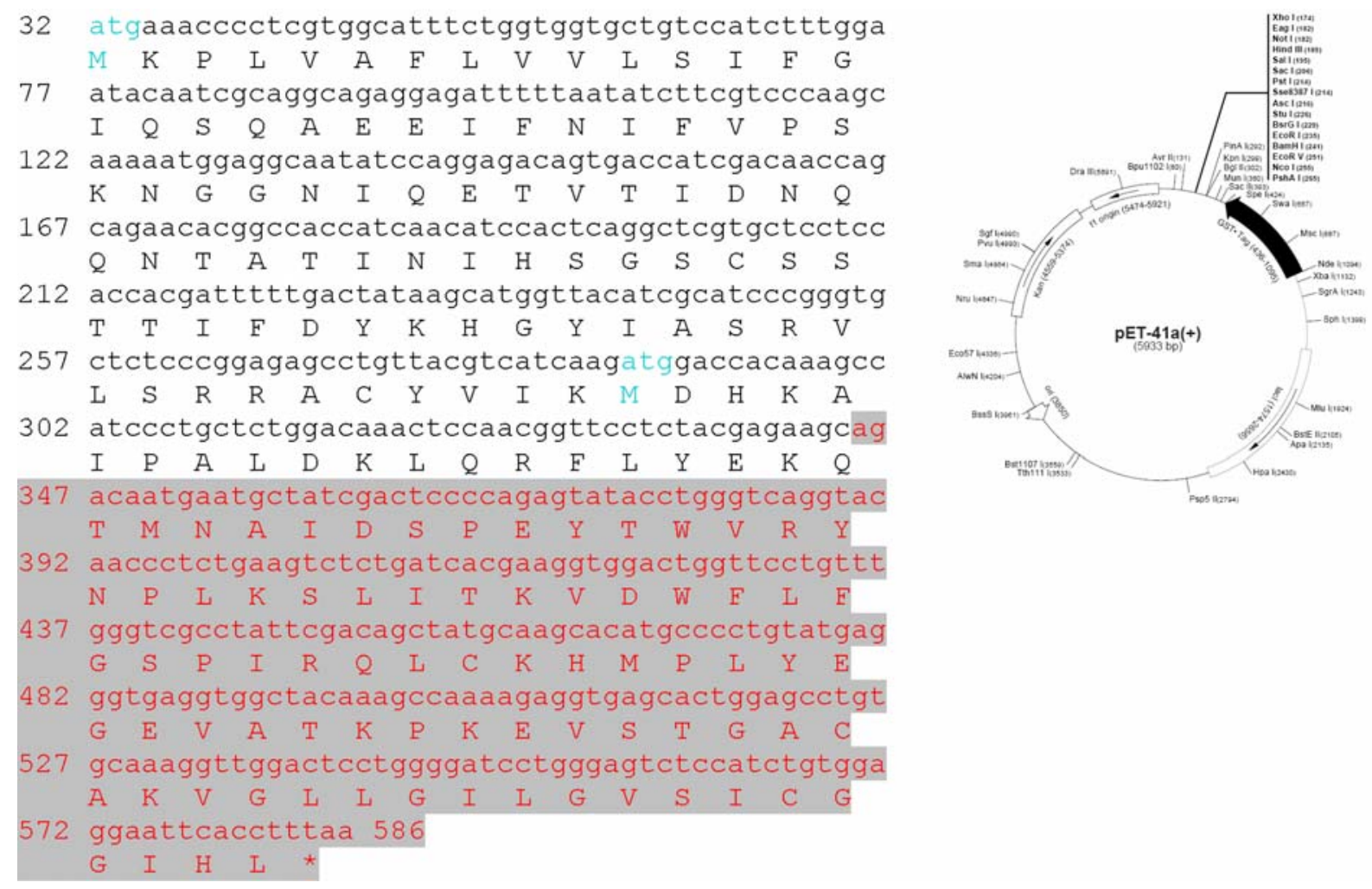

Abb. 3.10.6: Darstellung eines Gastrokine 2-GST-Fusionsproteins

Um ein Fusionsprotein für die Generierung eines Antikörpers gegen Gastrokine $2 \mathrm{zu}$ erstellen, wurde der C-terminale Bereich (grau unterlegt) in die multiple Klonierungsregion des GST-Expressionsvektor pET41a(+) kloniert. 
Das Gastrokine 2-GST-Fusionsprotein wurde mittels dreistündiger IPTG-Induktion (1mM) im 1L-Kulturmaßstab in pBL21(DE3)-Bakterienzellen erzeugt. Die Proteine wurden aus den Bakterienzellen isoliert und das Fusionsprotein wurde mittels GST-Affinitätspurifikation über eine Glutathionsäule aufgereinigt. Nach einer Kontrolle durch eine SDS-Gelelektrophorese mit anschließender Coomassie-Färbung (Abb.3.10.7) wurde damit begonnen, Kaninchen durch Injektion des Fusionsproteins zu immunisieren.

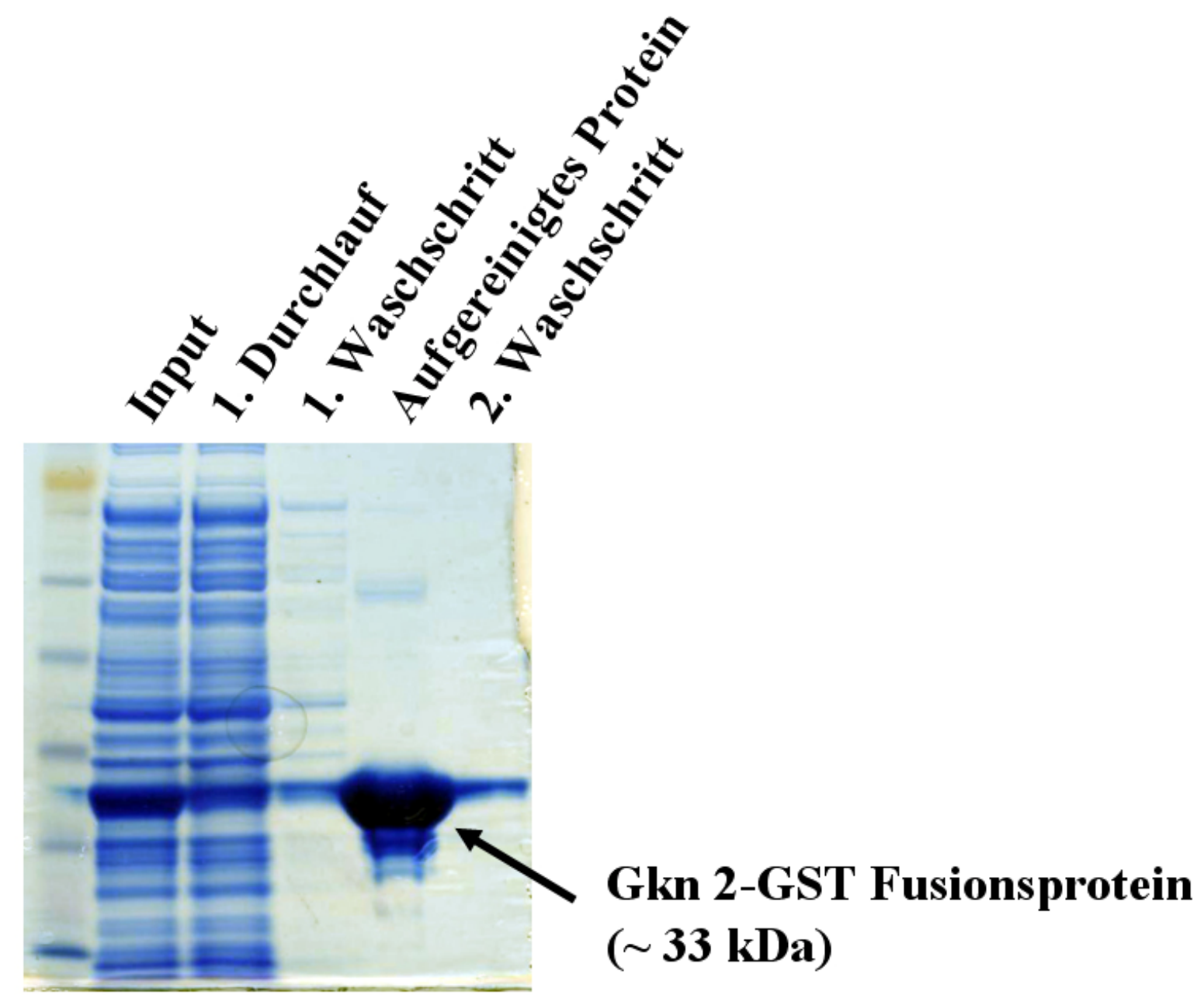

Abb. 3.10.7: Aufreinigung des Gastrokine 2-GST Fusionsproteins

Zur Eluierung des Fusionsproteins wurde das isolierte Gesamtprotein (Input) mittels einer Glutathion-Affinitäts-Säule aufgereinigt. Der Durchlauf und die einzelnen Waschlösungen wurden anschließend mit auf das SDS-Testgel aufgetragen, um die Effektivität der Eluierung zu überprüfen. Wie zu erkennen, ließ sich eine sehr gute Aufreinigung und Konzentrierung des Gastrokine 2-GST Fusionsproteins erreichen. 
Um eine funktionelle Analyse des Gastrokine 2 Gens vornehmen zu können, wurde mit der Erstellung eines Konstruktes für die Deaktivierung von Gastrokine 2 mittels homologer Rekombination begonnen (Abb. 3.10.8). Hierfür sollte ein $7 \mathrm{~Kb}$ großes SstI-Fragment in den BamHI/EcoRI restringierten pPNT-Vektor gebracht werden. Dafür mussten die überhängenden Enden (,sticky ends“) des Vektors und des Fragments mit einer Polymerasereaktion ,,aufgefüllt“" werden, so dass glatte Enden („blunt ends“) entstehen. Dieses Fragment soll dann in den pPNT-Vektor kloniert werden, wo es als 3'Arm fungiert. Anschließend soll als 5'Arm ein 2,8 Kb großes BamHI/PstI-Fragment nach Umklonierung in pBluescript mittels NotI/XhoI-Restriktion in den NotI/XhoI restringierten pPNT-Vektor eingebracht werden. Nach Linearisierung durch eine NotI-Restriktion soll das Konstrukt für die homologe Rekombination in ES Zellen verwendet werden. Das Screening der ES Zellen auf homologe Rekombinanten erfolgt mittels SstI-Restriktion der genomischen ES Zell-DNA mit anschließender Southern Blot Hybridisierung mit Hilfe einer 5' externen Sonde. Mit SstI restringiertes Wildtypallel liefert hierbei ein Hybridisierungssignal bei einer Größe von $6 \mathrm{~Kb}$. Da durch die Auffüllreaktion der überhängenden Enden eine SstI-Restriktionsschnittstelle im rekombinanten Allel zerstört wird, hybridisiert das SstI restringierte rekombinante Allel mit der externen Sonde bei einer Größe von $13 \mathrm{~Kb}$. 


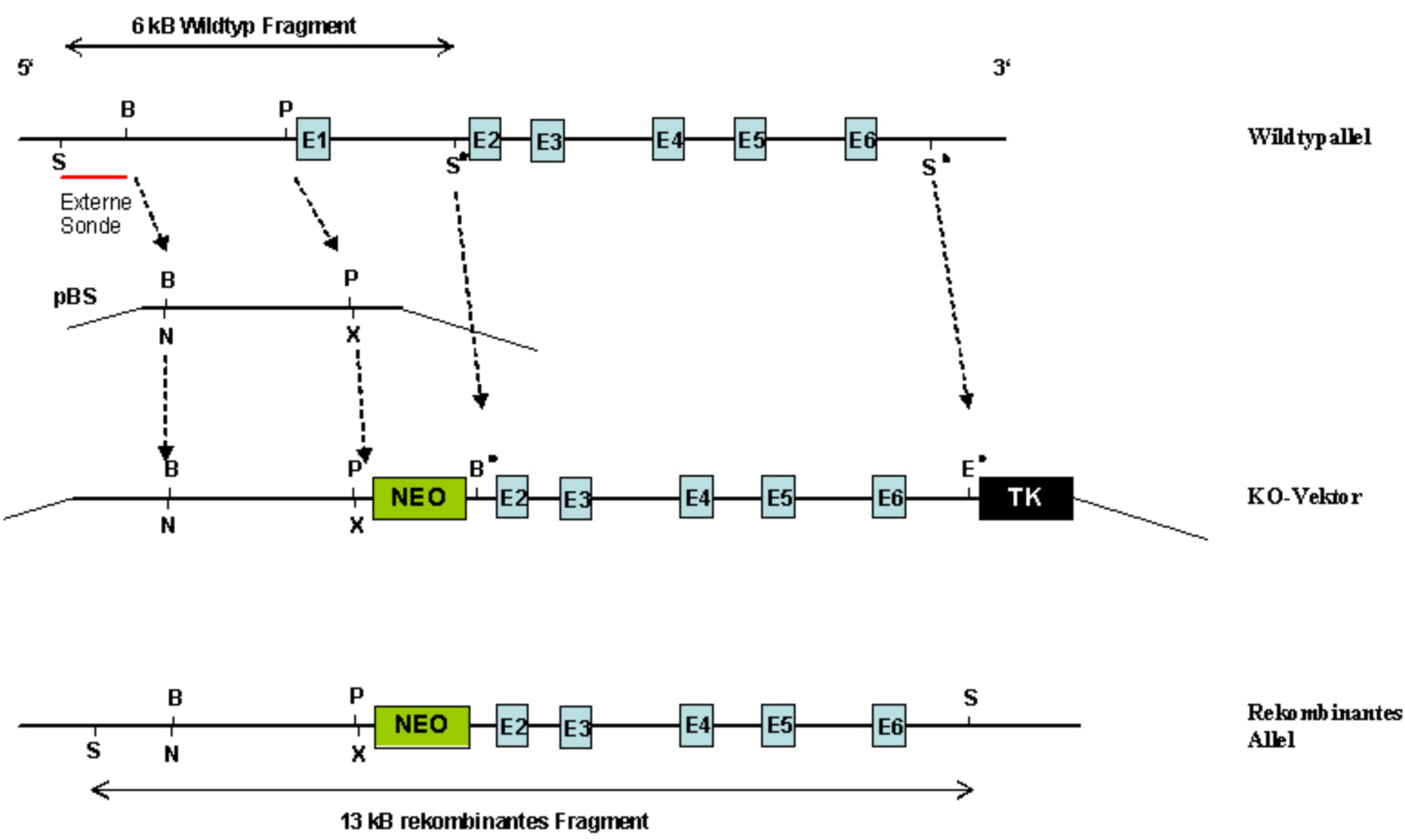

Abb. 3.10.8: Strategie für die homologe Rekombination des Gastrokine 2-Gens

Für die Erstellung des KO-Konstruktes soll ein 2,8 Kb großes BamHI/PstI-Fragment nach Umklonierung in pBluescript als 3'Arm und ein $7 \mathrm{~Kb}$ großes SstI-Fragment als 5'Arm in den pPNT-Vektor gebracht werden. Das ES Zellscreening erfolgt über SstIRestriktion der genomischen ES Zell-DNA mit anschließender Southern-Blot Analyse mittels 5' externer Sonde. Das Wildtypallel liefert hierbei ein Hybridisierungssignal bei 6 $\mathrm{Kb}$, wohingegen das rekombinante Allel ein Signal bei $13 \mathrm{~Kb}$ aufweist. $\mathrm{S}=$ SstI; $\mathrm{B}=$ BamHI; P = PstI; N = NotI; X = XhoI; NEO = Neomycinkassette; TK = Thymidinkinase; $\star=$,,aufgefüllte“ überhängende Enden 


\subsection{Charakterisierung des Admp Gens}

Das Admp Gen lokalisiert in der Maus auf Chromosom 3 E3 und kodiert für eine mRNA von 1765 Nukleotiden. Das Admp Gen erstreckt sich über etwa 40000 Basenpaare und besteht aus drei Exons (Abb. 3.11.1).

$\mathbf{A}$

1 gctggggaga agccagagca tctaagctca ctctaaggca ggagacgaag aaataaagcc

61 cagagaggag aataatcta caccagattg ttcagaggaa aagcatcacc gagtaccaag

121 cctggatact cctgcacagg cagactttc ccagcttaag gaagagccat ggattcaag

181 cgcgtgaagg agtattttgc ctggctctat tatcaatacc agatcatcac ctgctgtgct

241 gtcatggagc cttgggaaca atcgatgctc aacaccatca tactgaccat tgtggctatg

301 gtggtataca ctgcctatgt cttcatcccc atccacatcc gcctggcttg ggaattttc

361 tccaaatat gtggctatga cagttccatt tctaactgat ctcatctgaa ttcggtgaaa

421 gggcataacg tgttcacatt gcttacaact tactgacttg ggtgaccgta tcatcttca

481 cctctgacct gaccagcact ctctctatgc actgtcccgc acatcctgcc tggagtatga

541 gataggttt cccccacttg cttttgtaca tgcaatattg tgcatcaggt gatagaaag

601 gcgatgactt taaccccata gcccacatt gctcaactct atggctttag gtttctttg

661 aatcaggat gcttgaaat aaactttc tggaaatag gcttataaga gacatgacaa

721 agtcatatt acattactct cttcatatta ttctatacta aaggatatgt tacaaagta

781 ttctttatag gctactgtca aaagtaccct gtacttgttt acaatttatt aaagatggg

841 aataalaga tgaacctta aagtcttatt ttctgggaaa tagctaatac ctaaaattcg

901 tttcttcttc tttttaaat tttcatttc tttgctttag ctaaaattct tttagtttaa

961 agtaacaggc cagagacagt tatctttct tcagattttg tttcagcatc gtttcaatg

1021 ctcctgaaat ctagctttat tacagcttta aaggaatgac ttttttccc cctaggtaaa

1081 caataacta ttatacgaga gaataattta agtttaagaa acaaggata atcaagcaa

1141 attcagatac tgtgactttg gatcacgccc cactttacat gatgctggag acagaagaag

1201 agagattgtt gtttgctgt gccttcagtg aaaggaaggg aagctgtgtg tcctaggcta

1261 caggaagaaa agctaataaa taggctggaa gtaatagcca ggcagcaggg agtcgggagc

1321 tccagttaaa ggcttgata tagcagctcc tttgcacagc agaaacaaa tttattaaat

1381 ttctctcaaa atgtttatct tcaaagcaga tgtaagattt taattatagt gctgagtcaa

1441 acataaaagc caaagaccaa gccttgcagc ttttctttcc tctcaataa tattaacatt

1501 agtgattctg gtaalataaa taaataaatg aaccggcttt ggacaatatt ggcacctttg

1561 ttttaggaga gaaatcttcc aagtagacat ccaaagaaag ttatttggca cgcaaaatc

1621 aacctgcatg tctgtttaaa aaacaaat gtacatttta aagagaaacc agatatgaaa

1681 tatatactta ctgatttttg caaataaa tgaagtttac ttttataagc aaaaaaaaa

1741 aaaaaaaaa aaaaaaaa aaag

B

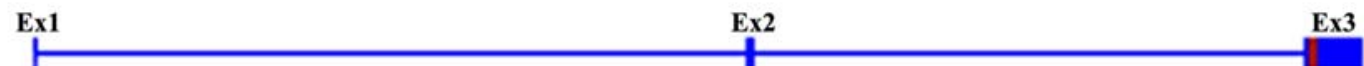

- kodierende Region a - nicht kodierende Region

\begin{tabular}{|l|l|l|l|l|}
\cline { 2 - 5 } & Organismus & $\begin{array}{l}\text { Name des } \\
\text { Gens }\end{array}$ & $\begin{array}{l}\text { Homologie } \\
\text { Aminosäure } \\
(\%)\end{array}$ & $\begin{array}{l}\text { Homologie } \\
\text { Nukleotide } \\
(\%)\end{array}$ \\
\hline H. sapiens & LOC653814 & 85.5 & 85.5 \\
\hline G. gallus & LOC425008 & 68.0 & 73.8 \\
\hline
\end{tabular}




\section{Abb. 3.11.1: Datenbankanalyse des Admp Gens}

Mittels Datenbankanalyse wurde die (A) mRNA Sequenz von Admp beschrieben. Die grau unterlegten Bereiche wurde für die Generierung zweier spezifischer Sonden (5'-Sonde = hellgrau unterlegt; 3'-Sonde $=$ dunkelgrau unterlegt) für die Northern-Blot Analyse verwendet. Putative Polyadenylierungssignale sind rot unterlegt. Darstellung der ExonIntron-Struktur (B) des Admp Gens und der Domänenstruktur (C) des korrespondierenden Proteins. (D) Tabellarische Auflistung der Homologien der putativen orthologen Gene zu Admp aus Mus musculus. Homologien sind auf Aminosäure- und Nukleotidebene angegeben $\mathbf{E x}=$ Exon; = putative Transmembrandomäne.

Die gesamte kodierende Region befindet sich in Exon 3. Die mRNA-Sequenz weist zwei putative Polyadenylierungssignale auf, die in Transkripten von ungefähr 800 Nukleotiden und 1500 Nukleotiden resultieren. Datenbankanalysen sagen für das korrespondierende putative Protein, das aus lediglich 76 Aminosäuren zusammengesetzt wird, eine Transmembrandomäne voraus. Admp ist vermutlich sowohl auf Aminosäureebene als auch auf Nukleotidebene hoch konserviert in Amniota. Es weist eine hohe Homologie zu seinen putativen orthologen Proteinen in Homo sapiens und Gallus gallus auf.

Mittels einer Northern-Blot Analyse mit RNA aus unterschiedlichen Geweben konnte eine starke magenspezifische Expression des Admp Gens in allen Magenteilen beobachtet werden (Abb. 3.11.2). In dieser Analyse wurde die 5'-Sonde (siehe Abb. 3.11.1 A) verwendet, die Transkripte mit beiden putativen Polyadenylierungsmöglichkeiten detektieren kann. Durch Verwendung dieser Sonde waren zwei Hybridisierungssignale zu erkennen, die mit den erwarteten Größen der prognostizierten Transkripte von 1500 Nukleotiden bzw. 800 Nukleotiden korrelieren. Des Weiteren ließ sich die Expression beider Admp-Transkripte in allen Magenteilen beobachten. Die anderen untersuchten Gewebe zeigten keine Admp Expression. 


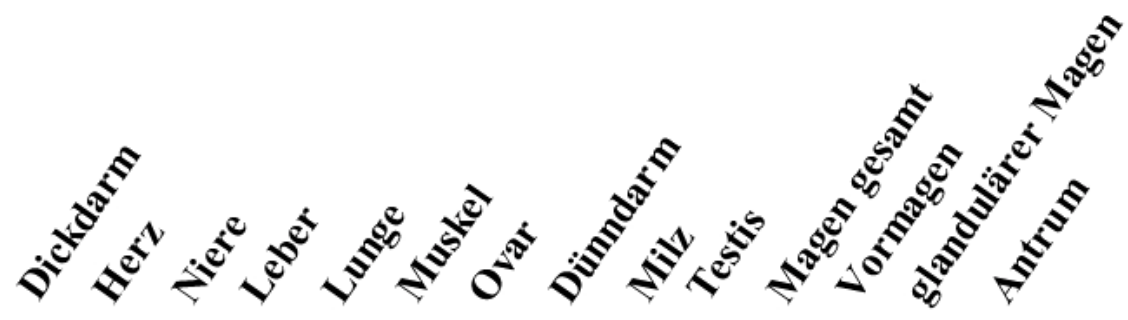

Admp

$\beta$-Aktin

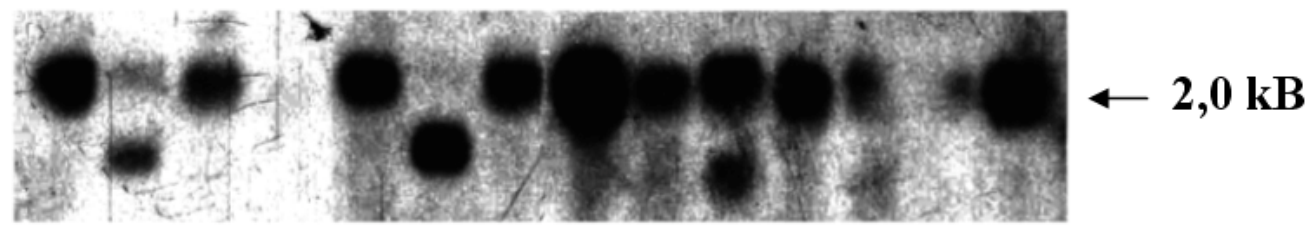

Abb. 3.11.2: Gewebespezifische Expression von Admp

Northern-Blot Analyse mit einer Admp-spezifischen 5'-Sonde. Es wurden zwei unterschiedlich große Signale in allen Magenteilen detektiert, die von der Größe her mit den vorhergesagten Transkripten korrelieren.

Um zu überprüfen, ob beide Transkripte tatsächlich aus der Verwendung unterschiedlicher Polyadenylierungssignale hervorgehen, wurde eine Northern-Blot Analyse an Magen RNA mit einer 3'-Sonde, die hinter dem ersten Polyadenylierungssignal lokalisiert ist, durchgeführt (siehe Abb. 3.11.1 A). Hierbei sollte lediglich das 1500 Nukleotide große Transkript, das durch Verwendung des späteren Polyadenylierungssignals erzeugt wird, zu detektieren sein. Die Northern-Blot Hybridisierung zeigte nur ein Transkript in der erwarteten Größe von 1500 Nukleotiden (Abb. 3.11.3). Ein weiteres Signal war nicht zu beobachten. 


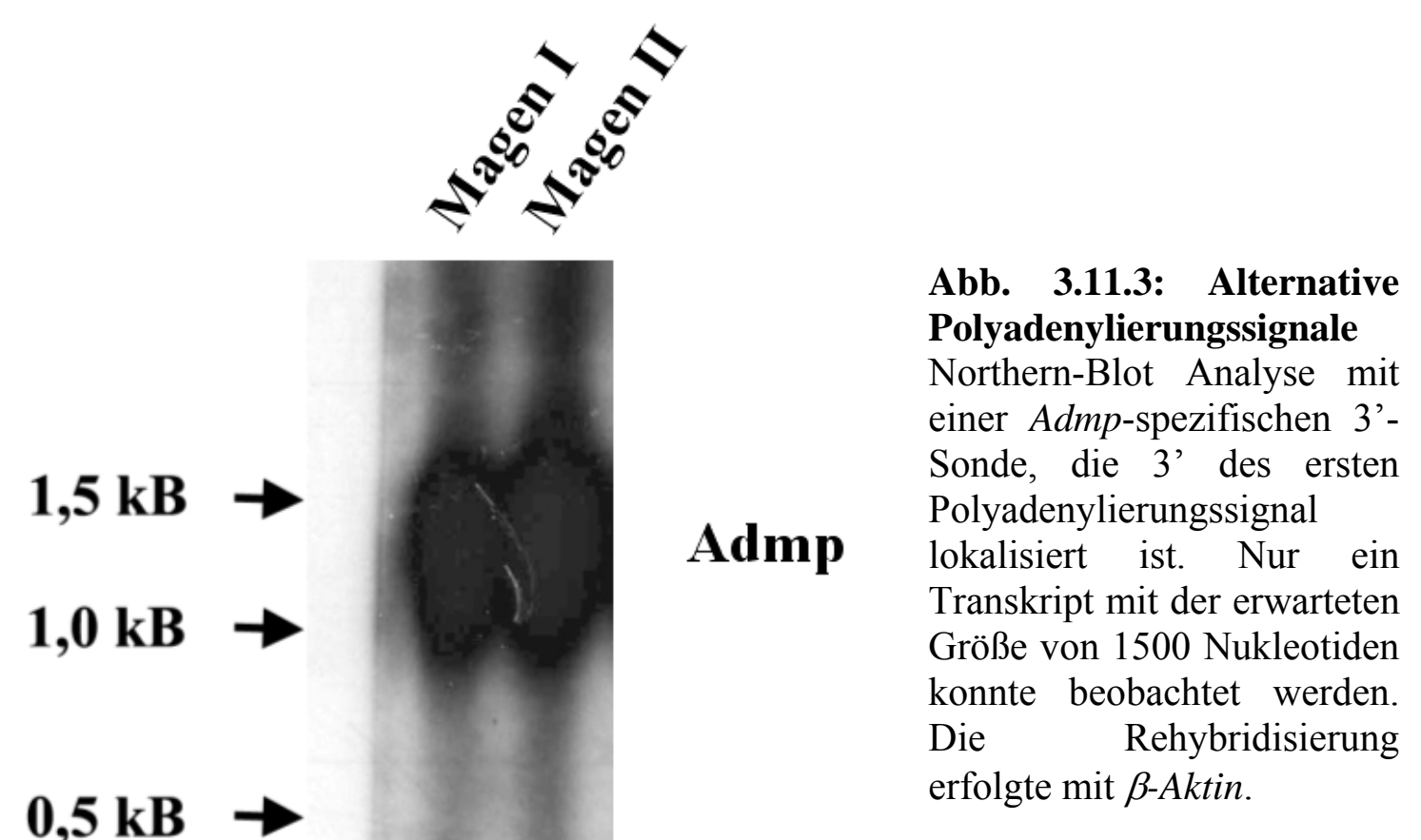

$2,0 \mathrm{kB} \rightarrow \quad \beta$-Aktin

Wie schon in 3.11.2 gezeigt, ließ sich Admp in allen Magenteilen nachweisen. Es sollte nun untersucht werden, ob der Verpflegungsstatus der Maus eine Auswirkung auf die Expression von Admp im Magen hat. Hierfür wurde, wie schon vorher beschrieben, RNA aus dem Magen von Mäusen isoliert, denen vorher das Futter entzogen wurde bzw. die normal ernährt wurden. Die Hybridisierung mit der 5'-Sonde ließ keine signifikanten Unterschiede in der Admp Expression zwischen den beiden Gruppen erkennen (Abb. 3.11.4). In allen drei Magenteilen ist die Expression beider Transkripte von Admp nicht abhängig vom Ernährungszustand der Mäuse. 


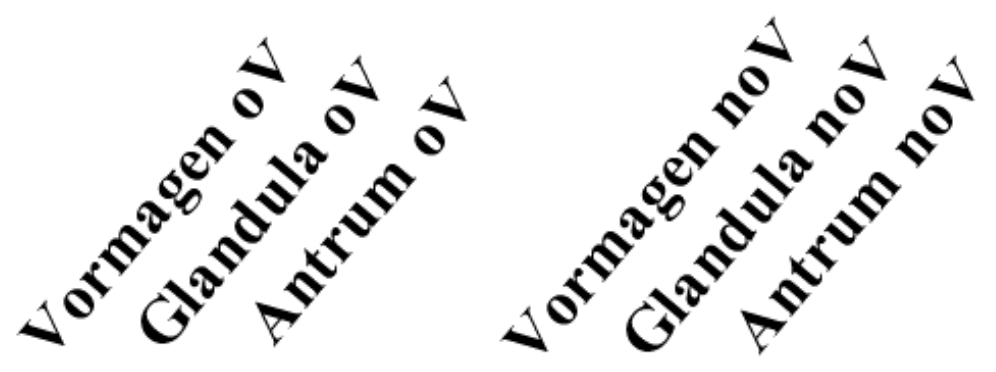

\title{
Admp
}

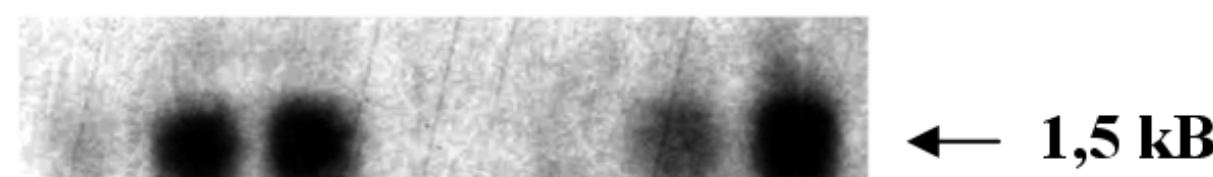

\section{$\beta$-Aktin}

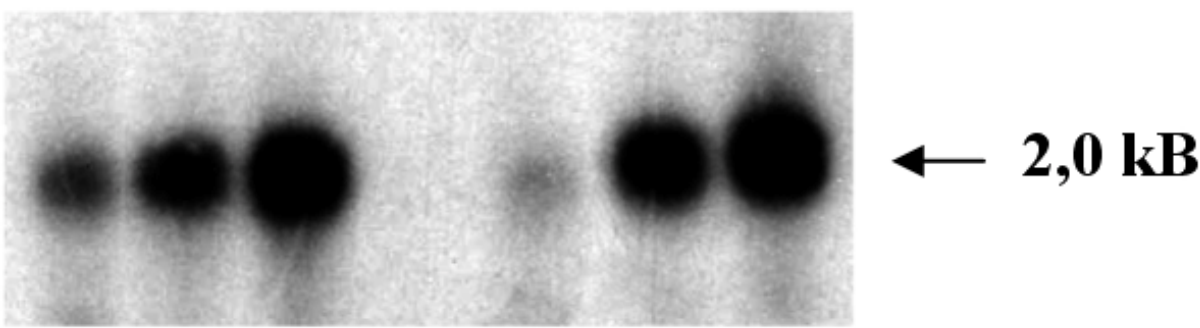

\begin{abstract}
Abb. 3.11.4: Northern-Blot Analyse des Admp Gens mit RNA aus unterschiedlichen Magenteilen

Eine Northern-Blot Analyse wurde mit RNA aus unterschiedlichen Magenteilen mit unterschiedlicher Ernährungslage (oV und noV) durchgeführt. Eine Expression ist in beiden Gruppen in allen Magenteilen zu beobachten. Die Rehybridisierung erfolgte mit $\beta$-Aktin. $\quad \mathrm{oV}=$ ohne Verpflegung; Nahrungsentzug über Nacht; noV $=$ normale Verpflegung
\end{abstract}

Um zu untersuchen, zu welchem Zeitpunkt der prä- bzw. postnatalen Magenentwicklung die Admp Expression beginnt, wurde eine Northern-Blot Analyse mit RNA unterschiedlicher Entwicklungsstadien des Mausmagens durchgeführt. Die hier verwendete 5'-Sonde sollte ferner darüber Aufschluss geben, ob die Expression beider Transkripte während der Magenentwicklung zum gleichen Zeitpunkt beginnt oder ob hier Unterschiede festgestellt werden können. Mittels dieser Northern-Blot Analyse konnte gezeigt werde, dass die 
Expression des größeren, 1500 Nukleotide umfassenden Transkripts schon am Tag 17,5 dpc in Magen-RNA nachzuweisen ist (Abb. 3.11.5). Der Beginn der Expression des kleineren Transkripts ließ sich mittels dieser Hybridisierung nicht genau datieren. Es ist definitiv ein Signal am Tag 5 postnatal $\mathrm{zu}$ erkennen. Leider ist die Intensität des kleineren Hybridisierungssignals hier schwächer als die des Größeren, was nicht mit den vorherigen Northern-Blot Analysen korreliert. Hier wies das kleinere Signal immer die höhere Intensität auf. Aufgrund dessen ist die Festlegung des Expressionsbeginns des kleineren Transkripts nicht eindeutig möglich und bedarf eines erneuten Versuchs.

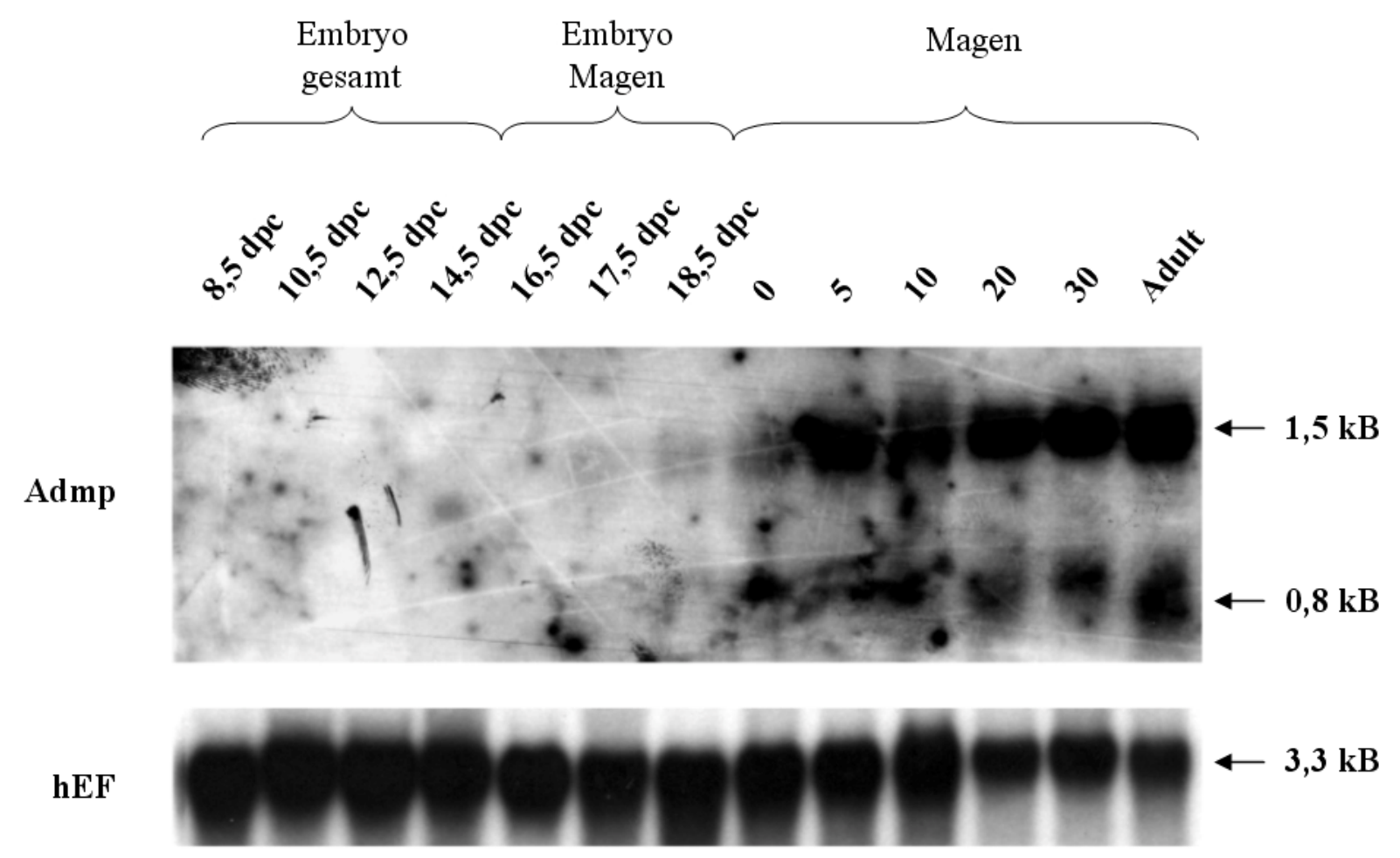

Abb. 3.11.5: Northern-Blot Analyse für Admp mit RNA unterschiedlicher Entwicklungsstadien Mittels einer Northern-Blot Analyse an Gesamt- bzw. Magen-RNA unterschiedlicher prä- und postnataler Entwicklungsstadien konnte der Beginn der Admp Expression auf Tag 17,5 pc datiert werden. Die Expression des kleineren Transkripts ist an Tag 5 postnatal zu erkennen. Die Rehybridisierung erfolgte mit $h E F$. 


\subsection{Charakterisierung des SA11 Gens}

Um das SA11 (ㅌtomach autosomal gene on chromosome 11) Gen zu charakterisieren, wurden zunächst Datenbankinformationen zusammengetragen. Da es sich um ein unbekanntes Gen handelt, wurde es aufgrund seiner Lokalisation auf Chromosom 11 (11 C) SA11 genannt. Es erstreckt sich im Genom über etwa 6000 Basenpaare und besteht aus 3 Exons mit einer mRNA von 376 Nukleotiden, wobei die kodierenden Bereiche in den Exons 1 und 2 liegen (Abb. 3.12.1 B).

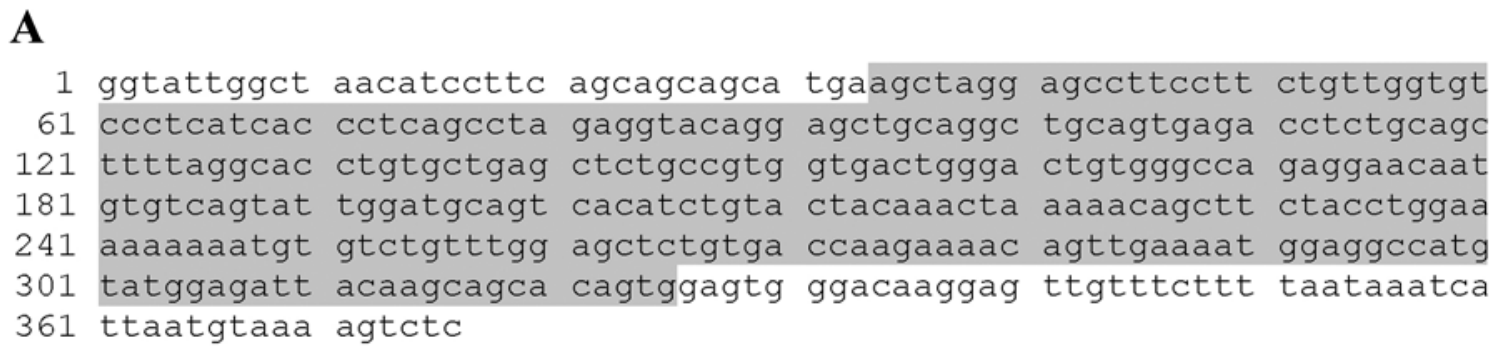

B

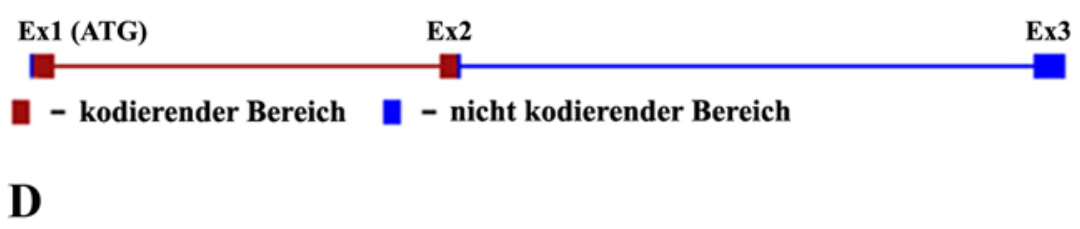

C

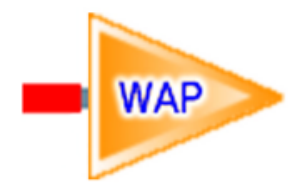

SA11Mus WDNM1-homologRat

Wdnm1Mus WDNM1Bos WDNM1Rat

WapMus

WAPRat

SA11Mus
WDNM1-homologRat
Wdnm1Mus
WDNM1Bos
WDNM1Rat
WapMus
WAPRat
SA11Mus
WDNM1-homologRat
Wdnm1Mus
WDNM1Bos
WDNM1Rat
WapMus
WAPRat
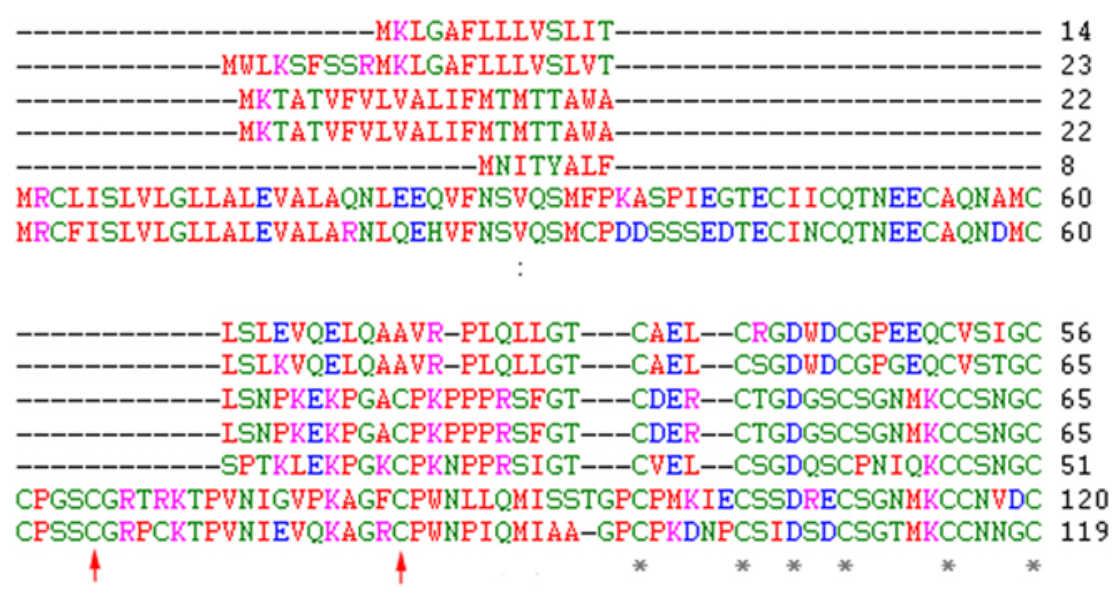

SHICTTN----_------- 63

SNVCATS------------ 72

GHACKPPVF---------- 74

GHACKPPVF--------- 74

GHVCKSPVF---------- 60

VMTCTPPVP----VITLQ 134

IMSCMDPEPESPTVUSFQ 137 


\section{Abb. 3.12.1: Datenbankanalyse des SA11 Gens}

Mittels Datenbankanalyse wurde die (A) mRNA Sequenz von SA11 beschrieben. Der grau unterlegte Bereich wurde für die Generierung einer spezifischen Sonde für die Northern-Blot Analyse verwendet. Darstellung der Exon-Intron-Struktur (B) des SA11 Gens und der Domänenstruktur (C) des putativen SA11 Proteins. (D) Vergleich verschiedener Proteine der WAP (Whey Acidic Protein)-Familie. Die charakteristischen Cysteine sind mit einem Stern gekennzeichnet. Die in SA11 fehlenden Cysteine sind durch einen roten Pfeil markiert.

$\mathbf{E x}=$ Exon; $=$ putatives Signalpeptid; ${ }_{\text {wap }}=$ Four-disulfide core-Domäne

Datenbankanalysen des SA11 Gens beschreiben SA11 als putatives sekretorisches Protein mit einer Four-disulfide core-Domäne. Diese ist durch 8 charakteristisch angeordnete Cysteine gekennzeichnet, die an vier Disulfidbindungen (Four-disulfide core) beteiligt sind. Hieraus lassen sich strukturelle Homologien der WAP (Whey Acidic Protein)-Proteine ableiten. SA11 besitzt allerdings wie sein homologes Protein, das WDNM1-like Protein der Ratte, nur 6 der charakteristischen Cysteine (3.12.1 D). Andere Mitglieder der WAP -Familie wie WDNM1 aus Mus musculus, Rattus norvegicus und Bos taurus besitzen 7 der charakteristischen Cysteine. Darüber hinaus weist SA11 eine hohe Homologie von 85,7\% auf Aminosäureebene und 93,1\% auf Nukleotidebene zu dem WDNM1-like Protein aus Rattus norvegicus auf.

Um die gewebespezifische Expression von SA11 zu untersuchen, wurde eine Northern-Blot Analyse mit RNA aus unterschiedlichen Geweben mit einer spezifischen SA11 Sonde durchgeführt. Es konnte festgestellt werden, dass ein etwa 350 Nukleotide großes Transkript von SA11 prädominant in der Leber exprimiert wird (Abb.3.12.2). Eine starke Expression ließ sich auch im Magen nachweisen. Interessanterweise konnte im Magen ein weiteres Transkript von etwa 700 Nukleotiden beobachtet werden. Dieses Transkript wird nur im glandulären Bereich und im Antrum exprimiert, in dem sich das kürzere Transkript nicht nachweisen ließ. Im Vormagen wurde einzig das kürzere Transkript beobachtet. Überaschenderweise konnte das kürzere Transkript nicht in RNA aus Gesamtmagen detektiert werden. Neben diesem zeigte sich noch eine schwache Expression des kleineren SA11-Transkripts in der Milz. 

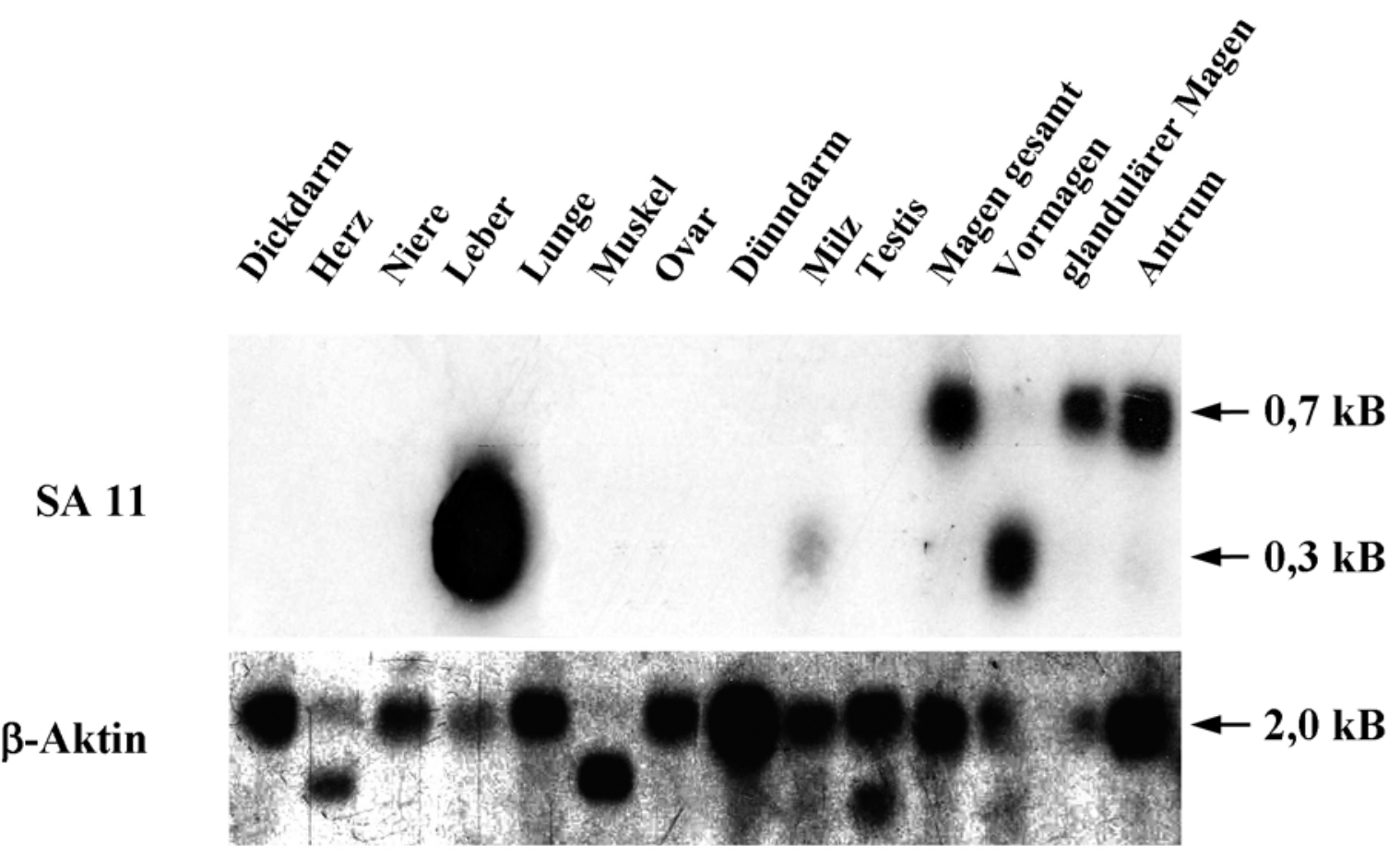

Abb. 3.12.2: Gewebespezifische Expression von SA11

Northern-Blot Analyse mit einer spezifischen SA11 Sonde. Es wurden ein starkes, etwa 350 Nukleotide großes Signal in der Leber und ein sehr schwaches Signal gleicher Größe in der Milz beobachtet. Im Magen konnte ein Signal dieser Größe nur im Vormagen detektiert werden. Ein etwa 700 Nukleotide großes Transkript konnte dagegen im glandulären Magen und im Antrum beobachtet werden. Interessanterweise ließ sich das Vormagen-spezifische Signal nicht im Gesamtmagen nachweisen. Die Rehybridisierung wurde mit $\beta$-Aktin durchgeführt.

Ob der Verpflegungsstatus einen generellen Einfluss auf die Expression von SA11 hat oder eine Regulation eines der beiden Transkripte bewirkt, sollte mittels einer Northern-Blot Analyse mit RNA der Magenteile von Mäusen mit Nahrungsentzug bzw. mit normaler Verpflegung abgeklärt werden. Es zeigte sich, dass die Expression der beiden SA11 Transkripte unabhängig ist von der Nahrungsaufnahme (Abb. 3.12.3). 

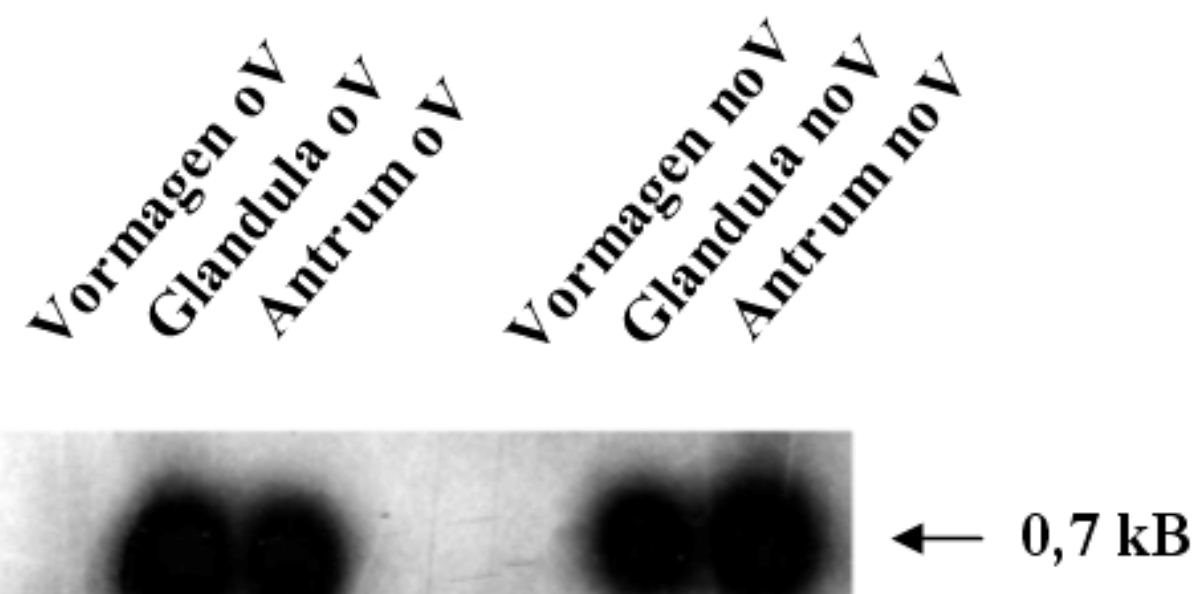

SA 11

$\beta$-Aktin

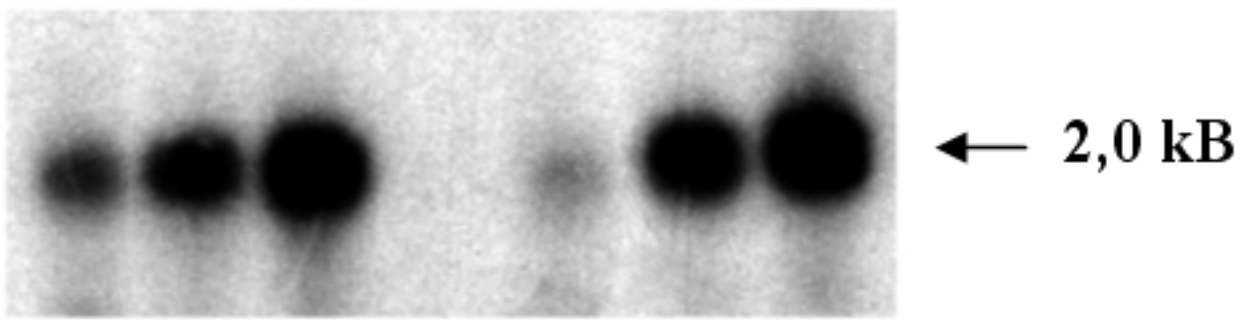

Abb. 3.12.3: Northern-Blot Analyse des SA11 Gens mit RNA aus unterschiedlichen Magenteilen

Eine Northern-Blot Analyse wurde mit RNA aus unterschiedlichen Magenteilen mit unterschiedlicher Ernährungslage (oV und noV) durchgeführt. In beiden Gruppen ist eine Expression des kleineren Transkripts nur im Vormagen zu beobachten. Ausschließlich das größere Transkript kann in Glandula und Antrum der beiden Gruppen detektiert werden. Die Expression beider Transkripte ist nicht von der Nahrungsaufnahme abhängig. Die Rehybridisierung erfolgte mit $\beta$-Aktin. oV $=$ ohne Verpflegung; Nahrungsentzug über Nacht; noV = normale Verpflegung

Um den Ursprung des zweiten, größeren Transkripts aufzuklären, müssen noch Untersuchungen durchgeführt werden. Hierbei sollte vor allen Dingen überprüft werden, ob eine alternative Polyadenylierungsstelle 3' der bekannten Sequenz vorhanden sind. Alternatives Spleißen von weiteren bis dato nicht bekannten Exons könnte ebenfalls ein Grund für das alternative Transkript sein. Des Weiteren könnte man eine zusätzliche Polyadenylierung der mRNA in Erwägung ziehen. 


\section{DISKUSSION}

\subsection{Der Magen}

Der Magen der Maus entwickelt sich aus Anteilen des primordialen Vorderdarms und zeigt bereits am 9.-10. Embryonaltag ein einfaches Lumen. Das Magenepithel wird durch die differentielle Expression der hedgehog-Gene Sonic hedgehog (Shh) bzw. Indian hedgehog (Ihh) im anterioren bzw. posterioren Magen differenziert (Litingtung et al., 1998). Histologisch besteht der Mausmagen aus zwei unterschiedlichen Epithelien: einem verhornten Plattenepithel, welches den Vormagen auskleidet und einem differenzierten Drüsenepithel, das den glandulären Anteil des Magens und den Antrumbereich bildet. Dieses Drüsenepithel wird durch Invagination in das umgebende Mesoderm in die Länge gezogen und bildet die Drüsenschläuche oder gastrischen Einheiten des Magens. Erste primitive Drüsenschläuche sind am 15.-16. Embryonaltag bereits zu erkennen (Fukamachi et al., 1979). Die gastrische Einheit des Mäusemagens besteht hauptsächlich aus 5 verschiedenen Zelltypen: Pit-, Neck-, Parietal-, Zymogenen- und Entero-endokrinen Zellen (Abb. 4.1). Die Parietalzellen der gastrischen Mucosa sezernieren die im Magensaft enthaltene Salzsäure in das gastrische Lumen (Dibona et al., 1979; Berglindh et al., 1980). Das saure Milieu des Magensafts ermöglicht die autoproteolytische Spaltung von Pepsinogen, das von den Zymogenen-Zellen sezerniert wird, zur aktiven Protease Pepsin (Khan und James, 1998). Sowohl Pit- als auch Neckzellen sezernieren Bicarbonathaltigen Schleim, der die Auflösung der Magenschleimhaut durch Salzsäure und Pepsin verhindert (Allen und Flemstrom, 2005). Da die Magensäure im Magensaft essentiell für die Funktion des Magens ist, unterliegt ihre Sekretion

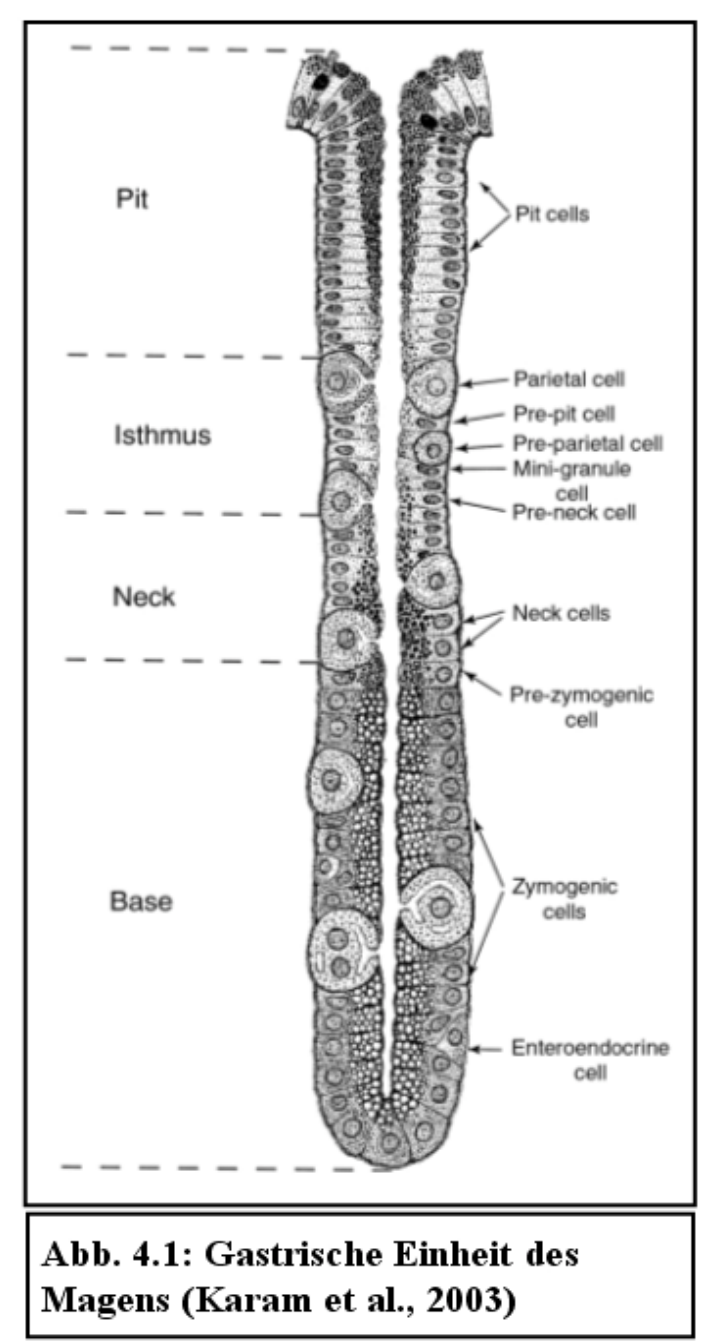


durch die Parietalzellen einer komplexen Regulation. Die Regulation der Magensäuresekretion wird durch unterschiedliche Mechanismen auf neuronaler, hormoneller, para- und autokriner Ebene reguliert, wobei die wichtigsten aktivierenden Elemente Histamin, Gastrin und Acetylcholin sind (Black et al., 1972; Hersey und Sachs, 1995). Somatostatin fungiert als inhibierendes Element auf die Sekretion der Magensäure (Saffouri et al., 1979; Chiba et al., 1981; Holst et al., 1992). Gesteuert wird die Regulation der gastrischen Säuresekretion von Enterochromaffin-ähnlichen (ECL) Zellen, G- und D-Zellen (Pearse und Bussolati, 1972; Polak et al., 1975; Hakanson et al., 1986), die drei unterschiedliche Typen von gastrischen endokrinen Zellen darstellen, und Acetylcholin, das durch seinen spezifischen Rezeptor direkt auf Parietalzellen wirkt (Wilkes et al., 1991). Die Sekretion von Histamin durch ECL Zellen steht dabei im Mittelpunkt der Regulation durch Gastrin, Acetylcholin und Somatostatin (Abb. 4.2).

Wird Histamin durch ein stimulierendes Gastrinbzw. Acetylcholin-Signal sekretiert, so gelangt es mittels parakriner Diffusion $\mathrm{zu}$ den benachbarten Parietalzellen und bindet am spezifischen

Histaminrezeptor $\mathrm{H} 2$ (Black et al., 1972; Fykse et al., 2006), der in der Plasmamembran der

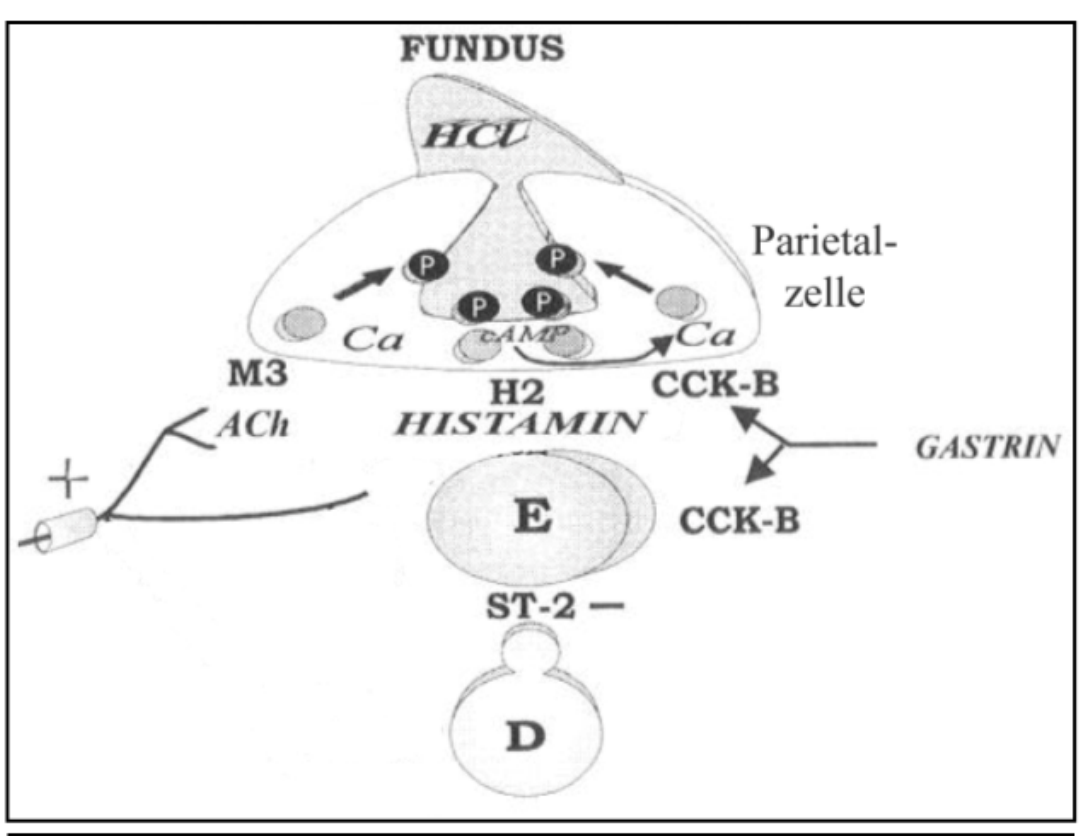

Abb. 4.2: Regulation der Magensäuresekretion (modifiziert nach Hersey und Sachs, 1995) Die Sezernierung der Magensäure durch die Parietalzellen wird durch den Einfluss von Gastrin, Histamin, Acetylcholin und Somatostatin reguliert. Ach = Acetylcholin; $\mathrm{Ca}=$ Calcium-Ionen; $\mathrm{cAMP}=$ zyklisches Adenosinmonophosphat; $\mathrm{CCK}-\mathrm{B}=$ Cholecystokinin B Rezeptor; D = D-Zelle; E = Enterochromaffinähnliche (ECL) Zelle; $\mathrm{HCl}=$ Salzsäure; H2 = Histamin 2 Rezeptor; M3 = Muscarin 3 Rezeptor; $\mathrm{P}=\mathrm{H}^{+}, \mathrm{K}^{+}$-ATPase; $\mathrm{ST}-2=$ Somatostatinrezeptor 2

Parietalzellen lokalisiert ist (Fukushima et al., 1999). Der Histaminrezeptor H2 besitzt typische Eigenschaften eines G Protein gekoppelten Rezeptors (Dohlman et al., 1991). Die Stimulierung des Rezeptors geht einher mit der Aktivierung von Adenylat Cyclase und der Formierung von zyklischem Adenosinmonophosphat (cAMP) (Chew, 1985). Die Aktivierung des cAMP-abhängigen Protein Kinase (PKA) Signalwegs innerhalb der Parietalzellen führt letztendlich zur Sekretion von $\mathrm{H}^{+}$-Ionen durch die $\mathrm{H}^{+}, \mathrm{K}^{+}$-ATPase (Forte et al., 1975; Urushidani und Forte, 1997). In nicht stimulierten Parietalzellen ist die $\mathrm{H}^{+}, \mathrm{K}^{+}$-ATPase in der 


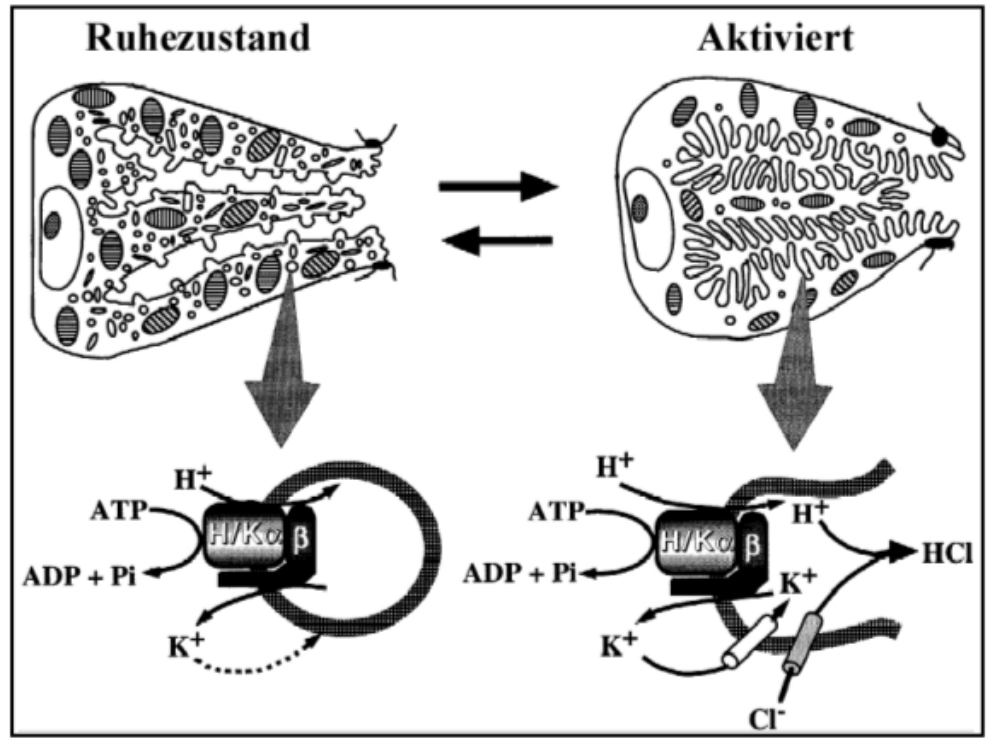

Abb. 4.3: Aktivierung der $\mathrm{H}^{+}, \mathrm{K}^{+}$-ATPase (Urushidani und Forte, 1997) Im Ruhezustand lokalisiert die $\mathrm{H}^{+}, \mathrm{K}^{+}$-ATPase in der Tubulovesikelmembran, wobei sie aufgrund der Limitierung von $\mathrm{K}^{+}$-Ionen inaktiv ist. Durch Aktivierung der Magensäuresekretion fusionieren Tubulovesikel mit der Canaliculusmembran. $\mathrm{K}^{+}$-Ionen im gastrischen Lumen führen zu einer Aktivierung der $\mathrm{H}^{+}, \mathrm{K}^{+}$ATPase und somit zur Sezernierung von $\mathrm{HCl}$.

Membran von cytoplasmatischen Vesikeln, den Tubulovesikeln, lokalisiert. Die Säuresekretion ist innerhalb der Vesikel durch eine Limitierung an $\mathrm{K}^{+}$-Ionen inhibiert. Die Aktivierung der Magensäuresekretion (Abb. 4.3) führt zur Fusion von Tubulovesikeln mit der Canaliculimembran, welche die $\mathrm{H}^{+}, \mathrm{K}^{+}$-ATPase mit dem gastrischen Lumen in Kontakt bringt (Forte et al., 1977; Urushidani und Forte, 1997). Die im gastrischen Lumen vorhandenen $\mathrm{K}^{+}$-Ionen ermöglichen die Sekretion von $\mathrm{H}^{+}$-Ionen durch die $\mathrm{H}^{+}, \mathrm{K}^{+}$-ATPase (Forte, 2004). Die Fusion der Tubulovesikel mit der apikalen Canaliculimembran geht einher mit der Expansion der intrazellulären Canaliculi, die teilweise auch im Lichtmikroskop $\mathrm{zu}$ beobachten ist (Sawaguchi et al., 2005).

\subsection{Die Rolle von Foxq1 bei der Magensäuresekretion}

Im Rahmen dieser Arbeit konnte die Expression von Foxq1 in Parietalzellen der gastrischen Mucosa durch in situ Hybridisierung mittels Digoxigenin-markierter RNA-Sonde an Paraffinschnitten gezeigt werden. Die Expression von Foxq1 im gastrischen Epithel wurde schon im Jahr 2000 in einer Veröffentlichung beschrieben (Hoggatt et al., 2000). Die damals verwendete Methode mit ${ }^{35}$ S-markierter RNA-Sonde an Kryoschnitten konnte allerdings die Foxq1-exprimierenden Zellen innerhalb des gastrischen Epithels nicht detektieren. Die Expression von Foxq1 während der prä- und postnatalen Magenentwicklung ließ eine Beteiligung von Foxq1 an der Entwicklung des Magens, insbesondere an der Entwicklung von Parietalzellen oder deren Distribution innerhalb der gastrischen Mucosa vermuten. Foxq1-defiziente Mäuse zeigen allerdings keine Veränderung im Aufbau der gastrischen 
Mucosa. Die Organisation und die Anzahl der Parietalzellen sind nicht verändert. Funktionelle Studien der Magensäuresekretion ließen eine Störung der Magensäuresekretion von Foxq1-defizienten Mäusen erkennen. Nach Sekretagog-Stimuli mittels Gastrin und Histamin konnte keine bzw. nur eine sehr geringe Änderung des pH-Wertes des Magensafts beobachtet werden. Der basale pH-Wert des Magensafts von gefasteten Foxq1 ${ }^{-/}$-Mäusen zeigt keinen signifikanten Unterschied zur Wildtypkontrolle.

Fehlende Magensäuresekretion (Hypochlorhydrie/Achlorhydrie) ist in vielen Fällen mit einer Hypertrophie der Magenschleimhaut verbunden. Für Atp4a-defiziente Mäuse, die keine $\mathrm{H}^{+}, \mathrm{K}^{+}$-ATPase exprimieren, wurde eine fehlende Magensäuresekretion beschrieben (Spicer et al., 2000). Neben der Achlorhydrie konnte für Atp $4 a^{-/-}$-Mäuse eine Hypergastrinämie und eine Hypertrophie der gastrischen Mucosa gezeigt werden. Gastrin ist neben seiner Funktion als Induktor der Magensäuresekretion auch als ein Wachstumsfaktor der gastrischen Mucosa beschrieben worden. Hierbei wird ein direkter Einfluss auf die gastrischen Stammzellen mittels eines spezifischen Rezeptors (Nakajima et al., 2002) gegenüber einem indirekten Mechanismus durch Aktivierung des Heparin-bindenden EGF-ähnlichen (Epidermal Growth Factor-like) Wachstumsfaktors HB-EGF (Miyazaki et al, 1999) kontrovers diskutiert. Zusätzlich konnte eine erhöhte Expression von verschiedenen Liganden der EGF-Rezeptor Familie unter Gastrineinfluss gezeigt werden (Tsutsui et al., 1997; Miyazaki et al., 1999, Wang et al., 2000).

Für Slc4a2-defiziente Mäuse, denen der AE2 $\mathrm{Cl}^{-} / \mathrm{HCO}_{3}{ }^{-}$Anionenaustauscher (AE2) fehlt, wurde trotz erhöhter Gastrinexpression keine Hypertrophie der Magenschleimhaut beschrieben (Gawenis et al., 2004). AE2 spielt eine wichtige Rolle bei der Magensäuresekretion und AE2-defiziente Mäuse sezernieren keine Magensäure. Da eine Hypertrophie als ein Langzeiteffekt durch anhaltende Achlorhydrie beschrieben wird (Jansen et al., 1990; Lamberts et al., 1993; Jensen, 2006), könnte das Ausbleiben der Hypertrophie des Magens von AE2-defizienten Mäusen aus dem Alter der untersuchten Tiere resultieren. Die für die Untersuchung in dieser Studie verwendeten Tiere waren lediglich 18 Tage alt, so dass eine Veränderung der Magenschleimhaut vermutlich noch nicht eingetreten ist.

Foxq1-defiziente Mäuse zeigten keine Hypertrophie der gastrischen Mucosa. Die untersuchten Mäuse waren drei Monate alt und somit im Alter vergleichbar mit den untersuchten Atp $4 a^{-/-}$-Mäusen (Spicer et al., 2000). In diesem Alter ist im Normalfall bei einer vorhandenen Achlorhydrie schon eine Hypertrophie der Magenschleimhaut zu erkennen. Es kann vermutet werden, dass Foxq1-Defizienz zwar zu Achlorhydrie führt, jedoch wird eine Hypertrophie der gastrischen Mucosa verhindert. Studien an Chrm3- 
defizienten Mäusen, denen das Gen für den Acetylcholin-spezifischen M3 Muscarinrezeptor fehlt, zeigen trotz Achlorhydrie und erhöhtem Serum-Gastrinspiegel, der einhergeht mit einer erhöhten G-Zellzahl, ansonsten keine Veränderungen der gastrischen Mucosa über den untersuchten Zeitraum von 18 Monaten (Aihara et al., 2003). Die Autoren vermuten eine Beteiligung des M3 Muscarinrezeptors am EGF Rezeptor Signalweg, der eine Rolle beim Wachstum der Mucosa spielt (Friis-Hansen, 2002) und spekulieren über eine Beteiligung von Parietalzellen an der Wachstumregulation der gastrischen Mucosa (Aihara et al., 2003).

Neben der Achlorhydrie weisen Foxq1 ${ }^{-/-}$-Mäuse eine verringerte Somatostatin Expression auf. In zahlreichen in vitro Studien konnte gezeigt werden, dass Somatostatin negativ regulierend auf Gastrin und die Magensäuresekretion wirkt (Saffouri et al., 1979; Karnik et al., 1989; Karnik und Wolfe, 1990). Im Gegensatz dazu führt die Inhibierung der Magensäuresekretion durch die Injektion von Omeprazol, einem wirkungsvollen Inhibitor der Magensäuresekretion, zu einer Reduzierung von antralem Somatostatin, ohne dabei die Zahl der D-Zellen zu verändern (Lamers, 1988; Pashankar et al., 2001; Yip et al., 2004). Holst et al. (1992) postulierten, dass Hypochlorhydrie zu einer Erhöhung des Gastrin-Level durch eine Reduzierung der Somatostatinexpression führt.

Eine erhöhte Gastrinexpression bei Hypochlorhydrie, wie sie auch in anderen Veröffentlichungen beschrieben wurde (Aihara et al., 2003; Gawenis et al., 2004) konnte in dieser Arbeit nicht beobachtet werden. Es lässt sich zum einen vermuten, dass die reprimierte Expression von Somatostatin noch ausreichend für die Regulierung der Gastrinexpression ist. Als weitere Alternative könnte ein zusätzlicher Regulationsmechanismus für die Modulation der Gastrinexpression verantwortlich sein. So wurde eine alternative Somatostatinunabhängige Inhibierung der Gastrin-induzierten Magensäuresekretion durch Galanin beschrieben, die einhergeht mit einer Reprimierung der Gastrinsekretion (Madaus et al., 1988; Hakanson et al., 2001; Piqueras et al., 2004).

Die elektronenmikroskopischen Analysen des Magens Foxq1-defizienter Mäuse zeigten keine ultrastrukturellen Veränderungen der Parietalzellen im Ruhezustand. Dies weist darauf hin, dass Foxq1 nicht an der Differenzierung der Parietalzellen beteiligt ist. Nach Stimulation der Magensäuresekretion mittels Gastrin konnten in der Wildtypkontrolle signifikante Veränderungen beobachtet werden. Sekretagog-Stimulus führte zur Fusion der Tubulovesikel mit der apikalen Canaliculusmembran, was zu einer Vergrößerung der Canaliculi führte, die auch im Lichtmikroskop zu beobachten war. Dahingegen waren in der Ultrastruktur der Parietalzellen von Foxq1 $1^{-/}$-Mäusen keine Anomalien zu erkennen. Diese Beobachtung lässt 
eine Störung des Tubulovesikeltransports oder der Tubulovesikelfusion mit der Canaliculusmembran vermuten.

Tamura et al. (2005) beschrieben für Ezrin (Vil2) knockdown-Mäuse einen ähnlichen Phänotyp. Parietalzellen von Vil2 ${ }^{k d / k d}$-Mäusen zeigen im Ruhezustand keine Veränderungen der Ultrastruktur im Vergleich zu Wildtypmäusen. Nach Histaminstimulation kann eine Veränderung der Ultrastruktur der Parietalzellen einhergehend mit der Fusion der Tubulovesikel mit der apikalen Canaliculusmembran nur in Wildtypmäusen beobachtet werden. Diese Fusion der Tubulovesikel erfolgte in Vil2 $2^{k d / k d}$-Mäusen nicht. Ezrin gehört zur Ezrin/Radixin/Moesin (ERM) Familie (Bretscher, 1983; Sato et al., 1992). ERM Proteine spielen eine Rolle in der Organisation des Plasmamembran-ständigen Aktinzytoskeletts (Tsukita and Yonemura, 1999; Bretscher et al., 2002). Ezrin ist ein Phosphorylierungssubstrat der Proteinkinase A (PKA) und ist beteiligt an der PKA-vermittelten Signaltransduktion innerhalb der Parietalzellen, die letztendlich zur Fusion der Tubulovesikel mit der Canaliculusmembran führt (Urushidani und Forte, 1997; Zhou et al., 2003).

Ein weiteres Bindeglied in der die Magensäuresekretion aktivierenden Signaltransduktion innerhalb der Parietalzellen ist die Myosin Light Chain Kinase (MYLK; MLCK; Telokin) (Urushidani und Forte, 1997), die in vivo mit Aktin assoziiert ist (Dabrowska et al., 1982; Blue et al., 2002). Die Inhibierung von MYLK führt zu einer veränderten Verteilung von Ezrin innerhalb der Parietalzellen und zu einer fehlenden Translokation von Tubulovesikeln (Urushidani et al., 1997; Urushidani und Forte, 1997). Hoggatt et al. (2001) konnten eine Reprimierung von Telokin (MYLK) durch Foxq1 in glatter Muskulatur mittels Luciferase Assay zeigen. Im Rahmen der vorliegenden Arbeit konnte mit Hilfe von semiquantitativen RT-PCRs jedoch keine veränderte Expression von MYLK und Ezrin im Magen von Foxq1defizienten Tieren gezeigt werden. Dennoch kann eine Beteiligung von Foxq1 an der Regulierung der Signaltransduktion zur Magensäuresekretion innerhalb der Parietalzellen vermutet werden. Hierbei sollte das Hauptaugenmerk in weiteren Untersuchungen auf einer Beteiligung von Foxq1 an der Regulation von Aktin-abhängigen Mechanismen des Tubulovesikeltransports bzw. der Tubulovesikelfusion mit der Canaliculusmembran gerichtet werden. 


\subsection{Funktion von Foxq1 in der Embryonal- und Haarentwicklung}

RT-PCR Analysen an RNA unterschiedlicher embryonaler Entwicklungsstadien zeigten eine Expression von Foxq1 bereits im Morulastadium der Embryonalentwicklung der Maus. Eine whole mount in situ Hybridisierung an Embryonen von 10,5 dpc ließ eine Expression von Foxq1 im Rhomb-, Mes- und Prosencephalon erkennen. Die zu vermutende Beteiligung von Foxq1 an der Embryonalentwicklung dieser Hirnstrukturen konnte im Rahmen der vorliegenden Arbeit bestätigt werden. Foxq1-defiziente Mäuse weisen eine etwa 50\%ige Letalität während der Embryonalentwicklung auf. Fehlbildungen der drei Ventrikel des Vorderhirns, die während der Embryonalentwicklung an Tag 10,5 pc bei der Hälfte der Foxq1 ${ }^{-/}$-Embryonen beobachtet wurden, könnten der Grund für die embryonale Letalität sein. Allerdings ist die Penetranz des Phänotyps nicht vollständig. Es lässt sich vermuten, dass der genetische Hintergrund eine Rolle bei der Ausbildung des Phänotyps spielt, da es nur zu einer Ausprägung der Hirnfehlbildung bei Mäusen mit C57BL/6Jx129/Sv Hybridhintergrund, jedoch nicht bei Mäusen mit 129Sv-Inzucht-Hintergrund kam. Im Laufe der letzten Jahre konnten einige Hintergrund-abhängige Phänotypen identifiziert werden (Montagutelli, 2000). So konnte für Mäuse, die defizient für Egfr (Epidermal Growth Factor Receptor) sind, eine Modulierung des Phänotyp durch den genetischen Hintergrund der Mäuse gezeigt werden (Threadgill et al., 1995). Homozygot mutante Mäuse auf CF-1 Hintergrund erreichen zwar das Blastozystenstadium, sterben aber kurz nach der Implantation am Tag 4,5 pc. Die Embryonen zeigten in diesem Stadium eine lose angeordnete innere Zellmasse ohne ausgeprägtes Endoderm. Auf CD-1 Hintergrund überleben einige Egfr-defiziente Mäuse länger als drei Wochen nach der Geburt (Threadgill et al., 1995; Strunk et al., 2004). Verglichen mit ihren normalen Geschwistern sind diese Mäuse klein und zeigen eine fortschreitende Degenerierung des Gehirns. Eine Modifizierung des Phänotyps konnte auch für den Tumorsuppressor p53 gezeigt werden. Brustkrebs beim Menschen geht häufig einher mit dem Verlust des p53-Tumorsuppressors. Jedoch entwickeln Trp53 ${ }^{--}$-Mäuse auf 129Sv/C57BL6-Hybridhintergrund innerhalb von 6 Monaten zwar viele Arten von Tumoren, diese sind in den meisten Fällen aber Lymphome und nur in seltenen Fällen Brusttumore. Heterozygote Mäuse auf 129Sv/C57BL6-Hybridhintergrund entwickeln erst sehr viel später Tumore, wobei auch hier nur selten Brusttumore zu finden sind (Donehower et al., 1992). Mäuse auf BALB/c-Hintergrund, die heterozygot für Trp53 sind, entwickeln dahingegen nach 8 bis 14 Monaten in 42\% der Fälle Brusttumore (Kuperwasser et al., 2000; Blackburn und Jerry, 2002). 
Die bei Foxq1-defizienten Embryonen beobachteten Fehlbildungen der Ventrikel des Vorderhirns weisen Ähnlichkeiten mit dem Phänotyp von Wasf2-defizienten Mäusen auf. Wasf2 $^{-/}$-Mäuse sterben am 12. Tag der Embryonalentwicklung und zeigen schwere Wachstumsstörungen mit Fehlbildungen der Vorderhirnventrikel (Yan et al., 2003). Wasf2 (WAVE2) ist mit dem Wiskott-Aldrich Syndrom assoziiert und ist in die Regulation der Aktinzytoskelett Reorganisation involviert. Hierbei fungiert es als zytoplasmatisches Molekül, das die Signaltransduktion der Rho GTPase Rac mit der Aktin-Assemblierung verknüpft (Suetsugu et al., 1999; Takenawa und Miki, 2001). Durch Rac Aktivierung stimuliert WAVE2 den Arp (Actin related protein) 2/3 Komplex, was zu einer Reorganisation des Aktinzytoskeletts führt. Diese Reorganisation ist letzten Endes für die Ausbildung von Lamellipodien verantwortlich (Miki et al., 1998b; Takenawa und Miki, 2001). Die Organisation der Aktinzytoskelett-Assemblierung spielt eine große Rolle bei der Determinierung der Zellpolarität, der Musterbildung und der Zellmigration (Takenawa und Miki, 2001). Die geordnete Zellmigration und Musterbildung ist von entscheidender Bedeutung für die Entwicklung einzelner Gewebe.

Die Ähnlichkeit der Fehlbildungen des Vorderhirnbereichs von Wasf2 $2^{-/}$-Mäusen und Foxq1 $1^{-/}$Mäusen lassen eine Beteiligung von Foxq1 an der Organisation der AktinzytoskelettAssemblierung vermuten. Unterstützt wird diese Vermutung durch die zuvor gezeigte putative Involvierung von Foxq1 an Aktin-abhängigen Mechanismen am Tubulovesikeltransport innerhalb von Parietalzellen im Magen.

Einen weiteren Hinweis auf die Beteiligung von Foxq1 an der Aktin-Cytoskelettorganisation liefert der beschriebene Haarphänotyp. Im Rahmen dieser Arbeit konnte dabei der von Hong et al. (2001) beschriebene auffällige Phänotyp der Haare bestätigt werden. Es wurde gezeigt, dass die seit längerer Zeit bekannte Satin (sa) Mausmutante, die ursprünglich durch Bestrahlung mit $\gamma$-Strahlen erzeugt wurde (Major, 1955), eine intragenische Deletion im Foxq1-Gen aufweist, die zu einem C-terminal verkürzten Foxq1 Protein führt (Hong et al., 2001). Mittels in situ Hybridisierung konnte die Foxq1 Expression in medullaren Vorläuferzellen im Haarbulbus nachgewiesen werden. Satin Mäuse zeigen eine Störung der inneren, medullaren Haarstruktur. Foxq1 $1^{-/}$-Mäuse weisen dieselbe Störung der medullaren Haarstruktur auf. Zusätzlich konnten Hong et al. (2001) durch elektronenmikroskopische Untersuchungen strukturelle Fehlbildungen in der Organisation der medullaren Zellen zeigen. Eine Anordnung der Zellkompartimente, wie sie in medullaren Zellen von Wildtypmäusen zu beobachten ist, konnte in Satin Mäusen nicht gefunden werden. In den medullaren Zellen von Satin Mäusen sind die lichtbrechenden Granula, die in medullaren Zellen von Wildtypmäusen 
bandenartig angeordnet sind, über die gesamte medullare Zelle verteilt und zeigen keinerlei Anordnung. Es ist bekannt, dass für die korrekte Anordnung der Zellkompartimente Transportmechanismen innerhalb der Zelle verantwortlich sind, die assoziiert sind mit der Organisation des Aktinzytoskelett (Kamal und Goldstein, 2000; Okamoto und Forte, 2001; Rodriguez-Boulan et al., 2005).

\subsection{Charakterisierung neuer magenexprimierter Gene}

Im Rahmen von Vorarbeiten zu dieser Dissertation wurde eine auf PCR basierende subtraktive cDNA-Bibliothek erstellt, die differentiell im Magen exprimierte Gene detektierte. Als Vergleich fungierte das Transkriptom aus Colongewebe. Im Rahmen dieser Promotionsarbeit wurden aus den Genen solche ausgewählt und untersucht, die nicht charakterisiert waren und eine prädominante Expression im Magen zeigten. Aus den 23 als differentiell im Magen exprimierten Genen wurden folgende drei Gene ausgewählt: Gastrokine 2, Admp und SA11.

\subsubsection{Gastrokine 2}

In der vorliegenden Arbeit konnte für das Gastrokine 2-Gen eine magenspezifische Expression gezeigt werden, wobei die Expression nicht abhängig von der Ernährung der Mäuse ist. Der Beginn der Expression von Gastrokine 2 konnte als perinatal am Tag 1 beschrieben werden. In situ Hybridisierungen an Paraffinschnitten ließen die Expression von Gastrokine 2 nur in Zellen der Pit- Region des gastrischen Epithels erkennen. Die Pit-Region setzt sich im Normalfall fast ausschließlich aus Pitzellen, die durch einen hohen Anteil an sekretorischen Granula gekennzeichnet sind, und deren Vorläuferzellen zusammen.

Das putative humane Ortholog von Gastrokine 2, TFIZ1, konnte als Interaktionspartner von TFF1 (Trefoil Faktor 1) identifiziert werden. TFF1 gehört zur Familie der Trefoil Faktor Peptide und wird prädominant im Magen exprimiert. Für Tff1 wurde gezeigt, dass es die Regeneration der Magenschleimhaut (Restitution) stimuliert (Lacy, 1988; Hoffmann, 2005). Zusätzlich ist bekannt, dass $T f f 1^{-/}$-Mäuse in 30\% der Fälle Adenokarzinome entwickeln, was auf eine Funktion von Tff1 als Tumorsuppressor Gen hinweist (Lefebvre et al., 1996). Diese Vermutung wird unterstützt durch die Beobachtung, dass TFF1 in Karzinomzellen in der 
Regel nicht exprimiert ist (Henry et al., 1991; Muller und Borchard, 1993). Des Weiteren wurde die Inaktivierung von TFF1 durch Loss of Heterozygosity (Park et al., 2000) und Hypermethylierung des TFF1-Promotors (Fujimoto et al., 2000) in Magenkarzinomen nachgewiesen. Der Verdacht auf eine putative Interaktion der beiden orthologen Proteine in der Maus, die aus den Beobachtungen der TFIZ1 Interaktion mit TFF1 beim Menschen resultiert, wird durch den Vergleich der Expression von Gastrokine 2 und Tff1 erhärtet. Die Expression des murinen Tff1 beginnt perinatal am Tag 1 nach der Geburt und konnte prädominant in Pit-Zellen der gastrischen Mucosa beobachtet werden (Karam et al., 2004). Wie gezeigt, beginnt die Expression von Gastrokine 2 auch perinatal und es wird ausschließlich in den Pit-Zellen der gastrischen Mucosa exprimiert. Die Ähnlichkeiten der Expressionsmuster und die Interaktion der humanen Orthologen sind Indizien für eine putative Interaktion von Gastrokine 2 mit Tff1.

Mittels Analysen in Proteindatenbanken wurde für das Gastrokine 2 Protein eine Brichosdomäne prognostiziert. Die Brichosdomäne ist eine erst vor kurzer Zeit beschriebene Proteindomäne die aus etwa 100 Aminosäuren besteht und sowohl konservierte Sequenzbereiche, als auch strukturelle Homologien aufweist (Sanchez-Pulido et al., 2002). Proteine mit einer Brichosdomäne werden unter anderem in Verbindung gebracht mit ARDS (Acute Respiratory Distress Syndrome) und Magentumoren. Mutationen in der Brichosdomäne von SP-C (Surfactant Protein C), das in der Lunge eprimiert wird, führen zu einer Störung des Ubiquitin/Proteasom Systems und zu Stress des ERs (Endoplasmatisches Reticulum), was in einer Aktivierung der Caspase 3 induzierten Apoptose in der Lunge resultiert (Mulugeta et al., 2005).

Für das humane Gastrokine 1 (GKN1) Gen, dessen korrespondierendes Protein ebenfalls eine Brichosdomäne aufweist, wird eine Involvierung in die Entstehung von gastrischen Tumoren prognostiziert (Yoshikawa et al., 2000; Shiozaki et al., 2001). Dafür spricht, dass immunhistochemische Analysen eine Expression von GKN1 im Oberflächenepithel der gastrischen Mucosa erkennen lassen und GKN1 Expression in gastrischem Tumorgewebe herunterreguliert ist (Shiozaki et al., 2001).

Otto und Thim (2005) spekulieren in ihrer Veröffentlichung über eine Beteiligung der Brichosdomäne an der Interaktion mit Trefoil Faktoren. Hierfür führen sie zum einen die Beobachtung an, dass Mutationen in der Brichosdomäne von SP-C zu Apoptose durch eine Aktivierung von Caspase 3 führt (Mulugeta et al., 2005). Andererseits ist bekannt, dass Trefoil Faktoren ein anti-apoptotisches Potential aufweisen (Kinoshita et al., 2000; Taupin et al., 2000; Siu et al., 2004). 
Um eine detaillierte Expression von Gastrokine 2 auf Proteinebene aufzudecken, wurde damit begonnen, einen Gastrokine 2 spezifischen Antikörper herzustellen. Durch in vitro Exprimente, wie GST-Pulldown und Immunopräzipitations-Ansätze, kann mit Hilfe dieses Antikörpers außerdem eine mögliche Interaktion von Gastrokine 2 mit Tff1 oder mit anderen Proteinen untersucht werden. Um eine funktionelle Analyse des Gastrokine 2 Gens vornehmen zu können, wurde mit der Erstellung eines Konstruktes für die Inaktivierung von Gastrokine 2 begonnen. Hierbei soll das Exon 1, das den Translationsstart beinhaltet, mittels homologer Rekombination deletiert werden.

\subsubsection{Admp}

Für das Admp-Gen (Androgen down regulated gene expressed in mouse prostate) konnte eine magenspezifische, von der Ernährung der Mäuse unabhängige Expression gezeigt werden. In allen Teilen des Magens ließen sich zwei unterschiedlich große Transkripte nachweisen. Es konnte gezeigt werden, dass die beiden Transkripte aus der Verwendung alternativer Polyadenylierungssignale resultieren. Der Beginn der Expression des größeren AdmpTranskripts konnte bereits an 17,5 dpc gezeigt werden. Der Beginn der Expression des kleineren Transkripts konnte postnatal am Tag 5 beobachtet werden.

Das Admp-Gen wird in der Prostata von hypogonadalen (hpg) Mäusen, die eine rudimentäre Androgen-unabhängige Prostata aufweisen, exprimiert. In normalem Prostata-Gewebe wird Admp nicht exprimiert, und es konnte gezeigt werden, dass Admp durch Androgeneinwirkung reprimiert wird (Singh et al., 2005). Es ist bekannt, dass die Progression von Prostatakarzinomen gekoppelt ist mit dem Verlust der Androgenabhängigkeit (Suzuki et al., 2003; Miyamoto et al., 2004). Des Weiteren wurde von Singh et al. (2005) eine Androgenabhängige Expression von Admp in Niere und Gehirn gezeigt.

Auch für andere Androgen-abhängige Gene konnte eine Expression in Geweben, die nicht zum Genitaltrakt gehören, nachgewiesen werden. So konnten für die Niere einige Gene beschrieben werden, die durch Androgeneinfluss reguliert werden (Berger und Watson, 1989). Das Kap-Gen (Kidney androgen regulated protein), das stark in der Niere exprimiert wird, besitzt eine Androgen-abhängige Regulation (Toole et al., 1979; Soler et al, 2002). Für die Dehydroepiandrosteron Sulfotransferase (Std) konnte eine Androgen-abhängige Leberspezifische Expression in der Ratte gezeigt werden (Demyan et al., 1992; Song et al., 1998). 
Im Magen wurde die Expression von Androgen-abhängigen Genen mit gastrischen Tumoren assoziiert (Kodama und Kodama, 2000). Zusätzlich wurden aufgrund der höheren Inzidenz gastrischer Tumoren beim Mann Vermutungen über eine Beteiligung von Androgenabhängigen Genen bei der Tumorbildung geäußert (Nakamura et al., 2006). Die Aufdeckung der Expression von Steroidhormonrezeptoren in verschiedenen gastrischen Tumoren unterstützt diese Vermutung (Polimeno et al., 1994; Wu et al., 1994; Nakamura et al., 2006). Die Bedeutung von Androgen-abhängig exprimierten Genen im normalen Magengewebe ist bis dato allerdings unklar. Funktionelle Analysen des Admp-Gens im Magen könnten hierbei zur Aufklärung beitragen.

\subsubsection{SA11}

Für das SA11-Gen (benannt nach der Lokalisation auf dem Chromosom 11 der Maus) wurde eine sehr starke Expression in der Leber, eine starke Expression in allen Magenteilen und eine schwache Expression in der Milz gezeigt. Dabei wurden im Magen zwei unterschiedliche Transkripte nachgewiesen. Im Vormagen wurde ein Transkript identifiziert, das von der Größe her mit den Transkripten in Leber und Milz korreliert. Im glandulären Magen und im Antrum wird dahingegen ein Transkript exprimiert, das um etwa 350 Bp größer ist als das andere Transkript. Eine Abhängigkeit der Expression beider Transkripte von der Ernährung konnte nicht beobachtet werden. Eine Erklärung für das Auftreten eines größeren Transkripts im glandulären Magen und im Antrum konnte bis dato nicht gefunden werden. Mittels Datenbankanalysen wurde für das aus drei Exons bestehende SA11-Gen kein zusätzliches Exon gefunden, das auf ein alternatives Spleißen der SA11-mRNA schließen ließe. Das in Leber, Milz und im Vormagen auftretende kleinere Transkript weist eine Größe von etwa 350 Nukleotiden auf und korreliert mit der in Datenbanken prognostizierten Transkriptgröße von 376 Nukleotiden. Das größere Transkript weist eine Größe von etwa 700 Nukleotiden auf und ist somit um ungefähr 350 Nukleotide größer. Das größere Transkript kann aus unterschiedlichen Polyadenylierungssignalen, wie für das Admp-Gen gezeigt, resultieren. Mittels Datenbankanalysen konnten allerdings keine alternativen Polyadenylierungssignale entdeckt werden. Als weitere Ursache für die beobachteten Größenunterschiede könnte eine zusätzliche, nachträgliche Polyadenylierung des SA11-Transkripts im glandulären Magen und im Antrum verantwortlich sein. Es ist bekannt, dass die Stabilität der RNA mit der Länge des Polyadenylschwanzes korreliert (Beelman und Parker, 1995; Meyer et al., 2004). 
Mechanismen, die zu einer zusätzlichen Polyadenylierung des Polyadenylschwanzes führen, sind bekannt. Für die Testis-spezifische, cytoplasmatische Poly(A) Polymerase (TPAP1) konnte gezeigt werden, dass sie an der zusätzlichen Polyadenylierung von mRNA im Cytoplasma von männlichen Keimzellen beteiligt ist (Kashiwabara et al., 2000; Kashiwabara et al., 2002).

Proteindatenbankanalysen beschreiben SA11 als putatives sekretorisches Protein mit einer Four-disulfide core-Domäne. Diese Domäne wurde bisher in einigen Genen beschrieben, die bei der Tumorgenese beim Menschen eine Rolle spielen (Bouchard et al., 2006). Ferner weist SA11 Homologien zu WDNM1 auf. In der Ratte wird das WDNM1 Protein in metastatischen Adenokarzinomen des Brustgewebes reprimiert (Dear et al., 1988; Dear und Kefford, 1991). Das WDNM1 Protein gehört zur Familie der extrazellulären Proteinase Inhibitoren (Expi) und spielt eine Rolle bei der Induktion der Apoptose in Brustkrebszellen (Jung et al., 2004). Aufgrund der Homologie zu WDNM1 kann über eine Beteiligung von SA11 an der Apoptose oder an der Tumorprogression spekuliert werden.

\subsection{Ausblick}

Anhand von Foxq1-defizienten Mäusen konnte eine Beteiligung von Foxq1 an der Sekretion der Magensäure, der embryonalen Entwicklung des Vorderhirns und der Entwicklung der Haare gezeigt werden. Die Analysen des Phänotyps und der Vergleich mit anderen funktionellen Analysen lassen eine Involvierung von Foxq1 an der Regulation der Aktinzytoskelett-Assemblierung vermuten. Um die Funktion von Foxq1 an der Assemblierung bzw. der Reorganisation des Aktinzytoskeletts näher zu untersuchen wären Analysen an isolierten Parietalzellen hilfreich. Hierfür können Zellkulturen von Parietalzellen aus Mägen von Wildtypmäusen und aus Mägen Foxq1-defizienter Mäuse produziert werden, an denen Untersuchungen zur Organisation des Aktinzytoskeletts und der daran beteiligten Proteine vorgenommen werden. Durch Verwendung spezifischer Antikörper gegen Proteine, die bei der Organisation des Aktinzytoskeletts eine Rolle spielen, kann mittels immunhistochemischer Methoden deren Organisation in Parietalzellen von Wildtypmäusen und Foxq1 $1^{-/}$-Mäusen verglichen werden. Als Beispiele sind hier die Proteine der ERMFamilie Ezrin, Radixin und Moesin zu nennen. Des Weiteren können Studien des Aktinzytoskeletts in Parietalzellen mit Hilfe Fluoreszenz-markierten Phalloidins vorgenommen werden. Phalloidin ist ein Toxin aus Amanita phalloides (Grüner 
Knollenblätterpilz), das spezifisch an F-Aktin bindet, so dass der Aufbau bzw. die Organisation des F-Aktins in Parietalzellen aus Wildtypmäusen und Foxq1-defizienten Mäusen miteinander verglichen werden kann. Diese Analysen können in der Zellkultur sowohl mit Parietalzellen im Ruhezustand als auch nach Induktion der Magensäuresekretion durch Histamin durchgeführt werden. Zusätzlich können mit Proteinextrakten aus den Parietalzellkulturen von Wildtypmäusen und Foxq1 ${ }^{-/}$-Mäusen die Expression verschiedener Gene, die an der Ausbildung und Organisation des Aktinzytoskeletts beteiligt sind, mittels Western-Blot Analysen untersucht werden.

Mit Hinblick auf die gestörte Embryonalentwicklung von 50\% der Foxq1 ${ }^{-/-}$-Embryonen könnten Zellkulturen embryonaler Fibroblasten von Wildtypmäusen und betroffener Foxq1defizienter Mäuse von Tag 10,5 post coitum ebenfalls zur Aufdeckung der Funktion von Foxq1 verwendet werden. Mit Hilfe der Fibroblastzellkulturen können Proliferations- und Migrationsassays durchgeführt werden.

Um Foxq1-regulierte Gene aufzufinden, können differentielle Expressionsstudien an den Transkriptomen bzw. Proteomen normaler und Foxq1-defizienter Parietalzellen bzw. embryonaler Fibroblasten durchgeführt werden. Für vergleichende Expressionsanalysen können auf RNA-Ebene cDNA-Mikroarray Analysen herangezogen werden. Analysen an Proteinextrakten aus den Zellkulturen mittels 2-dimensionaler Polyacrylamidgelelektrophorese (2D-PAGE) oder Isotope-coded affinity tagging (ICAT) können zum Vergleich der Proteome verwendet werden.

Mit Hilfe der Charakterisierung und der funktionellen Analyse neuer Gene, die im Magen exprimiert werden, können neue Erkenntnisse über die Funktion des Magens gewonnen werden. Zur näheren Charakterisierung der Gene wäre die Herstellung von spezifischen Antikörpern hilfreich. Mit Hilfe dieser Antikörper können Expressionsanalysen auf Proteinebene durchgeführt werden. Immunpräzipitations-Experimente unter Verwendung der spezifischen Antikörper eignen sich zur Aufdeckung von Interaktionspartnern der Proteine. Zur funktionellen Analyse der Gene ist die Generierung von Tieren, die defizient für die betreffenden Gene sind, ein probates Mittel. Die Auswirkung einer ektopischen Expression der Gene kann mittels transgener Mäuse untersucht werden. Des Weiteren können Funktionsanalysen mit Hilfe von in vitro Experimenten in Zellinien des gastrischen Epithels durchgeführt werden. In Zellkulturexperimenten können die Auswirkung einer gesteigerten bzw. einer reprimierten Expression der Gene in den Zellen untersucht werden. 
Im Rahmen dieser Arbeit wurde gezeigt, dass Foxq1 an der Magensäuresekretion beteiligt ist. Die durchgeführten Untersuchungen lassen dabei eine Beteiligung von Foxq1 an der Organisation des Tubulovesikeltransports bzw. der Tubulovesikelfusion mit der Canaliculusmembran innerhalb der Parietalzellen vermuten. Die Vermutung stützt sich zum einen auf die Ergebnisse der in situ Hybridisierung, die eine Lokalisation von Foxq1 in Parietalzellen der gastrischen Mucosa nachweist. Ein weiteres Indiz für diese Vermutung ist das Ergebnis der ultrastrukturellen Analysen der Parietalzellen nach Sekretagog-Stimulus. Eine Aktivierung der Magensäuresekretion durch Sekretagog-Stimulus führt in Parietalzellen von Foxq1 $1^{-/}$-Tieren zu keiner mit Wildtypmäusen vergleichbaren Reaktion. Für die normale Magensäuresekretion ist ein Transport der Tubulovesikel innerhalb der Parietalzellen mit einer anschließenden Fusion der Vesikel mit der Canaliculusmembran unabdingbar. Im Ruhezustand konnten dagegen keine Veränderungen im ultrastrukturellen Aufbau der Parietalzellen von Foxq1 ${ }^{-/-}$-Mäusen gegenüber Wildtypmäusen beobachtet werden. Dies weist darauf hin, dass Foxq1 nicht an der Differenzierung der Parietalzellen beteiligt ist. Die beobachteten Phänotyp-Ähnlichkeiten zwischen Foxq1-defizienten Mäusen und Mäusen, denen das zur ERM Familie gehörige Ezrin fehlt, das eine Rolle in der Organisation des Plasmamembran-ständigen Aktinzytoskeletts spielt, liefern zusätzliche Hinweise auf die Beteiligung von Foxq1 an der Organisation des Aktinzytoskelett abhängigen Vesikeltransports bzw. der Vesikelfusion.

Eine Assoziierung von Foxq1 mit der Organisation des Aktinzytoskeletts in der Zelle lassen auch die Untersuchungen der embryonalen Letalität von Foxq $1^{-/}$-Mäusen und die Fehlbildung der inneren, medullaren Haarstruktur vermuten. Die embryonale Letalität, die bei etwa 50\% der Foxq1 $1^{-/-}$-Embryonen beobachtet werden konnte, resultiert aus einer Fehlbildung der Ventrikel des Vorderhirns. Eine ähnliche Fehlbildung konnte auch an Wasf2 ${ }^{-/-}$-Embryonen gezeigt werden. Wasf2 (WAVE2) ist involviert in die Regulation der Aktin-Cytoskelett Reorganisation. Hierbei fungiert es als Mediator zwischen der Rac-Signaltransduktion und der Aktinassemblierung.

Die fehlerhafte Organisation der Zellkompartimente, die in den medullaren Zellen des Haarschaftes von Satin Mäusen zu beobachten ist, und die Expression von Foxq1 in deren Vorläuferzellen (Hong et al., 2001) sind ein weiteres Indiz für die Beteiligung von Foxq1 an 
der Organisation des Aktin-Cytoskeletts. Die richtige Anordnung der einzelnen Zellkompartimente innerhalb der Zelle ist abhängig von Transportmechanismen, die assoziiert sind mit der Organisation des Aktin-Cytoskelett.

Mit Hilfe einer subtraktiven cDNA-Bibliothek wurden Gene, die differentiell im Magen exprimiert werden, identifiziert. Nach Datenbankanalyse der identifizierten Gene wurden drei Gene für eine weitere Charakterisierung ausgewählt. Die Kriterien für diese Auswahl waren eine prädominante Expression im Magen und eine fehlende Charakterisierung der Gene in der Literatur. Für die drei ausgewählten Gene Gastrokine 2, Admp und SA11 konnte eine prädominante bzw. spezifische Expression im Magen nachgewiesen werden. Die Analyse der Expression während der prä- und postnatalen Magenentwicklung wurde für Gastrokine 2 und Admp durchgeführt. Die Gastrokine 2 Expression beginnt perinatal, während die Admp Expression ab Tag 17,5 post coitum nachzuweisen ist. Für das Gastrokine 2 Gen konnte zusätzlich mit Hilfe einer in situ Hybridisierung die Expression in Pit-Zellen der gastrischen Mucosa gezeigt werden. Eine weitere Charakterisierung dieser Gene und deren funktionelle Analyse können in Zukunft Aufschluss über die Funktion der Gene im Magen geben. 
Aihara T, Fujishita T, Kanatani K, Furutani K, Nakamura E, Taketo MM, Matsui M, Chen D, Okabe S. Impaired gastric secretion and lack of trophic responses to hypergastrinemia in M3 muscarinic receptor knockout mice. Gastroenterology. 2003; 125(6):1774-84.

Allen A, Flemstrom G. Gastroduodenal mucus bicarbonate barrier: protection against acid and pepsin. Am J Physiol Cell Physiol. 2005; 288(1):C1-19.

Beelman CA, Parker R. Degradation of mRNA in eukaryotes. Cell. 1995; 81(2):179-83.

Belo JA, Bouwmeester T, Leyns L, Kertesz N, Gallo M, Follettie M, De Robertis EM. Cerberus-like is a secreted factor with neutralizing activity expressed in the anterior primitive endoderm of the mouse gastrula. Mech Dev. 1997; 68(1-2):45-57.

Berger FG, Watson G. Androgen-regulated gene expression. Annu Rev Physiol. 1989; 51:51-65.

Berglindh T, Dibona DR, Ito S, Sachs G. Probes of parietal cell function. Am J Physiol. 1980; 238(3):G165-76.

Bieller A, Pasche B, Frank S, Glaser B, Kunz J, Witt K, Zoll B. Isolation and characterization of the human forkhead gene FOXQ1. DNA Cell Biol. 2001; 20(9):555-61.

Birnboim HC. A rapid alkaline extraction method for the isolation of plasmid DNA. Methods Enzymol. 1983; 100:243-55.

Birnboim HC, Doly J. A rapid alkaline extraction procedure for screening recombinant plasmid DNA. Nucleic Acids Res. 1979; 7(6):1513-23.

Black JW, Duncan WA, Durant CJ, Ganellin CR, Parsons EM. Definition and antagonism of histamine H 2 -receptors. Nature. 1972; 236(5347):385-90. 
Blackburn AC, Jerry DJ. Knockout and transgenic mice of Trp53: what have we learned about p53 in breast cancer? Breast Cancer Res. 2002;4(3):101-11.

Blue EK, Goeckeler ZM, Jin Y, Hou L, Dixon SA, Herring BP, Wysolmerski RB, Gallagher PJ. 220- and 130-kDa MLCKs have distinct tissue distributions and intracellular localization patterns. Am J Physiol Cell Physiol. 2002; 282(3):C451-60.

Bouchard D, Morisset D, Bourbonnais Y, Tremblay GM. Proteins with whey-acidicprotein motifs and cancer. Lancet Oncol. 2006; 7(2):167-74.

Bretscher A. Purification of an 80,000-dalton protein that is a component of the isolated microvillus cytoskeleton, and its localization in nonmuscle cells. J Cell Biol. 1983; 97(2):42532.

Bretscher A, Edwards K, Fehon RG. ERM proteins and merlin: integrators at the cell cortex. Nat Rev Mol Cell Biol. 2002; 3(8):586-99.

Chew CS. Parietal cell protein kinases. Selective activation of type I cAMP-dependent protein kinase by histamine. J Biol Chem. 1985; 260(12):7540-50.

Chiba T, Kadowaki S, Taminato T, Chihara K, Seino Y, Matsukura S, Fujita T. Effect of antisomatostatin gamma-globulin on gastrin release in rats. Gastroenterology. 1981; 81(2):321-6.

Chomczynski P, Sacchi N. Single-step method of RNA isolation by acid guanidinium thiocyanate- phenol-chloroform extraction. Anal Biochem. 1987; 162(1):156-9.

Clark KL, Halay ED, Lai E, Burley SK. Co-crystal structure of the HNF-3/fork head DNArecognition motif resembles histone H5. Nature. 1993; 364(6436):412-20.

Crean GP, Marshall MW, Rumsey RD. Parietal cell hyperplasia induced by the administration of pentagastrin (ICI 50,123) to rats. Gastroenterology. 1969; 57(2):147-55.

Dabrowska R, Hinkins S, Walsh MP, Hartshorne DJ. The binding of smooth muscle myosin light chain kinase to actin. Biochem Biophys Res Commun. 1982; 107(4):1524-31. 
Dear TN, Kefford RF. The WDNM1 gene product is a novel member of the 'four-disulphide core' family of proteins. Biochem Biophys Res Commun. 1991; 176(1):247-54.

Dear TN, Ramshaw IA, Kefford RF. Differential expression of a novel gene, WDNM1, in nonmetastatic rat mammary adenocarcinoma cells. Cancer Res. 1988; 48(18):5203-9.

Demyan WF, Song CS, Kim DS, Her S, Gallwitz W, Rao TR, Slomczynska M, Chatterjee B, Roy AK. Estrogen sulfotransferase of the rat liver: complementary DNA cloning and age- and sex-specific regulation of messenger RNA. Mol Endocrinol. 1992; 6(4):589-97.

DiBona DR, Ito S, Berglindh T, Sachs G. Cellular site of gastric acid secretion. Proc Natl Acad Sci USA. 1979; 76(12): 6689-6693.

Dohlman HG, Thorner J, Caron MG, Lefkowitz RJ. Model systems for the study of seven-transmembrane-segment receptors. Annu Rev Biochem. 1991; 60:653-88.

Donehower LA, Harvey M, Slagle BL, McArthur MJ, Montgomery CA Jr, Butel JS, Bradley A. Mice deficient for p53 are developmentally normal but susceptible to spontaneous tumours. Nature. 1992; 356(6366):215-21.

Forte JG. K+ channels in the secretory membrane of the parietal cell. focus on "Gastric parietal cell secretory membrane contains PKA- and acid-activated Kir2.1 K+ channels". Am J Physiol Cell Physiol. 2004; 286(3):C478-9.

Forte JG, Ganser A, Beesley R, and Forte TM. Unique enzymes of purified microsomes from pig fundic mucosa. $\mathrm{K}^{+}$-stimulated adenosine triphosphatase and $\mathrm{K}^{+}$-stimulated pNPPase. Gastroenterology. 1975; 69: 175-189.

Forte TM, Machen TE, Forte JG. Ultrastructural changes in oxyntic cells associated with secretory function: a membrane-recycling hypothesis. Gastroenterology. 1977; 73(4 Pt 2):941-55.

Frank, S. Isolierung und Charakterisierung von cDNA und Gen für das HNF-3/fork head homologe Protein MFK-1 der Maus und Analyse der Promotorregion 1997; Dissertation; Institut für Humangenetik Georg-August-Universität zu Göttingen. 
Frank S, Zoll B. Mouse HNF-3/fork head homolog-1-like gene: structure, chromosomal location, and expression in adult and embryonic kidney. DNA Cell Biol. 1998; 17(8):679-88.

Friis-Hansen L. Gastric functions in gastrin gene knock-out mice. Pharmacol Toxicol. 2002; 91(6):363-7.

Friis-Hansen L, Sundler F, Li Y, Gillespie PJ, Saunders TL, Greenson JK, Owyang C, Rehfeld JF, Samuelson LC. Impaired gastric acid secretion in gastrin-deficient mice. Am J Physiol. 1998; 274(3 Pt 1):G561-8.

Fujimoto J, Yasui W, Tahara H, Tahara E, Kudo Y, Yokozaki H, Tahara E. DNA hypermethylation at the pS2 promoter region is associated with early stage of stomach carcinogenesis. Cancer Lett. 2000; 149(1-2):125-34.

Fukamachi H, Mizuno T, Takayama S. Epithelial-mesenchymal interactions in differentiation of stomach epithelium in fetal mice. Anat Embryol (Berl). 1979; 157(2):15160.

Fukushima Y, Ohmachi Y, Asano T, Nawano M, Funaki M, Anai M, Ogihara T, Inukai K, Onishi Y, Sakoda H, Saitoh T, Matsuhashi N, Yazaki Y, Sugano K. Localization of the histamine H(2) receptor, a target for antiulcer drugs, in gastric parietal cells. Digestion. 1999; 60(6):522-7.

Fykse V, Solligard E, Bendheim MO, Chen D, Gronbech JE, Sandvik AK, Waldum HL. ECL cell histamine mobilization and parietal cell stimulation in the rat stomach studied by microdialysis and electron microscopy. Acta Physiol (Oxf). 2006; 186(1):37-43.

Gawenis LR, Ledoussal C, Judd LM, Prasad V, Alper SL, Stuart-Tilley A, Woo AL, Grisham C, Sanford LP, Doetschman T, Miller ML, Shull GE. Mice with a targeted disruption of the AE2 Cl-/HCO3- exchanger are achlorhydric. J Biol Chem. 2004; 279(29):30531-9.

Hakanson R, Bottcher G, Ekblad E, Panula P, Simonsson M, Dohlsten M, Hallberg T, Sundler F. Histamine in endocrine cells in the stomach. A survey of several species using a panel of histamine antibodies. Histochemistry. 1986; 86(1):5-17. 
Hakanson R, Chen D, Lindstrom E, Bernsand M, Norlen P. Control of secretion from rat stomach ECL cells in situ and in primary culture. Scand J Clin Lab Invest Suppl. 2001; 234:53-60.

Hakanson R, Sundler F. Proposed mechanism of induction of gastric carcinoids: the gastrin hypothesis. Eur J Clin Invest. 1990; 20 Suppl 1:S65-71.

Hanes J, Freudenstein J, Rapp G, Scheit KH. Construction of a plasmid containing the complete coding region of human elongation factor 2. Biol Chem Hoppe. 1992; Seyler 373 (4): 201-4.

Henry JA, Bennett MK, Piggott NH, Levett DL, May FE, Westley BR. Expression of the pNR-2/pS2 protein in diverse human epithelial tumours. Br J Cancer. 1991; 64(4):677-82.

Hersey SJ, Sachs G. Gastric acid secretion. Physiol Rev. 1995; 75(1):155-89.

Hoffmann W. Trefoil factors TFF (trefoil factor family) peptide-triggered signals promoting mucosal restitution. Cell Mol Life Sci. 2005; 62(24):2932-8.

Hoggatt AM, Kriegel AM, Smith AF, Herring BP. Hepatocyte nuclear factor-3 homologue 1 (HFH-1) represses transcription of smooth muscle-specific genes. J Biol Chem. 2000; 275(40):31162-70.

Holst JJ, Orskov C, Seier-Poulsen S. Somatostatin is an essential paracrine link in acid inhibition of gastrin secretion. Digestion. 1992; 51(2):95-102

Hong HK, Noveroske JK, Headon DJ, Liu T, Sy MS, Justice MJ, Chakravarti A. The winged helix/forkhead transcription factor Foxq1 regulates differentiation of hair in satin mice. Genesis. 2001; 29(4):163-71.

Jansen JB, Klinkenberg-Knol EC, Meuwissen SG, De Bruijne JW, Festen HP, Snel P, Luckers AE, Biemond I, Lamers CB. Effect of long-term treatment with omeprazole on serum gastrin and serum group $\mathrm{A}$ and $\mathrm{C}$ pepsinogens in patients with reflux esophagitis. Gastroenterology. 1990; 99(3):621-8.

Jensen RT. Consequences of long-term proton pump blockade: insights from studies of patients with gastrinomas. Basic Clin Pharmacol Toxicol. 2006; 98(1):4-19. 
Jung DJ, Bong JJ, Baik M. Extracellular proteinase inhibitor-accelerated apoptosis is associated with B cell activating factor in mammary epithelial cells. Exp Cell Res. 2004; 292(1):115-22.

Kaestner KH, Knochel W, Martinez DE. Unified nomenclature for the winged helix/forkhead transcription factors. Genes Dev. 2000; 14(2):142-6.

Kamal A, Goldstein LS. Connecting vesicle transport to the cytoskeleton. Curr Opin Cell Biol. 2000; 12(4):503-8.

Karam SM, Tomasetto C, Rio MC. Trefoil factor 1 is required for the commitment programme of mouse oxyntic epithelial progenitors. Gut. 2004; 53(10):1408-15.

Karnik PS, Monahan SJ, Wolfe MM. Inhibition of gastrin gene expression by somatostatin. J Clin Invest. 1989; 83(2):367-72.

Karnik PS, Wolfe MM. Somatostatin stimulates gastrin mRNA turnover in dog antral mucosa. J Biol Chem. 1990; 265(5):2550-5.

Kashiwabara S, Noguchi J, Zhuang T, Ohmura K, Honda A, Sugiura S, Miyamoto K, Takahashi S, Inoue K, Ogura A, Baba T. Regulation of spermatogenesis by testis-specific, cytoplasmic poly(A) polymerase TPAP. Science. 2002; 298(5600):1999-2002.

Kashiwabara S, Zhuang T, Yamagata K, Noguchi J, Fukamizu A, Baba T. Identification of a novel isoform of poly(A) polymerase, TPAP, specifically present in the cytoplasm of spermatogenic cells. Dev Biol. 2000; 228(1):106-15.

Khan AR, James MN. Molecular mechanisms for the conversion of zymogens to active proteolytic enzymes. Protein Sci. 1998; 7(4):815-36.

Kidd M, Modlin IM, Tang LH. Gastrin and the enterochromaffin-like cell: an acid update. Dig Surg. 1998; 15(3):209-17.

Kinoshita K, Taupin DR, Itoh H, Podolsky DK. Distinct pathways of cell migration and antiapoptotic response to epithelial injury: structure-function analysis of human intestinal trefoil factor. Mol Cell Biol. 2000; 20(13):4680-90. 
Kodama M, Kodama T. In search of the cause of gastric cancer. In Vivo. 2000; 14(1):12538.

Kuperwasser C, Hurlbut GD, Kittrell FS, Dickinson ES, Laucirica R, Medina D, Naber SP, Jerry DJ. Development of spontaneous mammary tumors in BALB/c p53 heterozygous mice. A model for Li-Fraumeni syndrome. Am J Pathol. 2000; 157(6):2151-9.

Lacy ER. Epithelial restitution in the gastrointestinal tract. J Clin Gastroenterol. 1988; 10 Suppl 1:S72-7.

Lamberts R, Creutzfeldt W, Struber HG, Brunner G, Solcia E. Long-term omeprazole therapy in peptic ulcer disease: gastrin, endocrine cell growth, and gastritis. Gastroenterology. $1993 ; 104(5): 1356-70$.

Lamers CB. Hormonal regulation of gastric acid in peptic ulcer disease. Scand $J$ Gastroenterol Suppl. 1988; 146:5-10

Larsson H, Carlsson E, Mattsson H, Lundell L, Sundler F, Sundell G, Wallmark B, Watanabe T, Hakanson R. Plasma gastrin and gastric enterochromaffinlike cell activation and proliferation. Studies with omeprazole and ranitidine in intact and antrectomized rats. Gastroenterology. 1986; 90(2):391-9.

Lee HC, Breitbart H, Berman M, and Forte JG. Potassium-stimulated ATPase activity and hydrogen transport in gastric microsomal vesicles. Biochim Biophys Acta. 1979; 553: 107131.

Lefebvre O, Chenard MP, Masson R, Linares J, Dierich A, LeMeur M, Wendling C, Tomasetto C, Chambon P, Rio MC. Gastric mucosa abnormalities and tumorigenesis in mice lacking the pS2 trefoil protein. Science. 1996; 274(5285):259-62.

Litingtung Y, Lei L, Westphal H, Chiang C. Sonic hedgehog is essential to foregut development. Nat Genet. 1998; 20(1):58-61.

Loh EY, Elliott JF, Cwirla S, Lanier LL, Davis MM. Polymerase chain reaction with single-sided specificity: analysis of T cell receptor delta chain. Science. 1989; 243 (4888): 217-20. 
Madaus S, Schusdziarra V, Seufferlein T, Classen M. Effect of galanin on gastrin and somatostatin release from the rat stomach. Life Sci. 1988; 42(23):2381-7.

Major MH. Satin, sa. Mouse News Letter. 1955; 12:47

Meyer S, Temme C, Wahle E. Messenger RNA turnover in eukaryotes: pathways and enzymes. Crit Rev Biochem Mol Biol. 2004; 39(4):197-216.

Miki H., Suetsugu,S. and Takenawa,T. WAVE, a novel WASP-family protein involved in actin reorganization induced by Rac. EMBO J. 1998; 17, 6932-6941.

Miyamoto H, Messing EM, Chang C. Androgen deprivation therapy for prostate cancer: current status and future prospects. Prostate. 2004; 61(4):332-53.

Miyazaki Y, Shinomura Y, Tsutsui S, Zushi S, Higashimoto Y, Kanayama S, Higashiyama S, Taniguchi N, Matsuzawa Y. Gastrin induces heparin-binding epidermal growth factor-like growth factor in rat gastric epithelial cells transfected with gastrin receptor. Gastroenterology. 1999; 116(1):78-89.

Montagutelli X. Effect of the genetic background on the phenotype of mouse mutations. $J$ Am Soc Nephrol. 2000; 11 Suppl 16:S101-5.

Muller W, Borchard F. pS2 protein in gastric carcinoma and normal gastric mucosa: association with clincopathological parameters and patient survival. J Pathol. 1993; 171(4):263-9.

Mulugeta S, Nguyen V, Russo SJ, Muniswamy M, Beers MF. A surfactant protein C precursor protein BRICHOS domain mutation causes endoplasmic reticulum stress, proteasome dysfunction, and caspase 3 activation. Am J Respir Cell Mol Biol. 2005; 32(6):521-30.

Nakajima T, Konda Y, Izumi Y, Kanai M, Hayashi N, Chiba T, Takeuchi T. Gastrin stimulates the growth of gastric pit cell precursors by inducing its own receptors. Am $J$ Physiol Gastrointest Liver Physiol. 2002; 282(2):G359-66. 
Nakamura Y, Shimada N, Suzuki T, Imatani A, Sekine H, Ohara S, Shimosegawa T, Sasano H. In situ androgen production in human gastric carcinoma--androgen synthesizing and metabolizing enzymes. Anticancer Res. 2006; 26(3A):1935-9.

Okamoto CT, Forte JG. Vesicular trafficking machinery, the actin cytoskeleton, and H+$\mathrm{K}+-\mathrm{ATPase}$ recycling in the gastric parietal cell. J Physiol. 2001; 532(Pt 2):287-96.

Otto WR, Thim L. Trefoil factor family-interacting proteins. Cell Mol Life Sci. 2005; 62(24):2939-46.

Park WS, Oh RR, Park JY, Yoo NJ, Lee SH, Shin MS, Kim SY, Kim YS, Lee JH, Kim HS, An WG, Lee JY. Mapping of a new target region of allelic loss at 21q22 in primary gastric cancers. Cancer Lett. 2000; 159(1):15-21.

Pasche B. Promotoranalyse und Expressionsstudien der murinen und humanen fork head homologen Gene Foxq1 und FOXQ1. 2001; Dissertation; Institut für Humangenetik GeorgAugust-Universität zu Göttingen.

Pashankar DS, Israel DM, Jevon GP, Buchan AM. Effect of long-term omeprazole treatment on antral G and D cells in children. J Pediatr Gastroenterol Nutr. 2001; 33(5):53742.

Pearse AG, Bussolati G. The identification of gastrin cells as G cells. Virchows Arch A Pathol Pathol Anat. 1972; 355(2):99-104.

Piqueras L, Tache Y, Martinez V. Galanin inhibits gastric acid secretion through a somatostatin-independent mechanism in mice. Peptides. 2004; 25(8):1287-95.

Polak JM, Pearse AG, Grimelius L, Bloom SR. Growth-hormone release-inhibiting hormone in gastrointestinal and pancreatic D cells. Lancet. 1975; 1(7918):1220-2.

Polimeno L, Silecchia G, Spaziani E, Scucchi A, Dell'Aquila P, Ierardi E, Materia A, Giangaspero A, Basso N, Francavilla A. Estrogens, androgens, and EGF receptor expression in gastric carcinoma induced by N-methyl-N'-nitro-N-nitrosoguanidine. Dig Dis Sci. 1994; 39(3):635-40 
Rapp G, Klaudiny J, Hagendorff G, Luck MR, Scheit KH. Complete sequence of the coding region of human elongation factor 2 (EF- 2) by enzymatic amplification of cDNA from human ovarian granulosa cells. Biol Chem Hoppe Seyler. 1989; 370 (10): 1071-5.

Rodriguez-Boulan E, Kreitzer G, Musch A. Organization of vesicular trafficking in epithelia. Nat Rev Mol Cell Biol. 2005; 6(3):233-47.

Saffouri B, Weir G, Bitar K, Makhlouf G. Stimulation of gastrin secretion from the perfused rat stomach by somatostatin antiserum. Life Sci. 1979; 25(20):1749-53.

Saiki RK, Gelfand DH, Stoffel S, Scharf SJ, Higuchi R, Horn GT, Mullis KB, Erlich HA. Primer-directed enzymatic amplification of DNA with a thermostable DNA polymerase. Science.1988; 239 (4839): 487-91.

Sambrook J, Fritsch EF, Maniatis T. Molecular cloning: A Laboratorial manual. Zweite Auflage. Cold Spring Harbour, New York, USA. 1989.

Sanchez-Pulido L, Devos D, Valencia A. BRICHOS: a conserved domain in proteins associated with dementia, respiratory distress and cancer. Trends Biochem Sci. 2002; 27(7):329-32.

Sanger F, Nicklen S, Coulson AR. DNA sequencing with chain-terminating inhibitors. Proc Natl Acad Sci U S A. 1977; 74 (12): 5463-7.

Sato N, Funayama N, Nagafuchi A, Yonemura S, Tsukita S, Tsukita S. A gene family consisting of ezrin, radixin and moesin. Its specific localization at actin filament/plasma membrane association sites. J Cell Sci. 1992; 103 ( Pt 1):131-43.

Sawaguchi A, Aoyama F, Ide S, Suganuma T. The cryofixation of isolated rat gastric mucosa provides new insights into the functional transformation of gastric parietal cells: an in vitro experimental model study. Arch Histol Cytol. 2005; 68(3):151-60.

Shiozaki K, Nakamori S, Tsujie M, Okami J, Yamamoto H, Nagano H, Dono K, Umeshita K, Sakon M, Furukawa H, Hiratsuka M, Kasugai T, Ishiguro S, Monden M. Human stomach-specific gene, CA11, is down-regulated in gastric cancer. Int J Oncol. 2001; 19(4):701-7 
Singh J, Young L, Handelsman DJ, Dong Q. Molecular cloning and characterization of a novel androgen repressible gene expressed in the prostate epithelium. Gene. 2005; 348:55-63.

Siu LS, Romanska H, Abel PD, Baus-Loncar M, Kayademir T, Stamp GW, Lalani el-N. TFF2 (trefoil family factor2) inhibits apoptosis in breast and colorectal cancer cell lines. Peptides. 2004; 25(5):855-63.

Soler M, Tornavaca O, Sole E, Menoyo A, Hardy D, Catterall JF, Vandewalle A, Meseguer A. Hormone-specific regulation of the kidney androgen-regulated gene promoter in cultured mouse renal proximal-tubule cells. Biochem J. 2002; 366(Pt 3):757-66.

Song CS, Jung MH, Kim SC, Hassan T, Roy AK, Chatterjee B. Tissue-specific and androgen-repressible regulation of the rat dehydroepiandrosterone sulfotransferase gene promoter. J Biol Chem. 1998; 273(34):21856-66.

Spicer Z, Miller ML, Andringa A, Riddle TM, Duffy JJ, Doetschman T, Shull GE. Stomachs of mice lacking the gastric H,K-ATPase alpha -subunit have achlorhydria, abnormal parietal cells, and ciliated metaplasia. J Biol Chem. 2000; 275(28):21555-65.

Strunk KE, Amann V, Threadgill DW. Phenotypic variation resulting from a deficiency of epidermal growth factor receptor in mice is caused by extensive genetic heterogeneity that can be genetically and molecularly partitioned. Genetics. 2004; 167(4):1821-32.

Suetsugu S, Miki H, Takenawa T. Identification of two human WAVE/SCAR homologues as general actin regulatory molecules which associate with the Arp2/3 complex. Biochem Biophys Res Commun. 1999; 260(1):296-302.

Suzuki H, Ueda T, Ichikawa T, Ito H. Androgen receptor involvement in the progression of prostate cancer. Endocr Relat Cancer. 2003; 10(2):209-16.

Takenawa T, Miki H. WASP and WAVE family proteins: key molecules for rapid rearrangement of cortical actin filaments and cell movement. J Cell Sci. 2001; 114(Pt 10):1801-9.

Tamura A, Kikuchi S, Hata M, Katsuno T, Matsui T, Hayashi H, Suzuki Y, Noda T, Tsukita S, Tsukita S. Achlorhydria by ezrin knockdown: defects in the formation/expansion of apical canaliculi in gastric parietal cells. J Cell Biol. 2005; 169(1):21-8. 
Taupin DR, Kinoshita K, Podolsky DK. Intestinal trefoil factor confers colonic epithelial resistance to apoptosis. Proc Natl Acad Sci U S A. 2000; 97(2):799-804.

Threadgill DW, Dlugosz AA, Hansen LA, Tennenbaum T, Lichti U, Yee D, LaMantia C, Mourton T, Herrup K, Harris RC, et al. Targeted disruption of mouse EGF receptor: effect of genetic background on mutant phenotype. Science. 1995; 269(5221):230-4

Toole JT, Hastie ND, Held WA. An abundant androgen-regulated mRNA in the mouse kidney. Cell. 1979; (17), 441-448

Tsukita S, Yonemura S. Cortical actin organization: lessons from ERM (ezrin/radixin/moesin) proteins. J Biol Chem. 1999; 274(49):34507-10.

Tsutsui S, Shinomura Y, Higashiyama S, Higashimoto Y, Miyazaki Y, Kanayama S, Hiraoka S, Minami T, Kitamura S, Murayama Y, Miyagawa J, Taniguchi N, Matsuzawa Y. Induction of heparin binding epidermal growth factor-like growth factor and amphiregulin mRNAs by gastrin in the rat stomach. Biochem Biophys Res Commun. 1997; 235(3):520-3.

Urushidani T, Forte JG. Signal transduction and activation of acid secretion in the parietal cell. J Membr Biol. 1997; 159(2):99-111.

Urushidani T, Muto Y, Nagao T, Yao X, Forte JG. ME-3407, a new antiulcer agent, inhibits acid secretion by interfering with redistribution of $\mathrm{H}(+)-\mathrm{K}(+)$-ATPase. Am J Physiol. 1997; 272(5 Pt 1):G1122-34.

Wang TC, Dangler CA, Chen D, Goldenring JR, Koh T, Raychowdhury R, Coffey RJ, Ito S, Varro A, Dockray GJ, Fox JG. Synergistic interaction between hypergastrinemia and Helicobacter infection in a mouse model of gastric cancer. Gastroenterology. 2000; 118(1):36-47.

Weigel D, Jurgens G, Kuttner F, Seifert E, Jackle H. The homeotic gene fork head encodes a nuclear protein and is expressed in the terminal regions of the Drosophila embryo. Cell. 1989; 57(4):645-58.

Wilkes JM, Kajimura M, Scott DR, Hersey SJ, Sachs G. Muscarinic responses of gastric parietal cells. J Membr Biol. 1991; 122(2):97-110. 
Wood LR und Dubois A. Scanning electron microscopy of the stomach during modifications of acid secretion. Am. J. Physiol. 1983; 244(5):G475-G479.

Wu CW, Chang YF, Yeh TH, Chang TJ, Lui WY, P'Eng FK, Chi CW. Steroid hormone receptors in three human gastric cancer cell lines. Dig Dis Sci. 1994; 39(12):2689-94.

Yan C, Martinez-Quiles N, Eden S, Shibata T, Takeshima F, Shinkura R, Fujiwara Y, Bronson R, Snapper SB, Kirschner MW, Geha R, Rosen FS, Alt FW. WAVE2 deficiency reveals distinct roles in embryogenesis and Rac-mediated actin-based motility. EMBO J. $2003 ; 22(14): 3602-12$.

Yip L, Leung HC, Kwok YN. Effect of omeprazole on gastric adenosine A1 and A2A receptor gene expression and function. J Pharmacol Exp Ther. 2004; 311(1):180-9.

Yoshikawa Y, Mukai H, Hino F, Asada K, Kato I. Isolation of two novel genes, downregulated in gastric cancer. Jpn J Cancer Res. 2000; 91(5):459-63.

Zhou R, Cao X, Watson C, Miao Y, Guo Z, Forte JG, Yao X. Characterization of protein kinase A-mediated phosphorylation of ezrin in gastric parietal cell activation. $\mathrm{J}$ Biol Chem. 2003; 278(37):35651-9. 


\section{Danksagungen}

Herrn Prof. Dr. W. Engel danke ich für die Betreuung meiner Arbeit, seine hilfreichen Anregungen und Vorschläge, sowie die gründliche Durchsicht meiner Manuskripte.

Frau PD Dr. S. Hoyer-Fender danke ich für die freundliche Übernahme des Korreferats.

Meinen Betreuern Frau Prof. Dr. B. Zoll und Herrn PD Dr. I. Adham danke ich für die vielfältigen Anregungen, Diskussionen, Vorschläge und Hilfen, und natürlich für die Durchsicht und Korrektur meines Manuskriptes.

Des Weiteren möchte ich mich bei Herr PD Dr. J. Männer und bei Herrn PD Dr. M. Ochs für die durchgeführten Experimente bedanken.

Ein besonderer Dank gebührt den Mitarbeitern des Instituts, die durch ihre Freundlichkeit und Hilfsbereitschaft Anteil am Erfolg dieser Arbeit haben. Dies gilt insbesondere für die Mitarbeiter der Labore 107 und 108.

Meiner Familie möchte ich für ihre Zeit, ihre Unterstützung und ihre Liebe danken. 


\section{Lebenslauf}

Wolfgang Göring

11.02 .1975

Geboren als zweites Kind von Horst und Barbara Göring, geb. Warner in Duisburg

$1981-1985$

Besuch der Gemeinschaftsgrundschule an der Gartenstraße in Duisburg

$1985-1994$

Besuch des Elly-Heuss-Knapp-Gymnasiums in Duisburg

07.06.1994

Allgemeine Hochschulreife

01.08.1994-

31.10 .1995

Zivildienst beim Malteser Hilfsdienst Duisburg e.V.

$1995-2002$

Studium an der Heinrich-Heine-Universität Düsseldorf im Fach Biologie

12.02 .2002

Abschluss Diplom Biologe

$01.04 .2003-$

Beginn der Promotion am Institut für Humangenetik der

31.08 .2003

Universität Göttingen

$01.09 .2003-$

Weiterführung der Promotion im Graduiertenkolleg 242

31.03 .2006

Molekulare Genetik der Entwicklung

$01.04 .2006-$

Weiterführung der Promotion am Institut für Humangenetik der Universität Göttingen 